\title{
History and philosophy of logic from Humanism to Kant
}

\author{
Mirella Capozzi and Gino Roncaglia*
}

\section{Humanist criticisms of Scholastic logic}

The first impression of a reader who 'crosses the border' between medieval and Renaissance logic may be that of leaving an explored and organized field for a relatively unexplored and much less ordered one. This impression is emphasized by the fact that, while in the medieval period we can assume, despite relevant theoretical differences, some consensus about the nature and purpose of logic, such an assumption cannot be made with reference to the post-medieval and Renaissance period: the many 'logics' co-existing and challenging each other were often characterized by deeply divergent assumptions, articulations and purposes. As far as logic is concerned, we could almost be tempted to use this 'explosion of entropy' as the very marker of the shift between the medieval and the Renaissance period.

The development of Humanism, with its criticism of the late medieval logical tradition, is not the only factor contributing to this situation, but surely is a relevant one. Excessive and artificial subtlety, lack of practical utility, barbarous use of Latin: these are the main charges that humanist dialecticians made against Scholastic logic. Such charges do not simply point out formal deficiencies that could be eliminated within a common logical framework, but call for a change of the logical paradigm itself. The effort to address such charges had a deep influence on the evolution of logic, and resulted in a variety of solutions, many of which were based on contaminations between selected but traditional logical theories, on the one hand, and mainly rhetorical or pedagogical doctrines on the other. But the charges themselves were initially made outside the field of logic: one of the very first invectives against Scholastic logic came from Francesco Petrarca (1304-1374), hardly to be considered a logician (Petrarca 1933-42, I, 7).

The central point at issue is the role of language. The late medieval Scholastic tradition used language as a logical tool for argumentation, and favored the development of what J. Murdoch (1974) aptly called 'analytical languages': highly specialized collections of terms and rules which - once applied to specific and definite sets of problems - should help to guarantee the formal precision of reasoning. In this tradition, the use of a simplified and partly artificial Latin could help the construction of sophisticated formal arguments. The humanists, on the contrary, privileged the mastery of classical Latin. For them, language - together with a few simple and 'natural' arguments taken from ancient rhetoric - was a tool for an effective and well-organized social and pedagogical communication.

Besides the different theoretical standpoints, there is a social and cultural gap between two different intellectual figures. Scholastic-oriented teachers are usually university professors who tend to consider logic, philosophy and theology as specialized fields. For them, knowledge is reached through a self-absorbing (and largely self-sufficient) intellectual activity, whose formal correctness is regulated by logic. Many humanist dialecticians, on the contrary, do not belong to, and do not address themselves to, the academic world: they consider logic a tool to be used whenever language is used with rhetorical or practical purposes, and regard a broad 'classical' culture more important than a specialized and abstract one.

\footnotetext{
* Though we decided on the general structure of this chapter together, $\S \S 1-4$ and $\S 8$ are by Gino Roncaglia, while $\S \S 5-7$ and $\S \S 9-11$ are by Mirella Capozzi.
} 
One should be careful, however, in assessing the reasons for the privilege humanists accorded to rhetoric. For the humanists, logic - or rather dialectic, to use the term that, already present in the Ciceronian tradition and in the Middle Ages (cf. Maierù 1993), was preferred by most humanist and Renaissance authors - has to do with the use of arguments. But, in order to be practically effective, such arguments have to be natural, aptly chosen, easily stated and grasped, expressed in good, classical Latin. And they don't need to be demonstrative arguments: probable arguments are also included within the scope of dialectic.

One should also be careful in considering Humanism as a monolithic movement aimed at banishing all reminiscence of medieval logic. Humanism is not chronologically subsequent to Scholasticism, and many humanists knew late Scholastic logical texts fairly well, such as those by Paul of Venice. Some even praised them (Vasoli 1968, 20-23; Perreiah 1982, 3-22; Mack 1993, 14-15). Nevertheless, formally correct and truth-preserving arguments were considered as only some of the tools available to a good dialectician. The latter's aim is to master the art of using language (ars bene disserendi), the Ciceronian disserendi diligens ratio, and this requires not only demonstrative skills, but also the ability to persuade, to construct probable arguments, to obtain consensus.

The definition of dialectic provided by Rudolph Agricola (1444-1485) - one of the many Renaissance variations on Cicero's own - is representative of this point of view. According to it, dialectic is the "ars probabiliter de qualibet re proposita disserendi" (art of speaking in a probable way about any proposed subject). And the explication of 'probabiliter' clarifies the broad scope of the term (cf. Mack 1993, 169-173, where 'probabiliter' is translated as 'convincingly'): "probable (probabile) in speaking is not only what is actually probable, that is, as Aristotle states, what is accepted by all, or by the most part, or by the learned. For us, probable is what can be said about the proposed subject in an apt and adequate way" (Agricola 1967, 192). This meaning of the concept is broad enough to include good old-fashioned demonstrative arguments in the field of dialectic (Risse 1964-70, I, 1718), but they are no longer the only kind of arguments a dialectician should take into account.

A first introduction to sources, principles and precepts of humanist-oriented logic is provided by the works of the prominent humanist dialectician Lorenzo Valla (1407-1457), who, significantly, received his cultural training mostly within the humanist circles of the papal curia. While some of the earlier humanists were content with a dismissal of Scholastic logic - Petrarca's and Bruni's invectives against the barbari britanni being the most often quoted testimony of this attitude (Garin 1960, 181-195; Vasoli 1974, 142-54) - in his Repastinatio dialecticae et philosophiae (Valla 1982), Valla added to heavy criticism of traditional logical doctrines a complete and systematic reassessment of the nature and purpose of dialectic from a humanistic point of view.

According to Valla, dialectic deals with demonstrative arguments, while rhetoric deals with every kind of argument: demonstrative as well as plausible ones. Therefore dialectic is to be considered as a part of rhetoric, and rhetoric has to provide the widest spectrum of argumentative tools to all branches of learning. Moreover, dialectic should be simple and disregard all the questions that, though discussed by logicians with technical logical tools, actually pertain to Latin grammar. During the Middle Ages the relation between logic and grammar had been closely investigated by the so-called modist logicians. They worked at a sophisticated speculative grammar, based on an ontologically grounded correspondence between ways of being, ways of thinking and ways of signifying. Valla's grammar, on the contrary, is based on the Latin of classical authors, and therefore on a historically determined consuetudo in the use of language. Valla thus carries out what has been described as a 'deontologization' of language (Camporeale 1986, Waswo 1999).

Valla devotes the first of the three books of his Repastinatio to the foundations of dialectic and to a discussion of the Aristotelian doctrine of the categories. Here, too, Valla applies his general rule: simplification through reference to concrete uses of Latin, rather than 
to an abstract metaphysical system. The ten Aristotelian categories are thus reduced to three: substance, quality and action, and examples are given to show how the remaining categories can be reduced to quality and action. Similarly, the transcendental terms, which according to the medieval tradition 'transcend' the division among the ten categories and are reciprocally convertible, are reduced to the only term 'res'. The reason why Valla prefers the term 'res' to the traditional 'ens' is that 'ens' in classical Latin is not a noun but a participle that can be exposed as 'that thing (res) which is'. Therefore the term 'res' is the true fundamental one. This example shows how Valla explains problematic terms or sentences by offering a reformulation considered more precise, and easier to analyze. The practice of explanation through reformulation was familiar to medieval logicians under the name of exposition, but Valla uses expositio to reach linguistic, rather than logical clarification.

Valla's second book is devoted to proposition and addresses the question whether all propositions should be reduced to the basic tripartite form: subject - copula - predicate ("A est B'). This question was the object of a long debate, continued during the whole period we are dealing with (Roncaglia 1996), and had usually been investigated under the assumption that it was the logical structure of the proposition at issue. Valla, on the contrary, perceives the problem as related to the grammatical structure of the proposition, and accordingly offers a negative answer, since in the use of Latin the construction 'est + participle' (Plato est legens) is not equivalent to the use of an indicative form of the verb (Plato legit). The Spanish humanist Juan Luis Vives (1492-1540) will share the same attitude (cf. Ashworth 1983, 70).

To support his contention, Valla considers propositions like Luna illuminatur that - in Latin - can be transformed into a tripartite form only through a shift in meaning. A further argument is drawn from the idea that the participle form of the verb may be seen as somehow derivative with respect to the indicative form. Therefore - if something is to be reduced at all - it should be a participle like legens, to be reduced to qui legit (Valla 1982, 180). Logicians should not superimpose their logical analysis to the 'good' use of language, but should rather learn from it. Language should be studied, described and taught, rather than 'corrected' from an external point of view.

Valla did not consider the study of modal propositions as pertaining to logic (hence his complete refusal of modal syllogistic). This refusal - common to most humanistic-influenced Renaissance philosophy - is once again defended on linguistic, rather than purely logical, grounds. Why should we attribute to terms like 'possible' and 'necessary' a different status from that of grammatically similar terms like 'easy', 'certain', 'usual', 'useful', and so on? (Valla 1982, 238; cf. Mack 1993, 90, Roncaglia 1996, 191-192).

Valla's third book, devoted to argumentation, preserves the basic features of Aristotelian syllogistic, but dismisses the third figure and, as already noted, modal syllogisms. Owing to his desire to acknowledge not only demonstrative but also persuasive arguments, Valla pays great attention to hypothetical and imperfect syllogisms and to such non-syllogistic forms of argument like exemplum and enthymemes.

The final section of Valla's work is devoted to sophistic argumentations. Medieval discussions of sophisms allowed logicians to construct interesting, complex and borderline situations in order to test the applicability and the effectiveness of their logical and conceptual tools. Valla is fascinated by the persuasive and literary strength of 'classical' problematic arguments, such as the sorites (a speech proceeding through small and apparently unavoidable steps from what seems an obvious truth to a problematic conclusion) or the dilemma, in which all the alternatives in a given situation are considered, only to show that each of them is problematic. Valla does distinguish 'good' and 'bad' uses of these kinds of 'arguments', but his criterion is basically that of practical usefulness in persuasive rhetoric.

Valla's Repastinatio is also a typical example of the importance humanists assigned to the 'invention' (inventio) of arguments, connected with topics. Renaissance dialecticians considered Aristotle's Topica as a systematic treatment of practical reasoning, and 
complemented it with Cicero's Topica and with the treatment of topics included in Quintilian's Institutio oratoria, which - rediscovered in 1416 - had become one of the most popular textbooks on rhetoric by the end of the century, while Boethius' De differentiis topicis, widely used in the Middle Ages (Green-Pedersen 1984), had only few Renaissance editions (Mack 1993, 135). Both Cicero's and Quintilian's treatment of topics helped shift the focus from 'formal' disputations to rhetorical and persuasive ones.

The most complete and influential Renaissance study of topics is contained in Agricola's De inventione dialectica (Agricola 1967). Agricola grounds his conception of topics on his realist conception of universals (Braakhuis 1988). In his opinion, things are connected by relations of agreement and disagreement, and topics are orderly collections of common marks, which help us to organize and label relations, and to find out what can or cannot be said about a given thing in an appropriate way. While being systematically arranged, topics, according to Agricola, are not a closed system: the very possibility of viewing things from different angles and perspectives, of relating them in new ways, not only enables us to draw or invent arguments, but also allows us to find new common marks.

We have already considered Agricola's definition of dialectic. In his opinion, topics are the method of dialectical invention, while the discourse (oratio) is its context. There are, however, two different kinds of dialectical discourse: exposition (expositio) and argumentation (argumentatio). The former explains and clarifies, and is used when the audience doesn't need to be convinced, but only enabled to understand what it is said. The latter aims at 'winning' assent, i.e. at persuading. Although argumentation is connected with disputation, necessary arguments are not the only way to win a disputation: plausible, and even emotionally moving arguments should be considered as well. Agricola's concept of argumentation is thus connected with rhetoric, a connection strengthened by the fact that both use natural language. This explains why Agricola has no use for the kind of highly formalized, analytical language used by medieval and late medieval logic.

However negative Valla's and Agricola's attitude toward the logical tradition, it was never as negative as that of Petrus Ramus (Pierre del Ramée, 1515-1572). According to his biographer Freigius, Ramus' doctoral dissertation (1536) defended the thesis: "everything that Aristotle said is misleading (commentitium)". This does not imply - as many assumed - that Ramus considers all Aristotelian theories to be false: in his opinion, Aristotle is guilty of having artificially complicated and corrupted the simple and 'natural' logic which Aristotle's predecessors - notably Plato - had devised before him (Risse 1964-70, I, 123-4). Scholastic logic is obviously seen by Ramus as a further step in the wrong direction.

Various versions of Ramus' logic (including the 1555 Dialectique, in French: Ramus 1996; for a survey of the different editions of his works and of the stages marking the complex development of Ramus' dialectic cf. Bruyère 1984) were published between 1543 and 1573. After his conversion to Protestantism in 1561, his library was burned, and he had to flee from Paris. Ramus died on August 26, 1572, killed on the third day of the St. Bartholomew's massacre. His being one of the Huguenot martyrs undoubtedly boosted the fortune of his already popular works in Calvinist circles.

Ramus' concept of dialectic is based on three main principles: dialectic should be natural (its foundations being the "eternal characters" which constitute, by God's decree, the very essence of our reasoning), it should be simple (it deals with the correct way of reasoning, but disregards metaphysical, semantic and grammatical problems as well as unnecessary subtleties), and it should be systematically organized, mainly by means of dichotomic divisions. Therefore, Ramus' books extensively used diagrams, usually in the form of binary trees: a feature that may be connected - as argued by Ong (1958) - with the new graphical possibilities offered by printed books, and that will influence a huge number of sixteenth and seventeenth century logic textbooks, not only within the strict Ramist tradition. 
The first and foremost division adopted by Ramus is Cicero's division between invention (inventio) and judgment (iudicium or dispositio). The latter are the first two sections of logic. A third section, devoted to the practical and pedagogical exercise of dialectic (exercitatio), is present in the first editions of Ramus' logical works but disappears after 1555 .

The inventio deals with the ways arguments are to be found. Since arguments are to be found and classified by means of topics, according to Ramus, the treatment of topics should precede, rather than follow (like in Aristotle), that of judgment. Ramus' table of topics, organized by means of subsequent dichotomic divisions, is strongly influenced by Agricola and by Johannes Sturm (1507-1589), who taught dialectic and rhetoric in Paris between 1529 and 1537 and greatly contributed to the popularity of Agricola in France.

Ramus' treatment of judgment is also unconventional. While in traditional logic this section presupposes an extensive treatment of proposition, Ramus deals with this subject in a sketchy way and adds an independent (albeit short) section on the nature and structure of proposition only in the 1555 and successive editions of his work. In the last edition Ramus follows Cicero in using the term axioma to refer to a categorical proposition (having used earlier the term enuntiatio or enuntiatum), while he always gives the more specific meaning of major premise of a syllogism to the term propositio.

Syllogism and its various forms (including induction, example and enthymeme) constitute the core of the 'first judgment': the first of the three sections in which Ramus divides his treatment of judgment in the earlier editions of his dialectic. Ramus' explicit effort is that of simplifying Aristotelian syllogistic, but during the years between the 1543 edition of the Dialecticae institutiones and his death, his syllogistic underwent so many changes that it is impossible to give a faithful account of it in a few pages. Typical of Ramus' syllogistic is his use of the terms propositio, assumptio and complexio to refer to the major premise, minor premise and conclusion of a syllogism, and his tendency to favour a classification of syllogisms according to the quantity of the premises, considering as primary moods those with two universal premises. In the earlier editions of his dialectic, Ramus held that all moods with particular premises should be reduced to universal moods. He admitted some of them later on, but banned the reductio ad impossibile used to reduce second and third figure moods to the first figure. But Ramus' better known innovation in the field of syllogistic is the socalled 'Ramist moods': syllogisms in which both premises are singular, accepted on the ground that individuals could be seen as (lowest) species. The discussion about 'Ramist moods' will keep logicians busy for most of the subsequent century.

The second section of Ramus' treatment of judgment (called 'second judgment' in the earlier editions of his work) deals with the ways to connect and order arguments by means of general principles. Ramus attributes great importance to this 'theory of method', which he further develops in the later editions of his logical works, and which in his opinion shapes the whole system of science (also offering the conceptual foundation for an extensive use of dichotomies). According to Ramus, the dialectical method (methodus doctrinae) goes from what is most general to what is most particular. This is done by means of divisions that, in turn, are drawn on the base of definitions expressing the essence of the concepts involved. Division and definition are thus the two main tools of method. The opposite route, going from particular instances to more general concepts (methodus prudentiae), might be used when either the lack of a more general conceptual framework or reasons of practical convenience force us to dwell upon single or partial pieces of information. However, it cannot guarantee certainty; and is therefore mainly used in rhetorical discourse aiming at persuasion, rather than in demonstrative reasoning. In Ramus' opinion, however, the distinction between methodus doctrinae and methodus prudentiae does not imply that we have two methods: we have only one method - based on an ideal 'knowledge space' organized by means of definitions and divisions - that, in given and concrete situations, also allows for tentative and partial bottom-up routes. 
Thus conceived, the dialectical method is governed by three laws, which constitute the Ramist counterpart of the Aristotelian-Scholastic de omni, per se and universaliter primum principles. Ramus calls them the laws of truth, justice and wisdom: in the field of science every statement (i) should be valid in all its instances; (ii) should express a necessary (essential) connection of the concepts involved; (iii) should be based on subject and predicate that are proper and proportionate (allowing for simple conversion).

Ramus' logic was very influential in the second half of the sixteenth and in the first half of the seventeenth century (Feingold, Freedman and Rother 2001). However, 'pure' Ramist scholars - mostly active in the Calvinist areas of Germany, in Switzerland, in Holland and in England - were to face an almost immediate opposition not only in Catholic but also in Lutheran universities, and saw their influence decrease after the beginning of the seventeenth century. Much more influential (and more interesting) were the many 'eclectic' logicians who either tried to reconcile Ramus' and Melanchthon's logical views (Philippo-Ramists), or introduced some Ramist themes within more traditional (and even Aristotelian) contexts.

\section{The evolution of the Scholastic tradition and the influence of Renaissance Aristotelianism}

Despite humanist criticisms, the tradition of Scholastic logic not only survived during the sixteenth and seventeenth centuries, but evolved in ways which are much more interesting and articulated than most modern scholars suspected until a few decades ago. Our knowledge of this evolution is still somehow fragmentary, but the scholarly work completed in recent years allows some definite conclusions. We can now say that in this evolution of the late Scholastic logical tradition, six factors were particularly relevant: (i) the work of a group of Spaniards who studied in Paris at the end of the fifteenth and at the beginning of the sixteenth century and later taught in Spanish universities, influencing the development of logic in the Iberian peninsula; (ii) a renewed attention toward metaphysics, present in the Iberian Second Scholasticism and most notably in the works of Francisco Suárez (1548-1617), whose Disputationes Metaphysicae (Suárez 1965) influenced many authors all across Europe; (iii) the crucial role of the newly formed (1540) Society of Jesus, whose curriculum of studies (Ratio Studiorum) was to shape institutional teaching in all of Catholic Europe; (iv) the complex relations with humanism, and the influence of logicians like Agricola, whose doctrines, while taking as their starting point a humanist conception of logic, were nevertheless susceptible of somehow being absorbed or integrated within a more traditional framework; (v) the 'new Aristotelianism' of authors like Jacopo Zabarella (1533-1589) and Bartholomaeus Keckermann (1572?-1609); and (vi) the renewed interest in Scholastic logic, discernible in reformed Europe (and most notably in Germany) as a consequence of the doctrinal and theological conflicts with the catholic field and within the reformed field itself. In the following pages, we will attempt to provide some details on this complex development.

At the end of the fifteenth century and in the first decades of the sixteenth, the Paris college of Montaigu became a centre of logical research in which the late medieval logical (especially nominalist) tradition survived and to some extent flourished. A group of Spanish and Scottish logicians, lead by the Spaniard Jeronimo Pardo (d.1505) and by the Scottish John Mair (1467/9-1550), debated themes such as the nature of supposition and signification, the distinction between categorematic and syncategorematic terms, the role of beings of reason (entia rationis), the nature of proposition (further developing the late medieval discussions on mental propositions), modality, and the theory of consequences. Somehow connected to this Paris group, or active there at the beginning of the sixteenth century, were the Spaniards Antonio Núñez Coronel (d.1521), Fernando de Encinas (d.1523), Luis Núñez Coronel (d.1531), Juan de Celaya (1490-1558), Gaspar Lax (1487-1560), Juan Dolz (fl. 1510), the 
Frenchman Thomas Bricot (d. 1516), the Belgian Pierre Crockaert (Pierre of Brussels, d.1514), and the Scot George Lokert (d. 1547).

Particularly interesting is their discussion about the nature of complexe significabile (propositional complex), a subject already debated by medieval logicians. The medieval defenders of this theory, associated with the name of Gregory of Rimini (c.1300-1358), held that the object of science is not the proposition itself, but what is signified by it (and determines its truth or falsity); such total and adequate meaning of the proposition is neither a physical nor a purely mental being, and is not reducible to the meaning of its parts. It is rather similar to a state-of-affairs, which can be signified only by means of a complex (the proposition) and is therefore called complexe significabile. The discussion on the nature (and usefulness) of the complexe significabile was connected to the discussion on the role of the copula, since the copula was usually considered as the 'formal' component of the proposition, 'keeping together' subject and predicate. The copula was thus considered as a syncategorematic term: a term that does not possess an autonomous meaning, but helps to determine the meaning of the proposition as a whole. The defenders of a 'strict' complexe significabile theory did not need a separate discussion of the mental copula, since in their opinion the complexe significabile is a unity and cannot be analyzed in term of its parts. But many authors - among them John Buridan (c.1295-c.1356) - assigned a much more relevant role to the copula, seen as the (syncategorematic) mental act that, in connecting subject and predicate, establishes the proposition. It is this very theory that was discussed by many of the above-mentioned late fifteenth and early sixteenth century Paris-based logicians (see Ashworth 1978 and 1982, Nuchelmans 1980, Pérez-Ilzarbe 1999). Pardo's position in this discussion was the most original. In his opinion, the copula is not purely syncategorematic: it is subordinate to a conceptual schema that represents something (i.e. the subject) as related in a certain way to something else (i.e. the predicate) or to itself (Nuchelmans 1980: 49). In this way the copula, while retaining its formal function, also signifies something (aliquid), i. e. the subject, as considered in a given way (aliqualiter), namely as modified by the relation with its predicate. The idea of the copula signifying aliquid aliqualiter, and not simply aliqualiter, and the special relevance attributed to the subject in determining the meaning of the copula and of the proposition as a whole, were discussed, and generally criticized, by Pardo's successors. They especially investigated the role of impossible propositions, as well as propositions with a negative, privative or impossible subject, and the problem of whether a quasi-syncategorematic nature could be attributed to the proposition as a whole.

The Iberian Peninsula was one of the strongholds of Catholicism. Moreover, as we have seen, it inherited many features (as well as textbooks and Paris-trained professors) from Parisian late Scholasticism. This made the influence of the humanist movement - albeit discernible - less radical than elsewhere. Therefore, the Iberian Peninsula was the ideal context in which Catholic logicians - dwelling upon the Scholastic (chiefly Thomist) logical and philosophical tradition - could pursue the work of doctrinal and pedagogical systematization that was required by the struggle against the reformed field.

The Carmelite universities of Salamanca (Salamanticenses) and Alcalà (Complutenses) and the Jesuit university of Coimbra (Conimbricenses) each produced a complete philosophical course, including specific volumes devoted to logic. Of these the most influential was probably the Coimbra Logic, compiled by Sebastian Couto (1567-1639) but partially dependent upon Pedro da Fonseca (1528-1599), who had been teacher in that university. Fonseca, the 'Portuguese Aristotle', published the Institutionum Dialecticarum Libri VIII (Fonseca 1964) in 1564, a logical treatise built on the model of Peter of Spain and widely read throughout Europe. Fonseca's logic interprets the traditional emphasis on terms by giving a theoretical priority to the conceptual moment over the judicative one (truth and falsity are in concepts rather than in judgment), and, among concepts, to singulars over abstracts and universals. In order to reconcile God's foreknowledge and human free will, and 
to handle the problem of future contingents - a theme of special interest for all Iberian philosophers - Fonseca developed, independently from Luis de Molina (1535-1600), a theory of the scientia media, or, as he says, of 'conditioned futures', by which God foreknows all the consequences of any possible free decision.

Placing Fonseca's theories within a wider and more systematic treatment, the Coimbra Logic offers a translation and a detailed commentary of Aristotle's Organon, which, in the form of questions, includes a discussion of most of the topics debated by sixteenth and seventeenth century logicians. The Conimbricenses reject the idea that beings of reason are the object of logic (in the Scholastic tradition logical concepts such as 'genus' and 'species' were considered to be entia rationis, and the Thomist tradition considered them as the formal object of logic): dwelling upon the idea of logic as ars disserendi, they prefer to characterize it as a 'practical science' dealing with the construction of correct arguments. Argumentation is, therefore, the first and main object of logical enquiry. Particularly interesting is the long section devoted to the nature of signs at the opening of the commentary on Aristotle's $D e$ Interpretatione (cf. Doyle 2001). The concept of sign is here taken in a broad meaning, as to include not only spoken, written and mental 'words', but also iconic languages and arithmetical signs. It is to be remarked that the influence of Coimbra logic was not limited to Europe: Jesuits missionaries used it in Latin America and even in China.

If the teaching of logic in Coimbra is connected to Fonseca, another important figure of Iberian logic and philosophy, Domingo de Soto (1494/5-1560), is connected to Alcalà and Salamanca, where he taught. Soto made important contributions to a plurality of fields, so much so that it was said 'qui scit Sotum, scit totum' (who knows Soto, knows everything). Despite his endorsement of Thomism - testified by his defence of the theory that the object of logic are beings of reason - Soto was open to Scotist, nominalist and even humanist influences, and his commentary on Aristotle's logic (Soto 1543) criticizes the 'abstract sophistries' of late Scholastic logical tradition. This, however, did not prevent him from discussing and adopting many late Scholastic logical theories, including large sections of medieval theories of terms. His Summulae (Soto 1980) are a commentary on one of the key works of medieval logic, Peter of Spain's Tractatus (best known as Summulae Logicales: see previous chapter), and include an ample discussion of signification, supposition and consequences (cf. d'Ors 1981, Ashworth 1990, Di Liso 2000). Soto adopts an apparently Ciceronian definition of dialectic, considered as the art of discussing probabiliter. As remarked by Risse (1964-70, I, 330), however, this should not be considered a rhetorical attempt to establish apparent plausibility, but rather as an attempt to establish rational assertibility. Among the interesting points of the Summulae are the treatment of induction in terms of ascensus (the passage from a conjunction of singular propositions - or from a proposition with a copulative term as subject or predicate - to a universal proposition, or to a proposition with a general term as subject or predicate), and a complex square of modalities, which takes into account the quantity of the subject. Soto's discussion of second intentions offers what has been interpreted as a sophisticated theory of higher-level predicates (Hickman 1980).

One of Soto's students in Salamanca was Franciscus Toletus (1533-1596), who later taught both in Zaragoza and Rome, in the Jesuit Collegium Romanum, and was the first Jesuit to be appointed cardinal. Toletus wrote both an Introduction and a Commentary on Aristotle's logic (Toletus 1985). Like Soto, Toletus adopts some humanist theories - he takes the definition of logic as ratio disserendi from Boethius and divides it into invention and judgment - but his logic is actually a synthesis of Aristotelianism and Thomism, deeply influenced by the late medieval logical tradition. He considers beings of reason as formal objects of logic - thus partly endorsing the Thomist position - but maintains that logic's material object is constituted by our concepts of things and, ultimately, by things themselves, for logical beings of reason are only second intentions, based upon first-order concepts - thus 
partly endorsing the position of Arab commentators of Aristotle (Ashworth 1985b: xli). Of special interest is his extensive use of physical and geometrical examples within the discussion of categories, and his long discussion of contingent futures within the commentary on De Interpretatione.

The most important Jesuit philosopher working in Spain at the end of the Sixteenth Century was Francisco Suárez (1548-1617). His Disputationes Metaphysicae, first published in 1597 (Suárez 1965), constituted a reference text and a model for further works both in the Catholic and in the Reformed fields. According to Suárez, metaphysics offers a general and unified theory of real being (ens reale) and of its divisions, whereas logic deals with the way of knowing and explaining such divisions. Though the Disputationes Metaphysicae is not a logic textbook, it discusses many issues relevant to the philosophy of logic. Suárez pays great attention to relations, subdivided into real relations (only conceptually and not really distinct from the things on which they are grounded, but nevertheless to be considered as a category of beings) and conceptual relations, which are only a product of the mind and as such do not have any ontological status. Suárez's detailed discussion of both kinds of relations helps to explain the special interest that many Scholastic-oriented logicians devoted to this topic in the seventeenth century.

The last of the Disputationes - disputation LIV - is devoted to a subtle discussion about beings of reason (entia rationis) and relations of reason. According to Suárez, beings of reason are not 'real' (actual or possible) beings and do not share a common concept with real beings; their only reality is that of being object of the understanding (they only have objective existence in the intellect). Therefore, they are not to be included within the proper and direct object of metaphysics. They can nevertheless be dealt with within the context of metaphysical research, given their nature of "shadows of being" (Suárez 1996: 57) and given their usefulness in many disciplines, especially logic and natural philosophy. Suarez's opinion on entia rationis is thus different both from that of those - like the Scotist Francis of Mayronnes (1280?-1327?) - who simply denied their existence, and from that of those - like many Thomists, including Cardinal Cajetanus (Tommaso de Vio, 1469-1534) - who thought that there is a concept common to them and to real beings. Suárez included impossible objects in the range of entia rationis: his discussion is thus especially relevant for the history of the logical and ontological status of impossible entities (Doyle 1987-88, 1995). The discussion on the nature of entia rationis was a lively one in sixteenth century Spain, and was bound to continue in Catholic Europe during most of the seventeenth century. An interesting example is that of the Polish Jesuit Martinus Smiglecius (1564-1618). In his opinion, the opposition between ens reale and ens rationis is not grounded on the fact that the ens rationis is not a form of being, but on the fact that it is by definition a being which is not, and cannot possibly be, an ens reale. A being of reason is thus, according to Smiglecius, one whose essence implies the impossibility of its real existence. The fact that entia rationis cannot have real existence is, according to Smiglecius, a logical and not just a physical impossibility. They, however, can have conceptual (and hence intentional) existence.

In the later Middle Ages, English logicians had been famous for their subtleties: the logical, physical and epistemic sophisms discussed by the so-called calculatores, working at Merton College in Oxford, deeply influenced late fourteenth and early fifteenth century logic both in Paris and in Italy, and were exactly the kind of logical subtleties rejected by humanist logicians. During the fifteenth and in the first decades of the sixteenth century, however, the English logical tradition declined (cf. Giard 1985). This did not prevent a slow penetration of humanist ideas, testified by the 1535 statutes for the university of Cambridge, recommending the reading of Agricola and Melanchthon as substitutes for late medieval Scholastic texts, and by the Dialectica published in 1545 by the Catholic John Seton (c.1498-1567). The latter offers a drastically simplified treatment of traditional topics such as signification, supposition, categories, syllogism, but liberally uses non-formal arguments and literary examples, divides 
dialectic into invention and judgment, adopts Agricola's definition of dialectic as well as his classification of topics, and quotes, beside Cicero and Quintilian, modern humanists like Erasmus and Vives.

In the last decades of the sixteenth century the debate on Ramism was to shake both English and continental universities. In England, Ramus found in William Temple (15551627) a learned defender and commentator, who, despite the strong opposition of his fellow Cambridge teacher and former master Everard Digby (1550-1592), managed to make of Cambridge, albeit for a short time, a stronghold of Ramism. The penetration of Ramism in Oxford was less substantial, and by the beginning of the new century the anti-Ramist positions were predominant in both universities. The defeat of Ramism was accompanied by the propagation of Aristotelianism - tempered by humanist-oriented attention toward classical literary examples rather than purely logical ones and toward rhetorical practices such as the declamatio - and by the circulation of the leading logic books published in the continent (among them Zabarella and Keckermann). The Logicae Artis Compendium by the Oxford professor Robert Sanderson (1587-1663; Sanderson 1985) is a good example of this new situation. Sanderson abandons the division of logic into invention and judgment, favouring a threefold division according to the three acts of the mind: the first, dealing with simple concepts, is associated with the treatment of simple terms; the second, dealing with composition and division, is associated with propositions; and the third, dealing with discourse, is associated with argumentation and method. Though this threefold division is present in the medieval and late medieval tradition and is discussed by the Conimbricenses, Zabarella and Keckermann, Sanderson and other Oxford logicians seem to have been among the firsts to use it as the main division for logic textbooks (Ashworth 1985b: xli). In his logic, Sanderson includes medieval topics such as the theory of supposition and consequences, but their presentation is straightforward and not very elaborated. His discussion of method is more articulate, and gives a foremost role to pedagogical concerns.

We have already mentioned the Padua professor Jacopo Zabarella, who, advocating a renewed, 'pure' and philologically accurate Aristotelianism, absorbs both some humanist instances - visible in the pedagogical organization of his works and in the inclusion of Aristotle's Rhetoric and Poetic within a broad treatment of logic, on the ground of their dealing with probable arguments, such as rhetorical syllogisms and examples - and some features of the so-called 'Paduan Aristotelianism': a distinctive attention to the Arab interpretations of Aristotle (notably Averroes) and to Galen's concept of science. Zabarella wrote commentaries on Aristotle's logical works as well as autonomous logic tracts: among the latter are the De Natura Logicae (in Zabarella 1966), the De Methodis and the De Regressu (both in Zabarella 1985). According to Zabarella, logic deals with second intentions, that is, with the (meta)concepts produced by our intellect in reflecting on the first notions, those derived from and referring to real things. Since second intentions are products (and figments) of our intellect, logic is not a science, but an instrument, or, to be more precise, an instrumental intellectual discipline, aimed at devising conceptual tools for correct reasoning and for discriminating truth and falsity. Because of its instrumental nature, logic is somehow similar to grammar: just as grammar provides the tools needed to write and speak in an appropriate way, logic provides the tools needed to reason in an appropriate way.

According to Zabarella, order (ordo) and method (methodus) are among the main tools offered by logic: the first organizes the subject matter of a discipline and the knowledge we have acquired; the second gives the rules and procedures to be followed in order to acquire new knowledge, going from what we know to what we do not know. In dealing with contemplative sciences, the ordo goes from the universal to the particular and to the singular ('compositive order'), while in dealing with practical and productive arts it goes from the purposes to the principles that produce them ('resolutive order'). 
While order concerns a discipline as a whole, method always has to do with the handling of specific problems, of specific 'paths' going from what is known to what is unknown. Those paths are basically syllogistic demonstrations: the method is thus somehow a special case of syllogism. And since a syllogism can only go from cause to effect (compositive method or demonstratio propter quid) or from effect to cause (resolutive method or demonstratio quia), the same will hold for method. The resolutive method is used in the 'hunt' for definitions, and is most needed in natural sciences; the compositive method is used in mathematics, where we start from already known, general principles and try to demonstrate all their consequences. Both methods presuppose necessary connections and are therefore only valid within contemplative sciences: practical and productive arts, dealing with contingent truths, will have to content themselves with rhetorical and dialectical arguments, which, being only probable, are not subject to a rigorous application of method. However, even in contemplative sciences (especially in natural sciences), our knowledge of effects and of their causes is often far from clear, and we need a process of refinement which Zabarella calls regressus and which involves the use of both compositive and resolutive methods: (1) we first use the resolutive method to go from a confused knowledge of the effect to a confused knowledge of its cause; (2) we then examine and clarify the knowledge of the cause (examen) - an activity that Zabarella connects to a specific ability of the human mind interpreted by some modern scholars in terms of the construction of a model - and (3) we finally use the compositive method to go from a clear knowledge of the cause to a clear knowledge of the effect: this last stage is the highest sort of demonstration (demonstratio potissima), a notion already present in the Thomist tradition.

\section{Logic in reformed Europe: from Humanism to 'Protestant Scholasticism'}

It is unfortunate that most historical accounts of logic devote relatively little attention to Philipp Melanchthon (1497-1560), 'Germany's teacher' (praeceptor Germaniae), prominent reformer and close collaborator of Luther. Actually, in the overall context of European logic in the mid-sixteenth century, the role played by Melanchthon is one of the highest significance. From 1520, when, at the age of twenty-three, he published his Compendiaria dialectices ratio (Melanchthon, 1520), to 1560 - the year of his death - there are records of more than 60 different editions of his logic works. The last version of Melanchthon's dialectics, the Erotemata dialectics (Melanchthon 1846), was to be the standard reference for protestant logic until the beginning of the seventeenth century.

What makes Melanchthon's logic interesting and explains its influence is above all the very evolution of his works. In the Compendiaria Dialectices Ratio, a young, strongly antiScholastic Melanchthon offers a simplified and rhetorically oriented treatment of dialectic, purged of many "superfluous" Scholastic subtleties. Like many humanist dialecticians, here Melanchthon rejects the third syllogistic figure (which he considers "remote from common sense") and the treatment of modality (the Scholastic theories on modality are considered "tricky rather than true"). A few years later, however, Melanchthon's opinions on both matters (as well as on many others: cf. Roncaglia 1998) radically changed. In the De Dialectica libri IV (Melanchthon 1528) the third figure is accepted and discussed at length, and Melanchthon bitterly criticizes Valla for rejecting it, while in the Erotemata (Melanchthon 1846) the discussion of modal propositions is considered to be "true and perspicuous, useful in the judgment of many difficult questions". The evolution of Melanchthon's logic is thus marked by a progressive rejection of humanistic-rhetorical models and by a return to the Aristotelian and Scholastic tradition.

Two further aspects of the evolution of Melanchthon's dialectic deserve attention: the gradual shift from a bipartite toward a tripartite conception of the structure of the proposition, and the growing interest in fallacies. In 1520, Melanchthon endorses the theory that every 
proposition has two main components: subject and predicate. In 1528, the question is seen from a grammatical perspective, and noun and verb are considered as being the two main components of the proposition. The verb, however, is further subdivided: it may be a proper verb, or a construct made up of the substantive verb (the copula 'est') and a noun. And the copula acquires a fully autonomous role in the Erotemata, where every proposition is seen as having not two but three main parts: the subject, the predicate and an (explicit or implicit) copula, seen as the formal sign of the connection between subject and predicate. Such a theory will play an important role in subsequent logic, since the copula will be considered to be not only the logical 'glue' of the proposition, but the actual bearer of its modal and quality modifications (cf. Nuchelmans 1980, 1983, Roncaglia 1996).

The discussion of fallacies also testifies Melanchthon's increasing use of Scholastic doctrines. Absent in 1520, a short section on fallacies appears in 1528, accompanied, however, by the observation that anyone who has fully understood the precepts supplied for the construction of valid arguments doesn't need special rules to avoid paralogisms. But in the following editions of his dialectics Melanchthon systematically adds new divisions and new examples. He distinguishes between fault of matter and fault of consequence, corresponding to the traditional division of fallacies in dictione and extra dictionem, and presents the principal fallacies of both sorts. In the Erotemata, fallacies undergo a still closer scrutiny within a systematic framework clearly derived from Scholasticism.

Many elements indicate that there was one main and primary reason for this return to Scholasticism: the perception that the Reformed field - engaged in the sharp debate with Catholic theologians, and in the equally sharp debate among different Reformed confessions desperately needed effective logical tools. Rhetoric could be useful in winning popular support, but was much less effective in winning subtle theological debates. And in the complex theological and political struggle that was underway in Europe, universities were to become crucially relevant players. Logic was to become a weapon in the theological struggle, and Melanchthon was probably the first to perceive that clearly.

Melanchton's works on dialectic, together with the Dialectica by Johannes Caesarius (1460-1550), another interesting and influential mixture of humanist and Aristotelian elements, had thus the ultimate effect of paving the way that was to be followed by Protestant logicians: endorsement of some humanist doctrine (first and foremost the pivotal role of topics and inventio), and great attention to the pedagogical organization of their work, but within a context that retained many tracts of traditional logic; and that - given the relevance of logic for the theological debate - was to devote a renewed attention even to some of the once deprecated Scholastic subtleties.

It is therefore hardly surprising that the attempt, made by the so-called 'Philippo-Ramist' logicians, to conjugate Ramus' drive for simplicity and for systematic, method-oriented classification, with Melanchthon's humanist-influenced but somehow more conservative treatment of logic, was not destined to have a long success. Given the renewed role of logic in the interconfessional theological debate, the two paths were bound to diverge and the Ramist component was to succumb: at the end of the sixteenth century the antiRamist pamphlet was to become a well-established literary genus in the logic production of Protestant Germany. A fierce battle against Ramism was led by Cornelius Martini (15681621), among the founders of the so-called 'Protestant Scholastic". Martini endorses Zabarella's definition of logic as mental habitus dealing with 'second notions', i. e. concepts used to represent and classify, rather than immediately derived from perception. Martini divides logic into formal and material, with formal logic seen as dealing with the pure form of (syllogistic) consequences.

Zabarella's influence is also apparent in the work of Bartholomaeus Keckermann. In his Systema logicae (1600), the effort to organize logic as a discipline (largely on the basis of topics) is clear from the very definition of logic, which can be considered as a human ability - 
and is then to be regarded as a mental habitus - but can also be considered as the corpus of doctrines resulting from the use of this ability (ars externa): that is, as a system. In this perspective, knowledge of the historical constitution of this doctrinal corpus becomes important: therefore, it is not by chance that the short section on the history of logic, present in many sixteenth and seventeenth century treatises, acquires in Keckermann status, accuracy and completeness. Keckermann's interest in the history of logic is also connected with the eclectic tendency of many early seventeenth century logicians: given that in a Zabarella-oriented perspective logic is a human activity (and is also the systematically arranged, historical product of this activity), it is natural to try to collect the 'logical tools' developed by different logicians, in different times and contexts. This eclectic tendency is usually implicit, and is not necessarily connected with the endorsement of Zabarella's positions (some aspects of which were actually criticized by many systematic-oriented or eclectic logicians), but it is clearly present in the encyclopaedism of authors such as Johann Heinrich Alsted (1588-1638) or Franco Burgersdijk (1590-1636), whose Institutionum logicarum libri duo (1626) was the standard logic handbook in the Netherlands, and, like Keckermann, included a large section on the history of logic. A remarkable feature of this eclecticism is the tendency to re-absorb, within a context usually marked by Renaissance Aristotelianism, even some of Ramus' doctrines, notably the emphasis on the practical utility of logic and on the need of a well-arranged, easily graspable and pedagogically oriented method.

In the first half of the seventeenth century, in reformed Europe, despite the terrible destruction of the Thirty Years War, the university system was expanding, and acquiring a political relevance that was bound to transform any doctrinal difference in the occasion of sharp conflicts. This complex situation enhanced logical research and produced some new and interesting theories. In discussing the structure of the proposition, the Berlin-based Johannes Raue (1610-1679) proposed a new theory of the nature and role of the copula. In his opinion, the standard proposition of the form ' $\mathrm{S}$ is $\mathrm{P}$ ' should be analyzed as 'that what is $\mathrm{S}$ is that what is $\mathrm{P}^{\prime}$ (id quod est $S$ est id quod est $P$ ), that is, as having three copulas. The role of the main copula (the middle one, that Raue calls 'real copula') is then differentiated from that of the auxiliary ones: it can be used only in the present tense, while time and modal modifications are seen as operating on the auxiliary copulas. The pronoun 'id' stands for the 'third common entity' (tertium commune) in which subject and predicate are joined, and it has been observed that "Raue delights a Fregean reader when he emphasizes that ' $S$ ', the subject, (...) in his analysis is predicated of the tertium commune just as the predicate ' $\mathrm{P}$ '" (Angelelli 1990: 188). This 'newest theory', of which Raue is very proud, was criticized by Johannes Scharf (1595-1660): a polemical exchange that was well known to Leibniz. And Leibniz had the highest opinion of another famous logician of the time, Joachim Jungius (1587-1657). Jungius' Logica Hamburgensis, one of the most clear and complete logical works of the seventeenth century, deals at length with such relevant and 'advanced' topics as the theory of relations and the use of non-syllogistic consequences. Jungius is not the only one to deal with such theories, which were considered useful in theological disputations, but his treatment of them is always clear and insightful. This is especially true of his investigation of the inversio relationis (from 'David is the father of Solomon' to 'Solomon is the son of David') and of the consequence a rectis ad obliqua (from 'the circle is a figure' to 'he who draws a circle draws a figure'). Jungius' discussion of the latter - which he considers as a simple consequence (the consequent is inferred from the antecedent without the need of a middle term) - was the subject of a detailed analysis in the correspondence between Leibniz and Jungius' editor Johannes Vagetius (1633-1691), who tried to offer a formal representation of its structure (cf. Mugnai 1992: 58-62 and 152-153).

\section{Descartes and his influence}


"When I was younger I had studied, among the parts of philosophy, a little logic, and, among those of mathematics, a little geometrical analysis and algebra (...). But, in examining them, I took note that, as for logic, its syllogisms and the greater part of its other teachings serve rather to explain to others the things that one knows, or even, like the art of Lull, to speak without judgment about those of which one is ignorant, than to learn them (...). This was the reason why I thought that it was necessary to seek some other method, which, comprising the advantages of these three, were free from their defects" (Descartes 1994: 33-35).

This passage, from René Descartes (1596-1650) Discours de la méthode (1637), offers a good synthesis of Descartes' attitude toward traditional logic. Descartes' criticism of syllogism does not concern its validity, but its power as a tool for scientific research, and is clearly expressed in his Regulae ad directionem ingenii: "dialecticians are unable to devise by their rules any syllogism which has a true conclusion, unless they already have the whole syllogism, i.e. unless they have already ascertained in advance the very truth which is deduced in that syllogism" (Descartes 1974-86, X, 406). The core of the argument is a classic one, advanced in different forms at least since Sextus Empiricus (cf. Graukoger 1989: 6-25): syllogism is a circular form of reasoning, since it only holds if both its premises are already known to be true, but if both premises are already known to be true, the conclusion is already known to be true too. Therefore, to discover something new, we cannot depend on syllogism.

Pierre Gassendi (1592-1655) advanced a similar criticism. He observed that the evidence needed to accept one of the premises of a syllogism is provided or presupposed by its conclusion. Thus, in the Barbara syllogism "All $m$ are $p$, all $s$ are $m$, therefore all $s$ are $p$ ", the truth of 'All $m$ are $p$ ' can only be established by generalization of the fact that all instances of $m$ - including $s$ - are $p$ : the truth of the conclusion is presupposed by, rather than inferred from, the truth of the premises.

Descartes discusses a further argument against syllogism: the validity of a syllogism does not guarantee the truth of its conclusion, which depends upon the truth of the premises. The syllogism alone - while giving us the false impression of dominating the concepts we are dealing with - cannot establish it. This argument too is fairly traditional; in the period we are dealing with, we find a similar one in Francis Bacon (1561-1626): "We reject proofs by syllogism, because it operates in confusion and lets nature slip out of our hands. For although no one could doubt that things which agree in a middle term, agree also with each other (which has a kind of mathematical certainty), nevertheless there is a kind of underlying fraud here, in that a syllogism consists of propositions, and propositions consist of words, and words are counters and signs of notions. And therefore if the very notions of the mind (which are like the soul of words, and the basis of every such structure and fabric) are badly or carelessly abstracted from things, and are vague and not defined with sufficiently clear outlines, and thus deficient in many ways, everything falls to pieces" (Bacon 2000, 16). While in Bacon this argument is used to advocate the need of 'true induction' (progressive generalization accompanied by the use of his 'tables of comparative instances'), in Descartes it's used to advocate the role of intuition. According to Descartes, the process of knowledge acquisition depends on: 1) intellectual intuition, i.e. the intellectual faculty that allows a clear, distinct, immediate and indubitable grasp of simple truths, and 2) deduction, i.e. the grasp of a connection or relation between a series of truths. According to Descartes, deduction is therefore not to be seen as an inferential process governed by logical rules, but rather as the exercise of an intellectual faculty that is ultimately based on intuition. The process of mastering a long or complex deduction is a sort of intellectual exercise, consisting in the recursive application of intuition over each of its steps. The aim of this process is certainty: the idea of degrees of certitude or probability is totally alien to Descartes' intuition-based conception. And since for Descartes intellectual intuition is a natural faculty, there are no abstract rules or inference patterns governing intuition or deduction: we can only give 
precepts - like the well-known four regulae given in the Discours - helping us in the better use of this faculty.

One aspect of Descartes' concept should be stressed: the combined use of intuition and deduction allows us to attain knowledge, but does not suffice by itself to guarantee that the knowledge we attain is true. If a proposition $p$ is intuitively clear and evident for us, we are entitled to claim that it is true. But while this claim is justified, its correctness is not grounded on the fact that $p$ is perceived by us as clear and evident, since a deceptive God could give us a clear and distinct intuition of something that is not true (i.e. something that does not correspond to reality; from this point of view, Descartes is now generally considered as holding a correspondence theory of truth: cf. Gaukroger, 66). Therefore, the well-known cogito argument is needed to ensure God's external guarantee of our knowledge. According to Descartes, we only need (and we can only achieve) this external guarantee: God's knowledge is not a model for our knowledge, and there is no set of eternal truths binding God's knowledge and ours in the same way, since eternal truths themselves result from the joint action (or rather from the unique action) of God's will and understanding.

Descartes' resort to intellectual intuition as ultimate foundation of certainty is somehow at odds with his work in the field of algebra and geometry and with his discussion on the relevance of analysis. In Descartes' opinion, analysis is associated with the discovery of new truths (while synthesis has to do with presenting them in such a way as to compel assent), and its function is apparent in mathematics and in analytical geometry, when we use variables (general magnitudes) instead of particular values. Descartes, however, doesn't seem to perceive the possible connection of this method with deductive reasoning: on the contrary, he seems to associate deduction with the less imaginative, painstaking word of synthetically computing individual magnitudes.

The influence of Scholasticism on Descartes' philosophy is greater than one might suspect at first sight (cf. already Gilson 1913). For instance, hints at a 'facultative' concept of logic (see below sec. 6) were present in authors (among them Toletus, Fonseca and the Conimbricenses) he knew. But Descartes' concept of deduction differed very much from traditional logic. This did not prevent some Cartesian-Scholastic logicians to reconcile them. Johann Clauberg (1622-1665), in his aptly-named Logica vetus et nova (Clauberg 1658), defended Descartes' methodical rules against the charge of being too general or useless, attributing them the same kind of rigour and strength of Aristotle's logical rules. Johann Christoph Sturm (1635-1703) made a similar attempt.

More articulate was the position of Arnold Geulincx (1624-1669), who published a Logica Fundamentis suis restituta (1662), and a logic more geometrico demonstrata, the Methodus inveniendi argumenta (1663). Like most Dutch logicians, Geulincx was deeply influenced by the eclectic Aristotelianism of Burgersdijk (see above, sect. 3). He thus merged late Scholastic, Aristotelian and Cartesian themes in a logic that, with some hyperbole, he labelled 'geometric'. Its treatment includes the so-called De Morgan rules (well-known in medieval Scholastic logic, but less frequently dealt with by Renaissance logicians). He also devised a 'logical cube' whose faces represented all the axioms and argument forms of his logical system.

Descartes' influence is also evident in the Port Royal Logic, which we will discuss in the next section. Before dealing with it, however, there are two authors - somehow difficult to classify by means of traditional historiographic labels - which are worth mentioning: the French Jesuit Honoré Fabri (1607-1688) and the Italian Jesuit Gerolamo Saccheri (1667-1733). None of them was an 'academic' logician, and they both had wide-ranging interests. Fabri corresponded with most of the major philosophers and scientists of the time (including Descartes, Gassendi and Leibniz); was interested in philosophy, mathematics, astronomy (he discovered the Andromeda nebula), physics, and biology; and wrote on calculus and probabilism (his book on this subject was condemned by the Church). His 
Philosophia (1646) is influenced by Descartes, but the section on logic is pretty original: he developed a combinatorial calculus which allowed him to classify 576 syllogistic moods in all the four figures; he also used a three-valued logic (based on truth, falsity and partial falsity) which he applied to the premises and conclusions of syllogisms, and used disjunctions to express hypothetical judgments.

Wide-ranging were also the interests of Saccheri, who, besides working on logic, also wrote on mathematics and geometry. In trying to prove the parallel lines postulate, in the Euclides ab Omni Naevo Vindicatus (1733) he hints - against his will - to non-Euclidean geometries. Both in logic and in geometry he makes use of the consequentia mirabilis (well-known to the mathematicians of the time): if $p$ can be deduced from non-p, then $p$ is true. In his Logica demonstrativa (published anonymously in 1697) - a treatise on logic organized 'more geometrico' - he applies the consequentia mirabilis to syllogistic. One of his proofs refers to the rejection of AEE syllogism in the first figure. Saccheri shows that this very rejection (stated in E-form: "no AEE syllogism in first figure is valid") can be the conclusion of a first figure AEE syllogism with true premises. If such a syllogism is not valid, then it constitutes a counterexample to the universal validity of AEE syllogisms (which are thus to be rejected). If it is valid, the truth of its premises implies the truth of its conclusion. Such an elegant demonstration has been correctly seen as the mark of an argumentation strategy based on the skilful use of confutations and dilemmas (cf. Nuchelmans 1991, 133-7).

\section{The Port-Royal Logic}

A mixture of ancient and new doctrines characterizes the Logique ou l'Art de penser published anonymously in 1662 but written by Antoine Arnauld (1612-1694) and Pierre Nicole (1625-1695). The authors belonged to the Jansenist movement of Port-Royal, hence the current denomination of their work as the Port-Royal Logic (Arnauld-Nicole [1683]). According to widespread opinion, the authors endorse Descartes' philosophy. This is in many respects true, especially as regards the origin of ideas and the account of the scientific method. Indeed, in the 1664 edition of the book, the authors declare that the section on the analytic and synthetic method is based on the manuscript of Descartes' Regulae ad directionem ingenii. However, the Port-Royal Logic is not a straightforward Cartesian logic because it relies on many sources. Apart from the influence of Augustine and Pascal (1623-1662), the authors, though condemning Scholastic subtleties, acknowledge the utility of some Scholastic precepts and are not always adverse to Aristotle. True, they reject the Aristotelian categories and topics, but describe these doctrines and make them known to their readers.

The Port-Royal Logic is also different from a humanistic ars disserendi, and even more from an ars bene disserendi, as Ramus would have it, for it is intended to be an ars cogitandi, an art for thinking. The authors maintain that, since "common sense is not so common a quality as people think" (First Discourse 17, trans. 6), people ought to educate themselves to be just, fair, and judicious in their speech and practical conduct. Such an education should be offered by logic, but traditional logic pays too much attention to inference, whereas it should concentrate on judgment because it is in judging that we are liable to make errors compromising our rational and practical conduct. So, since judgment is a comparison of ideas, a detailed study of ideas must precede it.

In the Port-Royal Logic 'idea' is an undefined term: 'the word 'idea' is one of those that are so clear that they cannot be explained by others, because none is more clear and simple" (I, i, 40, trans. 25). 'Idea', therefore, is a primitive term that can only be described negatively. Accordingly, the authors maintain that ideas are neither visual images nor mere names, and are not derived from the senses, because, although the senses may give occasion to forming ideas, it is only our spirit that produces them. Once ideas are produced, logic investigates their possible relations and the operations one can perform on them. Such 
relations and operations are founded on a basic property of universal or common ideas (as different from singular ideas): the property to have a comprehension and an extension.

The comprehension of an idea consists of "the attributes that it contains in itself, and that cannot be removed without destroying the idea. For example, the comprehension of the idea of a triangle contains extension, shape, three lines, three angles, and the equality of these three angles to two right angles, etc." (I, vi, 59, trans. 39). The fact that the comprehension of 'triangle' contains not only three lines, but also the property proved by the theorem that the sum of its angles is equal to two right angles, gives way to speculations as to what extent humans dominate the comprehensions of their own ideas (Pariente 1985, $248 \mathrm{ff}$ ). The extension of an idea "are the subjects to which the idea applies. These are also called the inferiors of a general term, which is superior with respect to them" (I, vi, 59, trans. 40). The notion of extension is ambiguous. The subjects to which an idea applies can be intended either as the class of individuals of whom that idea can be predicated, or as the ideas in whose comprehension that idea is contained. In the latter sense, extension is clearly defined in terms of comprehension; therefore, comprehension is considered as a primitive notion in comparison with extension. The ambiguity of the notion of extension, already noticed by some interpreters (Kneale and Kneale 1962, 318-19), is somehow intended, for it serves, as we will see, to define different properties of the operations that can be performed on ideas, as well as to solve classical problems of quantification in the doctrine of judgment and reasoning.

If we subtract an attribute from the comprehension of an idea, by definition we obtain a different idea, in particular a more abstract one: given the idea 'man', whose comprehension certainly contains 'animal, rational', by subtracting 'rational' we destroy the idea 'man' and obtain a different and more abstract idea, which is the residual idea with respect to the original comprehension of 'man'. The operation just described is abstraction that, if reiterated, produces an ascending hierarchy of increasingly abstract ideas.

The operation of abstraction is the means by which the Port-Royal Logic introduces an inverse relation between comprehension and extension, often called the 'Port-Royal Law' in subsequent literature. For the authors maintain that in abstractions "it is clear that the lower degree includes the higher degree along with some particular determination, just as the I includes that which thinks, the equilateral triangle includes the triangle, and the triangle the straight-lined figure. But since the higher degree is less determinate, it can represent more things" (I, v, 57, trans. 38). This means that the smaller the comprehension, the larger the extension, and vice versa.

In order to move from a higher to a lower idea in the hierarchy we have to restrict the higher one. Restriction can be of two kinds. The first kind of restriction is obtained by adding a different and determined idea to a given one: if to the idea $\mathrm{A}$ (animal) we add the idea $\mathrm{C}$ (rational), so as to have a new idea composed by the joint comprehensions of $\mathrm{A}$ and $\mathrm{C}$, and if we call B (man) the idea thus composed, then B is a restriction of A and C and is subordinated to them in the hierarchy of ideas. This restriction cannot be obtained by adding to an idea some idea it already contains in itself, for the alleged restriction would be a mere explication of the given idea: if $\mathrm{B}$ contains $\mathrm{A}$, then by adding $\mathrm{A}$ to $\mathrm{B}$ we obtain $\mathrm{B}$, that is $\mathrm{BA}=\mathrm{B}$. The second kind of restriction consists in adding to a given idea "an indistinct and indeterminate idea of part, as when I say 'some triangle'. In that case, the common term is said to become particular because it now extends only to a part of the subjects to which it formerly extended, without, however, the part to which it is narrowed being determined" (I, vi, 59, trans. 40). The possibility of two kinds of restriction shows that comprehension and extension do not enjoy the same properties. While the first restriction modifies the comprehension of the restricted idea so that we get a different idea having a richer comprehension and a smaller extension, the second restriction concerns only the extension of the restricted idea with no modification of its comprehension: it remains the same idea. But this depends on the fact that the notion of 
extension of the Port-Royal Logic is, as already noticed, ambiguous. In this second case, the extension is obviously constituted by the individuals to whom the idea applies.

The Port-Royal Logic, also due to Augustine's influence, is very attentive to the linguistic expression of ideas. The authors maintain that: "if reflections on our thought never concerned anyone but ourselves, it would be enough to examine them in themselves, unclothed in words or other signs. But we can make our thoughts known to others only by associating them to external signs, and since this habit is so strong that even in solitary thought things are presented to the mind by means of the words we use in speaking to others, logic must examine how ideas are joined to words and words to ideas" (Untitled preface 38, trans. 23-24). This means that thought is prior to language and that a single thought can underlie different linguistic forms. This view of the relation between thought and language is one of the guidelines behind the project of a universal grammar contained in the Grammaire générale et raisonnée, published in 1660 by Arnauld in collaboration with Claude Lancelot (1616-1695) (Arnauld and Lancelot [1676]). This view, which has received great attention since Noam Chomsky's (1966) much-debated claim that it prefigures transformational generative grammar, is also relevant to logic.

Given that logic studies the properties of ideas, their mutual relations and the operations that can be performed on them, and given that ideas are designated by words which can be equivocal, the authors establish the convention that, at least in logic, they will treat only general or universal ideas (as different from singular ideas) and univocal words (I, vi, 58, trans. 39). Such are the words associated to ideas by way of a nominal definition, meant as the imposition of a name to an idea by way of a free, public and binding baptismal ceremony, of the kind used in mathematics and whose model is found in Pascal ([1658 or 1659], $242 \mathrm{ff}$ ). Nominal definitions make it possible to use words (particularly substantives) of ordinary language as if they were the signs of a formal language in which everything is explicit: "The best way to avoid the confusion in words encountered in ordinary language is to create a new language and new words that are connected only to the ideas we want them to represent. But in order to do that it is not necessary to create new sounds, because we can avail ourselves of those already in use, viewing them as if they had no meaning. Then we can give them the meaning we want them to have, designating the idea we want them to express by other simple words that are not at all equivocal" (I, xii, 86, trans. 60).

We can make not only abstractions and compositions of ideas, but also compare them and, "finding that some belong together and others do not, we unite or separate them. This is called affirming or denying, and in general judging" (II, iii, 113, trans. 82). Since judging is a comparison of ideas, and since the activity of making syllogistic inferences can be considered as a comparison of two ideas through a third one, syllogistic inferences loose much of their importance, while judging is established as the most important of our logical activities (Nuchelmans 1983, 70-87. This does not mean that the Port-Royal Logic neglects syllogisms. On the contrary, it contains an articulate doctrine of syllogism based on the fundamental principle that, given two propositions as premises, "one of the two propositions must contain the conclusion, and the other must show that it contains it" (III, xi, 214, trans. 165). It also contains a non-trivial treatment of syllogistic moods that was to be implemented by the young Leibniz in his De arte combinatoria (see below sec. 8). Such a treatment is based: on "the law of combinations", applied to "four terms (such as A.E.I.O.)" giving 64 possible moods, and on a set of rules that make it possible to select the well formed ones, so that, given rules for the valid moods in each figure, one can dispense with the doctrine of the reduction of other figures to the first: each mood of any figure is proved valid by itself (III, iv, 88-89, trans. 143-44). Indeed, though the first edition of the book contained a chapter on the reduction to the first figure, that chapter is left out of all subsequent editions. Nevertheless, though the authors seem competent in pointing out a frequent confusion between the fourth figure and the first figure with transposed premises (III, viii, 202, trans. 155), they are very traditional in 
other respects. For instance, they reduce the consequentiae asyllogisticae, called complex and composed syllogisms, to the classical categorical moods, thus provoking a reproach from Vagetius in the preface to the second edition of Jungius' Logica Hamburgensis (see above sec. 3).

The Port-Royal Logic attributes great importance to method, corresponding to the operation of the spirit called 'ordering'. Method is divided into two major sections: the first, devoted to demonstration and science, follows Descartes' methodical rules, thus giving an outline of the methods of analysis and synthesis; the second, devoted to opinion and belief, contains interesting observations about epistemic modalities and probability, as well as the outlines of Pascal's wager on the existence of God. By introducing the question of probability the Port-Royal Logic breaks away from one of the major tenets of Descartes' philosophy, and opens new perspectives for a probability not limited to games of chance, but extended also to events valuable on the basis of frequencies (Hacking, 1975b).

The Port-Royal Logic was highly successful, as can be gathered from its numerous editions (Auroux 1993, 87). Its influence, also thanks to Latin, English and Spanish translations (Risse 1964-70, II 79), is apparent in most of the subsequent European logical literature. Obviously some scholars still preferred the Aristotelian model. For instance, John Wallis (1616-1703), one of the best mathematicians of the time, though the Port-Royal Logic agreed with the argument he had already produced in 1638 that in syllogisms singular propositions must be considered as universal, rejects the Ramist syllogistic moods (Wallis 1687) on Aristotle's authority alone. A direct reaction to the Port-Royal Logic is presented by Henry Aldrich (1648-1710), whose Artis Logicae Compendium (Aldrich 1691), published anonymously, reprinted many times and still widely used in the Victorian era, preserves Scholastic doctrines and an account of the syllogism which "is the best available" (Ashworth 1974, 237). In some concluding remarks, Aldrich criticizes the fundamental principle of syllogism of the Port-Royal Logic, which he considers as a disguised version of the dictum de omni et nullo. Yet the very existence of such a criticism implicitly proves the fame the Port-Royal Logic had achieved (Howell 1971, 54-56). As for Port-Royal's seminal theory of probability, the young Leibniz already acknowledged its merits in 1667 (Leibniz 1923-, VI, i, 281 note), while Jakob Bernoulli wrote his Ars conjectandi, published posthumously (Bernoulli [1713]), as a development of that theory and as a complement to the Ars cogitandi, the Latin version of the Art de penser (Hacking 1975b, 78, Daston 1988, 49).

\section{The emergence of a logic of cognitive faculties}

Towards the end of the seventeenth century many logicians developed an interest in the analysis of cognitive faculties. Descartes moved in that direction when he focused his attention on the operations of intuition and deduction, but also the Port-Royal Logic considered the reflection on the nature of the mind as the means for a better use of reason and for avoiding errors. The study of cognitive faculties was not simply meant to provide an expositive framework for logical doctrines. As a matter of fact, dealing with the nature and object of logic and with the justification of the traditional partitions of logical treaties through a reference to mental operations had been a well-established practice since Aristotle's Organon: the operations of simple apprehension, judgment and reasoning had been mentioned as mental counterparts to the logical doctrines of concepts, judgments, and inferences (for a similar approach cf. Sanderson sect. 2 above). The novelty of what has been called the 'facultative logic' of the late seventeenth and eighteenth centuries (Buickerood 1985) is that the cognitive operations involved in the formation and use of ideas become a central concern of logicians.

The most important author working on a logic of cognitive faculties is John Locke (1632-1704). The Essay concerning Human Understanding (Locke 1690) is often quoted as a 
primary example of indifference, if not contempt, for logic. This is not true if it is intended to describe Locke's attitude to logic in general, rather than his attitude towards the doctrine of syllogism. Locke, who had been provided at Oxford with a sound Scholastic logical education (Ashworth 1980), asks logicians to give up their claim that they teach humans, who are born rational, how to reason by means of syllogisms (Essay, IV, xvii, 4). Logical research should rather investigate the way we form, designate, combine and, in general, use ideas.

This concept of logic attributes fundamental importance to language. If logic is the study of the faculties that produce and work with ideas, then it becomes impossible to ignore that we can work with ideas only in so much as we connect them to linguistic signs. This very connection of ideas to linguistic signs, although very useful, is a main source of our errors; therefore logic must provide a detailed treatment of the use and of the abuse of words. Indeed Locke compares logic to semiotic: " $\sigma \eta \mu \varepsilon \imath \omega \tau \iota \kappa \eta$, or the Doctrine of signs, the most usual

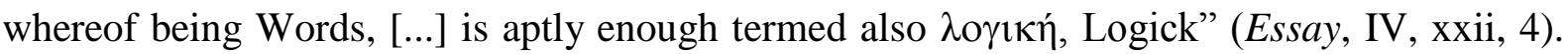
Locke does not intend to privilege the study of words over that of ideas, for he considers both ideas and words as signs, with the difference that ideas are signs of things and words are signs of ideas (cf. Ashworth 1984). Nevertheless it cannot be doubted that the success of Locke's philosophy contributed to the extraordinary importance language was to have for a large section of later philosophy and logic (cf. Hacking 1975a).

One could say that a logic centered on the study of faculties that produce ideas includes a good deal of epistemological, psychological and linguistic research (cf. Hatfield 1997). This is true, but one should consider that this is a consequence of a double effort. On the one hand, Locke wanted to continue the old battle against the ontological basis of the Aristotelian logical tradition by eliminating all talk about natural essences. On the other hand, he wanted to win the new battle against Cartesian innatism (accepted by the Port-Royal Logic) by investigating the empirical origin of our thought. A study of such questions and of the correct use of our ideas and their signs could provide a guide to man's intellectual conduct in the exercise of judgement, especially in an age characterized by a strong skeptical movement. But providing men with a guide in making judgements was seen as the purpose of logic: in this respect Locke had many predecessors, notably the authors of the Port-Royal Logic. It must also be considered that it was still left to logic, once the observation of cognitive operations was completed and a careful reflection on them was performed, to establish norms for the correct use of those very operations.

Defenders of the Aristotelian tradition, such as John Sergeant (1622-1707), criticized Locke's approach to logic (cf. Howell 1971, 61-71). But many more were Locke's admirers, and the impact of his views was impressive. Particularly successful was his refusal of innate ideas (Essay, I, ii), and his emphasis on probable knowledge, though he was far from considering probability from a quantitative point of view (cf. Hacking 1975b, 86-87). What interests us is that from a very early stage Locke's doctrines were included in logic textbooks, frequently in association with direct or indirect references to the Port-Royal Logic. This seems strange if one considers that Locke and the Port-Royalists were so far apart on the question of the origin of ideas. But this important difference was overlooked by taking into account what Locke and the Port-Royal Logic had in common: the purpose of logic as the guide for correct judgment, the idea that logicians should reflect on human understanding, the importance of the linguistic expression of our thoughts. Moreover, the Port-Royal Logic, whose intended readers included the students of the petites écoles of Port-Royal, who had to be prepared for the curricula of European universities, was a good source of information about traditional logical topics (such as syllogisms, fallacies, method) that the Essay lacked and that the Port-Royalists had treated without deference towards Aristotle.

Perhaps the first of such logic handbooks was the Logica sive ars ratiocinandi (Le Clerc 1692) written by the Swiss Jean Le Clerc (1657-1736), who adopted Locke's doctrine of judgement, his classification of ideas and his philosophy of language, and proposed a 
mixture of Locke's and Port-Royal Logic's theses as concerns the question of probability. A similar approach to logic is to be found in another Swiss scholar, Jean-Pierre Crousaz (1663-1750), who published a series of books on logic, the latest of which was Logicae systema (Crousaz 1724). As it can be expected, a number of British authors published Locke-oriented logic handbooks, most of which had several editions in Britain and elsewhere. Isaac Watts (1674-1748), in his Logick (Watts 1725) and in a popular supplement to it (Watts 1741), followed Crousaz and Le Clerc in offering a Lockean analysis of human nature (especially perception) with a preference for judgment and proposition, rather than syllogism. William Duncan (1717-1760), in his Elements of Logick (Duncan 1748), stated that the object of logic is the study of the faculties of the human understanding and of cognitive procedures, and divided logic into four parts according to the model of the Port-Royal Logic (cf. Yolton 1986). Francis Hutcheson (1694-1746) too, in his posthumous Logicae compendium (Hutcheson 1756), considered logic as the study of cognitive faculties, but also offered a kind of axiomatic presentation of syllogistic.

The Essay was promptly translated into Latin and French. By 1770, professors of Prussian universities were officially asked to follow Locke in their lectures on metaphysics (von Harnack [1900], I, i, 373). But much before that date Georg Friedrich Meier (1718-1777), the author of the text adopted by Kant for his logic courses (see below sec. 11), already used the Essay in his lectures. The reception of the Essay as a book of logical content was made easier by the inclusion of Locke's doctrines in logic handbooks such as those we have mentioned. But it was left to Locke's posthumous $O f$ the Conduct of the Understanding (Locke [1706] 1993), originally intended as an additional chapter to the fourth edition of the Essay, to enter directly into the field of logical literature. For in this small book Locke explicitly declares his views to be an improvement over the standard logic of his time (Buickerood 1985, 183). Of the Conduct of the Understanding was widely read not only in Locke's own country (Howell 1971, 275 ff.), but also in Germany. In the second decade of the eighteenth century, the Thomasian Johann Jakob Syrbius (1674-1738) used it as a guide for his lectures, and Wolff referred to it in his German Logic (Wolff [1713], Preface). Later on Georg David Kypke translated it into German (Locke [1755]), but at the time of this translation Locke had already been favourably discussed in the incipient German literature on the history of logic (Budde 1731).

In France, Locke's views were well received by authors who also supported Port-Royal's doctrines. This is the case of Jean Baptiste d'Argens (1704-1771) who, in the section devoted to logic of a philosophical treatise addressed to ladies, repeated the Lockean argument that all ideas originate from the senses, at the same time referring to the Port-Royal Logic (d'Argens 1737, Log. $\S \S 3,1$ ) in very positive terms. Among French scholars, Étienne Bonnot de Condillac (1714-1780), the influential promoter of a radically empiricist philosophy usually referred to as 'sensationism', deserves a special mention. In works of logical content written in the later part of his life - La Logique (Condillac [1780]) and the posthumous La langue des calculs (Condillac [1798]) - he developed a concept of logic that owes much to Locke, although he proudly maintains that it is similar to no one else's. Condillac describes logic as consisting of an analysis of experience by which we study both the origin of ideas and the origin of our own faculties (Condillac [1780], Preface). For, differently from Locke, who admitted sensation and reflection as sources of our ideas, Condillac admits sensation only and maintains that not only ideas, but also all our faculties originate from the use of the senses. This is possible because our senses are complemented by our fundamental linguistic capacity: we would not have complex ideas nor would we be capable of operating with them if we had no language. Consequently, Condillac maintains that any science is a well made language and such is also the art of reasoning, a conviction that made him reverse the priority order of grammar and logic (Auroux 1993, 93). He adds that, in order to build a well-made language, we need a method because language, despite its 
role in the acquisition of our cognitive faculties, has also been used to produce a jargon for false philosophies. The method Condillac recommends for the construction of a well-made language in any science is analysis, in particular analysis as it is used in mathematics, that he considers the paradigm of a well made science whose language is algebra.

\section{Logic and mathematics in the late seventeenth century}

At the end of the seventeenth century another image of the discipline began to emerge. It was borne out of a comparison of logic with mathematics, a comparison intended to prove the superiority of mathematics over logic.

Some authors ascribed the superiority of mathematics to its axiomatic-deductive method. This conviction had enjoyed considerable success (cf. De Angelis 1964), and was enhanced by an interpretation of Descartes' rules of method as recommendations to begin with a few simple and already known notions (axioms) and then proceed to unknown notions (theorems). Those who endorsed this interpretation seemed to draw the conclusion that the old logic centered on syllogism should be replaced by a new logic intended as a method to find and order truths according to the model of the mos geometricus.

Some authors attributed the superiority of mathematics to the problem-solving and inventive techniques of algebra. In this perspective, the search for equations relating unknown to given elements, exemplified in Descartes' Géométrie (1637), was interpreted as the true Cartesian logic and was absorbed into the tradition which viewed mathematics as a universal science of invention. In the seventeenth century, algebra was still a new technique, independent of logic, that many considered a rediscovery, but also an improvement of ancient mathematical doctrines. A reference to Descartes was somehow inevitable in this field too, since Descartes appreciated algebra as an intermediate step towards his more abstract mathesis universalis. (On the origins of algebraic thought in the seventeenth century see Mahoney 1980).

Naturally enough, some authors suggested that algebra could be a useful model for logic. This is the case of Ehrenfried Walter von Tschirnhaus (1651-1708). He left syllogisms and other traditional parts of logical treatises out of his logic but, as the title of his major work declares, he held that logic must provide a Medicina mentis, a remedy against the illness represented by our errors, and an aid for the healthy art of invention (Tschirnhaus [1695]). In particular, he claimed that his method of invention would have, in all fields of knowledge, the same function of algebra in the mathematical sciences. What he actually did, however, was to give an exposition of the methods of analysis and synthesis and a comment on Descartes' rules of method, albeit with a new attention to empirical sciences for which he envisaged a mixed method of a priori and a posteriori elements (Wollgast, 1988).

The assessment of the positive role that algebra could have for logic outlived the idea that logic should imitate, or even be substituted by, the axiomatic-deductive method. The latter was either reduced to a mere synthetic (top-down) order of exposition, or was declared inadmissible outside mathematics, either because of intrinsic differences between mathematics and other sciences (and philosophy), or because it was held responsible for the degeneration of Cartesianism into Spinozism. But also the algebraic model underwent profound changes. For the algebraic model, followed by many logicians from the late seventeenth century up to almost the end of the eighteenth century, is not the same as the algebraic model used in problem solving. Algebra is no longer considered as a methodical paradigm to be followed analogically by logic in order to restore the latter's function as an intellectual guide, but as a tool for logic. Many logicians now try to apply algebraic techniques directly to logical objects, i.e. to ideas and propositions. In other words, they try to build a logical calculus based on a symbolic representation of logical objects and on rules for manipulating signs, on the assumption that an adequate symbolism has been used. 
From this point of view doctrines of ideas such as those of the Port-Royal Logic and of the emergent logic of cognitive faculties, usually considered extraneous to the development of mathematically oriented logic, instead acted as stimuli and provided a field of application for the first tentative logical calculi. On the one hand, as it has been pointed out (Auroux 1993, 94), a calculus of ideas needs a theory of ideas. On the other hand, scholars who had welcomed a logic of cognitive faculties professed the highest esteem for algebra. We have mentioned Condillac's positive reference to algebra as the language of mathematics, but decades earlier Nicolas Malebranche (1638-1715) had claimed that "algebra is the true logic" (Malebranche [1674] 1962, VI, i, v). Also Locke, who belittled syllogistic and the axiomatic method, did not hide his admiration for algebra (Essay, IV, xii, 15). Locke, however, did not even think of applying the powerful tool of algebra to ideas. And neither did Thomas Hobbes (1588-1679), although in his De corpore published in 1655, whose first part is significantly entitled Computatio sive Logica, he maintained that reasoning is computation, where computing means adding several things or subtracting one thing from another in order to know the rest (Hobbes, [1839] 1961, I, i, § 2). But other scholars were ready to attempt the actual construction of logical calculi.

We will examine some of such attempts, but will first consider a declared failure to establish a parallelism between logical and algebraic reasoning, i.e. the Parallelismus ratiocinii logici et algebraici (Bernoulli [1685] 1969) of the above mentioned Jakob Bernoulli (1655-1705). This is an academic dissertation in which Jakob Bernoulli was the Praeses (and therefore the real author) and his younger brother Johann (1667-1748) was the Respondens, a circumstance that has often brought the attribution of the work to the 'Bernoulli brothers'. The parallelism concerns the objects, the signs, and the operations of both logic and mathematics.

The objects of logic are ideas of things, while the objects of mathematics are ideas of quantity. Likewise, the signs of ideas of things are words ('man, 'horse), while the signs of quantity are letters of the alphabet: $a, b, c$ for known quantities, and $x, y, z$ for unknown quantities. Bernoulli does not use literal symbols for ideas of things because, on a par with the Port-Royal Logic, he assumes that every idea of thing is (at least in logic) univocally designated by a word, so that every idea of thing has its own sign.

Bernoulli then introduces the operations we perform on both kinds of ideas 1) to put together, 2) to take away, 3) to compare.

1) Ideas of quantity are put together by the sign ' + ', as in ' $a+b$ '. Ideas of things are put together by the connective 'and', as in 'virtue and erudition'.

2) From an idea of quantity one can take away a smaller quantity, thus obtaining the difference: given $a$ and $b$, where $a$ is greater than $b$, the taking away of $b$ from $a$ is denoted by ' $a-b$ '. Similarly, from a complex idea of thing, one can take away one of the less complex ideas it contains, thus obtaining the difference: from the complex idea 'man' one can take away 'animal' and the difference is 'rational'.

3) Given two ideas of quantity, if the mind perceives an equality between them, it unites them by the sign ' $=$ ', as in ' $a=b$ '. If the mind perceives an inequality between them, it uses the signs ' $>$ ' and ' $<$ ', as in ' $a>b$ ', ' $a<b$ '. Given two ideas of things the mind can find: 1) agreement or identity between them, and in this case it will affirm one of the other; 2) disagreement or diversity between them, and in this case it will deny one of the other. Affirmation and negation take place thanks to an enunciation (enunciatio), and are expressed by 'it is' (est) and 'it is not' (non est), as in 'man is animal', 'man is not brute'.

While there is a parallelism between algebra and logic with respect to the operations of putting together and taking away, the parallelism breaks down in the case of comparison. Bernoulli first considers the case of agreement. Two ideas of quantity agree when a common measure, applied to them the same number of times, exhausts both, i.e. when they are equal. Two ideas of things agree, so that it is possible to affirm a predicate of a subject, provided that 
a third idea, common to both, exhausts at least the predicate: it is possible to affirm 'theft is sin', provided that some common idea is found in the 'theft' (no matter if 'theft' contains some other ideas besides) and exhaust 'sin'.

It is clear that Bernoulli intends the comparison of ideas of things as the comparison of their comprehensions. This is confirmed by the fact that 'theft is sin' is an indefinite proposition, i.e. a proposition whose subject is not quantified. Now, Bernoulli explains, in an indefinite proposition the predicate is found in the nature of the subject, which means that it cannot be taken away from the idea of the subject in which it is contained without destroying it, according to the Port-Royal Logic definition of comprehension.

We have seen that for Bernoulli the agreement or identity of subject and predicate subsists even if it is incomplete, i.e. if the third idea common to both exhausts the predicate without exhausting the subject. Here a problem arises: while the equality of quantities is mutual (if $a=b$, then $b=a$ ), an affirmative indefinite proposition expressing an incomplete agreement is not convertible: 'Man is rational' is true, but 'Rational is man' is false. Moreover: what happens if the predicate is not found in the nature of the subject, but is constituted by some accidental attribute? The answer is that it would be impossible to establish even a partial agreement and, strictly speaking, it would be impossible to affirm that predicate of the subject. Bernoulli decides to overcome these problems by quantifying over the subjects, i.e. by taking extensions into account. In this way it becomes possible to form true affirmative propositions such as 'All men are sinners' and 'Some men are learned', i.e. propositions that in the indefinite form ('Man is sinner' and 'Man is learned') are false. The proposition 'All men are sinners' is particularly interesting because it is a true universal proposition although 'sinner' is not found in the nature of 'man' (Jesus is (also) man, but is not sinner). Therefore, Bernoulli states that the subjects of universal and particular propositions are "the species or the individuals that are contained under that" (Bernoulli [1685] 1969, § 11, trans. 176).

But is it practical to consider which are the essential attributes of the subject and which are the accidental ones and, in the first case, be allowed to make indefinite judgments while, in the second case, resort to quantified ones? And how to overcome the problem of the impossibility of converting true indefinite propositions, which are exactly those that most resemble algebraic equations? Bernoulli suggests that one should always quantify all affirmative propositions, including true indefinite ones. Consequently, one will be allowed to say 'Some men are learned', which can be converted simpliciter into 'Some learned beings are men', as well as 'All men are sinners' and 'All men are rational', which can be both converted per accidens into 'Some sinners are men' and 'Some rational beings are men'.

Differences between algebra and logic also appear when a comparison of ideas shows their disagreement. In algebra, the disagreement of two ideas of quantity means that between them there is an inequality, a relation designated by the sign ' $<$ ' that is perfectly convertible: if ' $a<b$ ', then ' $b>a$ '. In logic the disagreement of two ideas of things is expressed by a negative indefinite proposition. But the subject and the predicate of negative indefinite propositions can be converted only if the disagreement depends on the opposition of the ideas considered, as in the case of 'man is not beast'. This means, as Bernoulli explained in later essays (cf. Capozzi 1994), that by converting 'Animal is not a man' one obtains 'Man is not animal', which is false, because man and animal are not opposite ideas. Also in this case logic has to resort to the quantified propositions of old syllogistic, but this means that there are no real logical equations between the ideas themselves. Not so in algebra, as it can be proved by the fact that every inequality is perfectly convertible. The conclusion is that no complete parallelism exists between algebra and logic. As a substitute, Bernoulli recommends the direct use of algebra in science by arguing that in science everything can be quantified and all that can be quantified can undergo algebraic treatment. His pioneering mathematical treatment of probability goes in that direction. 
Bernoulli's case is instructive. It shows that this is not a lethargic period of logic, as some historians have maintained (Blanché 1996, 169-178), but it also makes one wonder what made Bernoulli fail where other logicians - at the same time or a few decades later - made progresses. In our opinion the main reason for Bernoulli's failure was the doctrine of ideas he choose. We have already pointed out that Bernoulli depends on Port-Royal's view that every idea of thing can be univocally designated by a word (at least in logic), and that every idea of thing is endowed with an indestructible comprehension, conveyed by the word. In the case of affirmation, this makes Bernoulli consider only the relation of containment of the predicate in the subject as basic. Consequently, he is unable to deal with possible predicates that do not disagree with the content of the subject but are not contained in its comprehension.

In order to build a calculus it is not enough to have a rudimentary algebra and a doctrine of ideas. One has to choose a suitable doctrine of ideas.

\section{Leibniz}

The German logician and philosopher Gottfried Wilhelm Leibniz (1646-1716) has a foremost role in the history of formal logic. However, it is almost impossible (and probably misleading) to represent Leibniz's contributions to logic as a single and coherent set of theories nicely inserted within a linear path of development. There are at least three reasons that rule out such a reassuring view. In the first place, Leibniz contributed ideas - often through scattered and incomplete fragments rather than through structured and polished writings - to a plurality of logically relevant subjects: from the arithmetization of syllogistic to the theory of relations, from modal logic (and semantic of modal logic) to logical grammar; and the list could be easily extended. Moreover, relevant contributions are often found in works, fragments or letters not explicitly devoted to the field of logic.

In the second place, most of Leibniz's writings testify to a work in progress in the deepest meaning of the expression: different and sometimes incompatible strategies are explored in fragments dating back to the same years or even to the same months, corrections and additions may substantially modify the import of a passage, promising and detailed analysis remain uncompleted or are mingled with sketchy hints. Nevertheless, there is a method in Leibniz's passionate and uninterrupted research: a deeper unity that is given by a set of recurring problems and by the wider theoretical framework in which they are dealt with. Last but not least, it should always be kept in mind that Leibniz's works known by his contemporaries and immediate successors constitute a very limited subset of his actual production. It is only during the twentieth century that Leibniz's role in the history of logic came to be fully appreciated, and this appreciation is connected to at least two different moments: the publication by Louis Couturat, in 1903, of the Opuscules et fragments inédits de Leibniz (Leibniz 1966), many of which were devoted to logic, and the progress made during the second half of the century in the publication of the complete and critical edition of Leibniz's texts (Leibniz 1923- ). Almost three centuries after Leibniz's death, this edition (the so-called Akademie-Ausgabe) is, however, still to be completed.

Leibniz's interest in logic, and the amplitude of his logical background, is already evident in his youthful Dissertatio de Arte Combinatoria (Leibniz 1923- , VI, i, 163-230). This work is subdivided into twelve problemata (problems), mainly devoted to the theory of combinations and permutations, accompanied by a discussion of some of their usus (applications). Of greatest logical relevance are the combinatorial approach to syllogistic and the discussion of a symbolic language (characteristica) based on a numerical representation of concepts.

In dealing with syllogistic, Leibniz takes the work done by Hospinianus (Johannes Wirth: 1515-1575) as his starting point. Like him, Leibniz considers four different quantities - singular (S) and indefinite (I) propositions are added to universal (U) and particular (P) ones 
- and the two traditional qualities given by affirmative (A) and negative (N) propositions. Given that a syllogism consists of three propositions (the two premises and the conclusion), we have $4^{3}$ possible combinations of the four different quantities and $2^{3}$ possible combinations of the two different qualities. The number of possible different simple moods of the syllogism, valid and invalid, is therefore according to Leibniz $\left(4^{3} \times 2^{3}\right)=512$ : the same result obtained by Hospinianus. If we take into account the four different syllogistic figures (Leibniz includes and explicitly defends the fourth figure, which was rejected by Hospinianus), we get a total of $(512 \times 4)=2048$ 'moods in figure'. It is still through a combinatorial method, based on the exclusion of the syllogisms conflicting with four classic rules (nothing follows from pure particulars, no conclusion can be of stronger quantity than the weaker premise, nothing follows from pure negatives, and the conclusion follows the quality of the weaker premise) and of 8 further moods conflicting with the rules given for the four syllogistic figures, that Leibniz gets the number of 88 valid syllogistic moods.

While Hospinianus assimilated singular propositions to particular ones, Leibniz considers them similar to universal propositions, while indefinite propositions are connected to particular ones. In this way the number of valid moods in figure can be reduced to 24 (6 in each of the four figures): the 19 'classical' ones, plus 5 new ones which are actually the result of applying subalternation to the conclusions of the 5 'classic' moods with a universal conclusion.

The interest of Leibniz's treatment of syllogistic in the De Arte Combinatoria is not to be found in radical innovations concerning the number of moods of valid syllogisms, but rather in the fact that they are obtained through the systematic use of a combinatorial calculus, used as a sort of deductive device. The syllogistic 'deduction' of the rules of conversion is also part of this attempt, based - as in Ramus and in a number of sixteenth and seventeenth centuries German logicians, including Leibniz's former teacher Jakob Thomasius (1622-1684) - on the use of identical propositions. In a later fragment, the De formis syllogismorum mathematice definiendis (Leibniz 1966, 410-416), identical propositions are used in order to obtain a syllogistic demonstration not only of conversion but also of subalternation.

Since in this demonstration a first figure syllogism is used, Leibniz can 'deduce' all valid moods of the second and third figure using only the first four moods of the first figure, together with subalternation and the rule according to which if the conclusion of a valid syllogism is false and one of its premises is true, the second premise should be false, and its contradictory proposition should therefore be true (methodus regressus). The valid moods of the fourth figure can be deduced using conversion (the syllogistic proof of which only required moods taken from the first three figures). In this way, Leibniz will complete his construction of syllogistic as a sort of 'self-sufficient' deductive system.

The second result of the De Arte Combinatoria worth mentioning is the construction of a symbolic language in which numbers are used to represent simple or primitive concepts, and their combinations (subdivided in classes according to the number of primitive concepts involved) are used to represent complex or derivate concepts. Fractions are used to simplify the representation of complex concepts, with the numerator indicating the position of the corresponding term within its class and the denominator indicating the number of the class, i.e. the number of primitive concepts involved. In Leibniz's opinion, such a language would offer a solution to the main problems of the logica inventiva (logic of invention): finding all the possible predicates for a given subject, all the possible subjects for a given predicate, and all the possible middle terms existing between a given subject and a given predicate. This would also allow a mathematical verification of the truth of propositions and of the correctness of syllogistic reasoning. As we shall see, this project was to find a more developed and logically satisfactory form a few years later in 1679 . 
The idea of constructing a symbolic language in which numbers represent concepts is not new. Such an idea was already present in a number of attempts to construct a 'universal language', attempts which were often influenced by the combinatorial works of Ramon Llull. Leibniz himself makes reference to the works by Johann Joachim Becher (1635-1682?, Character pro notitia linguarum universali: 1661) and Athanasius Kircher (1602-1680, Polygraphia nova et universalis ex combinatoria arte detecta: 1663); similar attempts were made by Cave Beck (1623-1706?, The Universal Character: 1657) and others, and are described by Kaspar Schott (1608-1666, Technica Curiosa VII - Mirabilia graphica, sive nova aut rariora scribendi artificia: 1664). In the same period, the Spanish Jesuit Sebastian Izquierdo (1601-1681, Pharus Scientiarum: 1659), aiming at a sort of 'mathematization' of the ars lulliana, substituted numerical combinations for the alphabetical ones used by Llull, and something similar to a 'numerical alphabet' - highly praised by Leibniz - was developed by George Dalgarno (c. 1626-1687) in his Ars Signorum (1961).

In Leibniz, however, the construction of a numerical characteristica is not only a handy representational device: it is strictly connected with the idea of the inherence of the predicate in the subject in every true affirmative proposition (predicate-in-subject or predicate-in-notion principle). This idea was already present in the Scholastic tradition: in his Commentary on Peter of Spain's Tractatus, Simon of Faversham (c1240-1306) writes that propositions "are called complex because they are founded on the inherence of the predicate in the subject, or else because they are caused by a second operation of the intellect, namely the composition and division of simples" (Simon of Faversham 1969). During the Middle Ages, however, the inherence theory of the proposition was confronted with the idea according to which "in every true affirmative proposition the predicate and the subject signify in some way the same thing in reality, and different things in the idea" (Thomas Aquinas 1888-1889, I, xiii, 12).

The predicate-in-notion principle was to become a cornerstone of Leibniz's logical work, and Leibniz will apply it not only to analytical but also to contingent propositions: "always, in every true affirmative proposition, necessary or contingent, universal or singular, the concept of the predicate is included in some way or other in that of the subject" (Leibniz 1973, 63). In the De Arte Combinatoria, however, Leibniz only deals with propositions made of general terms, and - as it has been already mentioned - the principle is mainly used for the discovery of subjects and predicates within the context of the logica inventiva. Its explicit use as a method for checking the truth of a proposition given its subject and its predicate is to be found only in the 1679 essays (cf. Roncaglia 1988), where Leibniz chooses to represent simple or primitive terms by means of prime numbers.

The advantages of this notation were already stressed in a fragment, dated February 1678, known as Lingua generalis: "The best way to simplify the notation is to represent things using multiplied numbers, in such a way that the constituting parts of a character are all its possible divisors. (...) Simple elements may be prime or indivisible numbers" (Leibniz 1923-, VI, iv, 66). Just as compound (reducible) terms can be traced back - by means of definitions - to the simple, irreducible terms constituting them, the 'characteristic numbers' of compound terms will be obtainable from the multiplication of the characteristic numbers of the simple terms constituting them, so that the characteristic number of a compound term can always be univocally broken down into those of the simple (relative) terms composing it.

Even at the time of the De Arte Combinatoria, Leibniz was conscious of the difficulty in finding terms that are really simple, and had to be satisfied with simple terms of a relative and provisional nature. This difficulty was gradually to become, for Leibniz, an actual theoretical impossibility dependant on the limits of human understanding. While we can cope with abstract systems that are the result of human stipulation (and in which simple terms are established by us), only God can handle the much more complex calculus representing the 
infinite complexity of the actual world (and, as we shall see, of the infinite number of possible worlds among which the actual one has been chosen).

In order to give an example of his notation, Leibniz uses the definition of 'homo' as 'animal rationale', to which the following characteristic numbers are assigned:

animal $=2$

rationale $=3$

homo $=($ animal rationale $=2 \times 3)=6$

In order to verify the truth of a proposition, one has just to check whether the characteristic number of the predicate is or is not a prime factor of the characteristic number of the subject. The proposition "Homo est animal" is thus true, since the characteristic number of 'animal' (i.e. 2) is a prime factor of the characteristic number of 'homo' (i.e. 6).

A network of relations is thus established between the field of logic and its numerical 'model', allowing an actual logical 'interpretation' to be assigned to the numbers and arithmetical operations employed:

\begin{tabular}{|l|l|}
\hline Number & Term \\
\hline Prime number & Simple term \\
\hline Prime factorization of number & Analysis of term \\
\hline Number expressed in factorial notation & $\begin{array}{l}\text { 'Real' definition of term by means of its } \\
\text { component simple terms }\end{array}$ \\
\hline $\begin{array}{l}\text { Multiplication (calculation of the least } \\
\text { common multiple) }\end{array}$ & Conceptual composition \\
\hline $\begin{array}{l}\text { Exact divisibility of } a \text { by } b \text { (where } a \text { and } b \text { are } \\
\text { the characteristic numbers of the terms A and } \\
\text { B) }\end{array}$ & $\begin{array}{l}\text { Verification of the truth of the proposition 'A } \\
\text { is B' }\end{array}$ \\
\hline
\end{tabular}

This calculus, however, presents some difficulties if it is used as a device by which to verify all forms of syllogistic reasoning, as Leibniz intended to do. While it permits adequate representation of UA and PN propositions, it is clearly unsuitable - despite Leibniz's repeated attempts (including the use of fractions and square roots) to get around the problem - to represent UN and PA propositions.

The difficulties Leibniz encounters here are connected to the representation of the incompatibility between terms: while it is always possible to find the least common multiple of the characteristic numbers of two terms, it is not always possible to construct a term that includes any two given predicates. Some predicates are simply incompatible. It is then hardly surprising that, without a way to aptly 'restrict' the combinations of the terms' characteristic numbers (i.e. to restrict conceptual composition), Leibniz finds it 'too easy' to verify PA propositions and 'too difficult' to verify UN propositions.

To solve this problems, Leibniz modifies his notation, making it more complex but much more powerful. Instead of using only one characteristic number for each term, he uses a pair of numbers - one positive and one negative - with no common prime factors. The use of 'compound' (i.e. with a positive and a negative component) characteristic numbers allows for the following correspondences:

\begin{tabular}{|l|l|}
\hline 'Compound' characteristic number & Term \\
\hline Positive component of characteristic number & 'Affirmative' component of term \\
\hline Negative component of characteristic number & 'Negative' component of term \\
\hline $\begin{array}{l}\text { Prime factorization of 'compound' } \\
\text { characteristic number }\end{array}$ & Analysis of term \\
\hline $\begin{array}{l}\text { 'Compound' characteristic number expressed } \\
\text { in factorial notation, where no common prime }\end{array}$ & $\begin{array}{l}\text { 'Real' definition of term, demonstrating its } \\
\text { possibility by the absence of contradictions }\end{array}$ \\
\hline
\end{tabular}




\begin{tabular}{|l|l|}
\hline $\begin{array}{l}\text { factor is present in its positive and negative } \\
\text { components }\end{array}$ & within its definition \\
\hline $\begin{array}{l}\text { Presence of a common prime factor in the } \\
\text { positive and negative components of a } \\
\text { characteristic number }\end{array}$ & $\begin{array}{l}\text { Logical impossibility of the corresponding } \\
\text { term }\end{array}$ \\
\hline
\end{tabular}

Now, assuming that $\mathrm{a}(+)$ and $\mathrm{a}(-)$ represent the positive and negative components of the compound characteristic number assigned to the term $\mathrm{A}$, that $\mathrm{b}(+)$ and $\mathrm{b}(-)$ have the same function with respect to the term $\mathrm{B}$, and that $\mathrm{A}$ and $\mathrm{B}$ are possible terms (i.e. that no same primitive factor is present in either $\mathrm{a}(+)$ and $\mathrm{a}(-)$ or in $\mathrm{b}(+)$ and $\mathrm{b}(-))$ the following rules for the verification of propositions can be stated:

\begin{tabular}{|c|c|}
\hline $\begin{array}{c}\text { Presence in } \mathrm{a}(+) \text { and in } \mathrm{b}(-) \text { or in } \mathrm{a}(-) \\
\text { and in } \mathrm{b}(+) \text { of at least one common prime } \\
\text { factor }\end{array}$ & $\begin{array}{c}\text { Incompatibility between A and B: } \\
\text { verification of the proposition 'No A is B' } \\
(\mathrm{UN})\end{array}$ \\
\hline $\begin{array}{c}\text { Absence in } \mathrm{a}(+) \text { and in } \mathrm{b}(-) \text { or in } \mathrm{a}(-) \\
\text { and in } \mathrm{b}(+) \text { of common prime factors }\end{array}$ & $\begin{array}{c}\text { Compatibility of A and B: verification } \\
\text { of the proposition 'Some A is B' (PA) }\end{array}$ \\
\hline $\begin{array}{c}\text { Exact divisibility of } \mathrm{a}(+) \text { by } \mathrm{b}(+) \text { and } \\
\text { of } \mathrm{a}(-) \text { by } \mathrm{b}(-)\end{array}$ & $\begin{array}{c}\text { Verification of the proposition 'Every } \\
\text { A is B' (UA) }\end{array}$ \\
\hline $\begin{array}{c}\text { Non exact divisibility of } \mathrm{a}(+) \text { by } \mathrm{b}(+) \\
\text { and of a }(-) \text { by } \mathrm{b}(-)\end{array}$ & $\begin{array}{c}\text { Verification of the proposition 'Some } \\
\text { A is not B' (PN) }\end{array}$ \\
\hline
\end{tabular}

This more elaborate attempt is not without flaws, the most relevant being the problem of representing conceptual negation. Leibniz's proposal to obtain the characteristic number of a negative term like 'non-A' by simply changing the sign of the two components of the characteristic number of the corresponding positive term ' $A$ ' is ill-founded, and leads to inconsistencies in the calculus. The question raised here - the nature of conceptual negation has always raised problems for Leibniz (cf. Lenzen 1986), and is also connected to the more 'philosophical' problem of establishing the nature of incompossibility: a problem clearly stated in a famous passage of the fragment known as De veritatibus primis: "This however is still unknown to men: from where incompossibility originates, or what can make different essences conflict with each other, given the fact that all the purely positive terms seem to be compatible the one with the other" (Leibniz 1875-1890, VII, 195).

Nevertheless, Leibniz's logical essays of April 1679 represent one of the most interesting and complete attempts of arithmetization of the syllogistic, and offers a well developed - albeit not fully satisfactory - account of traditional logic by means of an intensional calculus. In a sense, they also represent a turning point in Leibniz's logical works. The unsolved difficulties in finding a numerical model for his still mostly combinatorial calculus, and the problems associated with the representation of negation, probably led Leibniz to a twofold shift in his strategies. On the one hand, despite the interest that notational systems will have for him during all his life, Leibniz became increasingly aware that the research of an apt notation should be accompanied by a closer investigation of the logical laws and principles that should constitute the structure of the calculus. On the other hand, semantic acquires a deeper role: Leibniz perceives that the rules governing conceptual composition cannot be reduced to a sort of 'arithmetic of concepts', and are much more complex. Negation, modality (with special emphasis on compossibility and incompossibility among concepts), relations (with special emphasis on identity), complete concepts of 
individual substances: much of Leibniz's logical and philosophical work in the following years will deal with these subjects.

The first tendency - a closer investigation of the logical laws and principles to be used in the calculus - is already clear in the Specimen calculi universalis and in its Addenda (both probably dating around 1680): here Leibniz abandons the exposition 'by examples' favouring the much more powerful algebraic notation, which uses letters to represent concepts. The perspective is still intensional, and the inclusion of the predicate in the subject remains the cornerstone of the system. According to the Specimen, the general form of a proposition is ' $a$ is $b$ ', and a per se true proposition is of one the three following forms: ' $a b$ is $a$ ', ' $a b$ is $b$ ' or ' $a$ is $a$ '. A per se valid conclusion is of the form 'if $a$ is $b$ and $b$ is $c$, then $a$ is $c$ ' (principle of syllogism), and according to Leibniz all true propositions can be derived from (or rewritten as) per se true propositions. The Specimen also contains the first clear formulation of one of Leibniz's key principles, that of substitution salva veritate: "Those are 'the same' if one can be substituted for the other without loss of truth" (Leibniz 1973, 34; for a discussion of this principle see Ishiguro 1991, 17-43). Among the principles used are those according to which in conceptual composition the order of terms and the repetition of a term are irrelevant (' $a b=b a$ ', and ' $a a=a$ '). The Addenda offer a short discussion of negation, which was not considered in the Specimen itself, and add some further proofs, including the theorem "if $a$ is $b$, and $d$ is $c$, then $a d$ will be $b c$ ". Leibniz calls it "praeclarum theorema" and proves it in this way: " $a$ is $b$, therefore $a d$ is $b d$ (by what precedes); $d$ is $c$, therefore $b d$ is $b c$ (again by what precedes), $a d$ is $b d$, and $b d$ is $b c$, therefore $a d$ is $b c$ " (Leibniz 1973, 41).

In the following years Leibniz will often use the signs '+' (or ' $\oplus$ ') and '-' to indicate logical composition and logical subtraction, stressing that the rules governing operations with concepts are different from those of arithmetical addition and subtraction: while in arithmetic ' $a+a=2 a$ ', in the case of conceptual composition ' $a+a=a$ '. Moreover, Leibniz will carefully distinguish between conceptual subtraction and logical negation: while in an abstract conceptual calculus it is always possible to 'subtract' from the concept of man that of rationality, seen as one of its intensional components, the result of denying it ('men non-rational') is a simple impossibility, given the fact that rationality is an essential part of the concept of man (Non inelegans specimen demonstrandi in abstractis, Leibniz 1923-, VI, iv, n. 178). These principles are among the ones governing the so-called 'plus-minus-calculus', that Leibniz developed in a number of fragments dating around 1687. The basic assumption of the plus-minus calculus is that ' $\mathrm{A}+\mathrm{B}=\mathrm{L}$ ' is to be interpreted as ' $\mathrm{A}$ (or $\mathrm{B}$ ) is included in $\mathrm{L}$ ', where the relation of inclusion is - as usual - the intensional inclusion between concepts. ' $\mathrm{L}-\mathrm{A}=\mathrm{N}$ ' is to be interpreted as conceptual subtraction: $\mathrm{N}$ is the intensional content of the concept $\mathrm{L}$ that is not included in the concept $\mathrm{A}$. If ' $\mathrm{A}+\mathrm{B}=\mathrm{L}$ ', the terms $\mathrm{A}$ (or $\mathrm{B}$ ) and $\mathrm{L}$ are said to be subalterns; two terms none of which is included in the other are said to be disparate, and two terms which have a common component are said to be communicating. It should be stressed that, here as elsewhere, Leibniz uses 'term' to designate not a linguistic entity but a concept: his calculus is thus directly an 'algebra of concepts'. The calculus uses 'nihil' to represent a term with empty intensional content, and the rules ' $\mathrm{A}+$ nihil $=\mathrm{A}$ ' and ' $\mathrm{A}-\mathrm{A}=$ nihil' are introduced. Leibniz also uses 'nihil' as a way to obtain 'privative' concepts: if ' $E=L-M$ ', 'L = nihil' and $\mathrm{M}$ is a non-empty concept, $\mathrm{E}$ will be a privative concept. This assumption has been criticized due to the fact that it introduces inconsistencies in the calculus (Lenzen, 2004), but can be seen as a further indication of the relevance that Leibniz attributed to the representation of negative or privative concepts within his logic, and of the difficulties connected with the difference between conceptual subtraction, arithmetical subtraction and logical negation.

The plus-minus calculus has recently been the subject of much interpretative work, also due to the publication of the long-awaited vol. VI, iv of the Akademie Ausgabe, which offers the first critical and complete edition of the relevant texts (Leibniz 1923- , VI, iv, vols. 
1-3). Among the problems debated (cf. Lenzen 2000, 2003 forth. and Schupp 2000) are the possibility of a set-theoretical representation of the calculus, and the relation between its intensional and extensional interpretations. As we have seen, Leibniz's approach is - in most of his logical writings - clearly intensional. However, Leibniz himself was well aware of the difference between intensional and extensional approaches, and considers the one as the reversal of the other: "the method based on concepts is the contrary of that based on individuals. So, if all men are part of all animals, or if all men are included in all animals, it is true that the notion of animal is included in the notion of man. And if there are animals that are not men, we need to add something to the idea of animal to get the idea of man. Since when the number of conditions grows, the number of individuals decreases." (Leibniz 1966, 235). This thesis may be (and has been) criticized, since the number of actually existing individuals falling under a given concept is usually contingent: from a Quinean point of view, "it might just happen that all cyclists are mathematicians, so that the extension of the concept being a cyclist is a subset of the extension of the concept being a mathematician. But few philosophers would conclude that the concept being a mathematician is in any sense included in the concept being a cyclist" (Swoyer 1995, 103). Nevertheless, as Lenzen (2003) correctly observes, this criticism cannot be applied (or at least not in such a naïve form) to Leibniz's logic: the (extensional) domain of Leibniz's logic is consistently characterized by Leibniz himself as one of possible rather than of actual individuals. The (possible) contingent coincidence of the sets of actually existing cyclists and mathematicians would by no means imply, from a Leibnizian point of view, that the two concepts have the same extension and therefore should have the same intensional content. In a later fragment, known as Difficultates quaedam logicae (Leibniz 1875-1890, VII, 211-217), Leibniz will even use the idea that the domain of his logic is one of possible rather than of actual individuals to justify the conversion per accidens of UA propositions (from 'All A are B' to 'Some B is A'), thus avoiding the problem of the existential import of PA propositions.

Despite the fact that they probably precede most of the texts on the plus-minus calculus, the 1686 Generales Inquisitiones (Leibniz 1982) are generally considered Leibniz's most developed and satisfactory attempt of logical calculus; Leibniz himself considered them a "remarkable progress" over his earlier works. The main feature of the Generales Inquisitiones is the attempt to offer a unified framework for a calculus of terms and a calculus of propositions. As far as terms (or concepts) are concerned, Leibniz distinguishes between integral terms (terms which can be the subject or the predicate of a proposition: the categorematic terms of Scholastic) and partial terms (terms like 'same' or 'similar', which are to be used only in conjunction with one or more integral terms, and specify or modify an integral term or a relation among integral terms: the syncategorematic terms of Scholastic). The introduction of partial terms and the discussion of oblique cases clearly testify to the new interest Leibniz devoted to relations. Being discussed at the term-level (and therefore at the level of concepts), relations and oblique cases are clearly not considered by Leibniz as mere linguistic accidents. The problem of the possible 'reduction' of partial or relational terms and of relational propositions to non relational ones is therefore not one of simple 'surfacestructure' reformulation of a spoken or written sentence, but rather one of logical analysis of the proposition and of its constituent terms. Leibniz was to devote much effort and a large number of texts and fragments to this analysis, clearly influenced by the late Scholastic discussion on relations and on the connection between the relation itself and its fundamenta, i.e. the concepts or the things among which the relation is established. Starting with Russell (1900), who attributed to Leibniz a straightforward and uniform reductionistic approach with respect to relations, criticizing it, Leibniz's treatment of relations has been the subject of much interpretative work. It is now clear that Leibniz offered different accounts for different kinds of relations and that, while he consistently denied relations an extra-mental reality independent from that of the related concepts, he thought that at least some relations (among 
those involving different individuals) are not reducible in a straightforward way to simple and non-relational monadic predicates. However, this does not imply, according to Leibniz, the need of propositions which are not in subject-predicate form, but rather the need (1) to consider within the properties pertaining to a given subject also those expressing relational accidents, and (2) to recognize the logical role of reduplicative terms, which can be used in connecting propositions referring to the different fundamenta of a same relation. Thus, the proposition "Paris loves Helen" can be reduced, according to Leibniz, to "Paris is a lover, and eo ipso (for this very reason) Helen is a loved one", rather than to the simple and independent propositions "Paris is a lover" and "Helen is a loved one" (Mugnai 1992). Reduplicative terms like quatenus, eo ipso etc., which were already studied by Scholastic and late-Scholastic logicians, in this way acquire a special role within Leibniz's logic.

In the Generales Inquisitiones, integral terms are further subdivided into simple, complex and derivative. The discussion of simple terms shows a clear shift when compared to the earlier combinatorial attempts: while general abstract terms like 'ens', derived from the Scholastic tradition and from the discussion on transcendental terms, are still present, Leibniz adds to the class of simple terms also terms connected to individuals and perceptions, like 'Ego' ('I') or the names of colours; a passage that somehow anticipates the discussion about simple and innate ideas that will be at the core of the much later Nouveaux Essais (Leibniz 1923- , VI, vi). However, as in the earlier attempts, the choice of simple terms remains provisional and is strongly influenced by the limits - both necessary and contingent - of our knowledge. A special case is that of the privative term non-ens: like nihil in the plus-minus calculus, non-ens corresponds here to a term with empty intensional content, and plays an important role in the axiomatization of the calculus.

Complex terms are obtained by composition from simple terms, while derivative terms are obtained from partial terms 'completed' by integral terms, i.e. from integral terms modified or connected by means of syncategorematic and relational terms or by the use of oblique cases.

In the Generales Inquisitiones, for the first time, Leibniz includes a discussion of complex terms referring to individuals (Leibniz 1982, 58-62) in his logical calculus. According to Leibniz, they are based on complete concepts, i.e. concepts that include all which can be said of that individual. Their complexity, however, is such that only God can carry out their complete analysis: men can only rely on experience to assert the possibility of a given complete concept (i.e. the absence of contradictions within its intension) and the inclusion of a given contingent predicate within a given complete concept. Complete concepts (corresponding to individual substances) are another theoretical cornerstone of Leibniz's philosophy, and it is no coincidence that in the very same year in which he was working at the Generales Inquisitiones Leibniz also wrote the Discours de métaphysique (Leibniz 1923- , VI, iv B, 1529-88), the text that offers for the first time and in a structured way the philosophical framework in which the theory of complete concepts is to be placed. Much of the interpretative work done on Leibniz's philosophy and philosophy of logic in the last three decades deals in one way or another with the discussion of complete concepts ${ }^{1}$ : from the possibility of distinguishing within them a 'core set' of essential properties, which could also allow for trans-world identification of individuals across possible worlds (each complete concept, if considered in its integrity, is 'bound' to a given possible world, and possible worlds themselves are seen by many interpreters as maximal sets of mutually compossible complete concepts), to the presence within complete concepts of relational predicates; from

\footnotetext{
1 Reference to secondary literature devoted to Leibniz's notion of complete concept could span over many pages. We will limit ourselves to the seminal papers by Mondadori (1973) and Fitch (1979), to the discussion included in Benson Mates (1986), and - for two recent accounts based on different interpretations - to Zalta (2000) and Lenzen (2003). Mondadori's and Fitch's papers are included, together with other relevant contributions, in Woolhouse (1993).
} 
the discussion of Leibniz's conception of contingency and of individual freedom to that of pre-established harmony.

Shifting from terms to propositions, Leibniz states in the Generales Inquisitiones that " $A$ is $B$ ' is the same as ' $A$ is coincident with some B', or A=BY" (Leibniz 1973, 56), where $\mathrm{B}$ is part of the intensional content of $\mathrm{A}$ : a formulation close to the ones we have already discussed, which, however, can be of interest if we consider the role attributed here to ' $\mathrm{Y}$ ', seen as a sort of existential quantifier applied to the predicate. Leibniz offers a wider discussion of predicate quantification in an undated fragment known as Mathesis Rationis (Leibniz 1966, 193-206, cf. Lenzen 1990), and in some of his (many) attempts of graphical representation of the basic notion of conceptual inclusion and of the four forms of categorical propositions, mainly based on the use of lines or circles (the fragment known as De formae logicae comprobatione per linearum ductus probably being the most notable among them: Leibniz 1966, 292-321).

In the Generales Inquisitiones, the connection between the treatment of propositions and that of terms is, if possible, even stronger than in the preceding essays, since Leibniz observes that the four traditional forms of categorical propositions can be rewritten in the following way (Leibniz 1982, 112; Leibniz's thesis is clearly indebted to the late-Scholastic treatment of the passage from proposition 'tertii adjecti' to propositions 'secundi adjecti'):

$\begin{array}{lll}\text { (PA) } & \text { Some A are B } & \text { AB est res } \\ \text { (PN) } & \text { Some A are not B } & \text { A(non-B) est res } \\ \text { (UA) } & \text { All A are B } & \text { A(non-B) non est res } \\ \text { (UN) } & \text { No A is B } & \text { AB non est res }\end{array}$

Here - if the proposition is not one about contingent existence - 'est res' is to be interpreted as 'is possible' (Leibniz 1982, 110), and possibility is in turn to be interpreted as absence of contradiction within the intension of the composed term. A similar conception is to be found in the Primaria Calculi Logici Fundamenta, dating to August 1690 (Leibniz 1903, 232-273).

This treatment of propositions leads to a term-oriented treatment both of syllogistic inferences and of hypothetical propositions. According to Leibniz, just like in a categorical proposition the subject includes the predicate, in a hypothetical proposition the antecedent includes the consequent. Therefore, an implication of the form 'If $p$, then $q$ ' is to be interpreted as 'If (A is $B)$ then $(C$ is $D)$ ', which in turn can be rewritten as ' $(A$ is $B)$ is $(C$ is D)', or '(A includes B) includes (C includes D)'. This idea, already present in a fragment known as Notationes Generales probably written between 1683 and 1685 (Leibniz 1923- , VI, iv, 550-557), will return in many later texts, and leads Leibniz to hold that the forms and modes of hypothetical syllogisms are the same as those of categorical syllogisms.

Leibniz never devoted a detailed analysis to the logic of propositions, but in many of his works and fragments refers to propositional rules derived from the medieval tradition of consequences and from the late-Scholastic discussion on topical rules; clearly, in his opinion, an 'algebra of propositions' can only be grounded on the algebra of concepts.

As already noted, most of the logical texts and many of the most remarkable achievements of Leibniz's logic were not known to his contemporaries and to his immediate successors. Nevertheless, Leibniz's logic cannot be considered simply an isolated product of a genial mind: Leibniz had a deep knowledge of the late-Scholastic logical tradition, from which he derives not only many topics he deals with, but often also the approaches adopted in dealing with them. And he also had a wide net of relationships - both through letters and by personal acquaintance - with many of the most prominent figures of the European learned world (Arnauld, Tschirnhaus, Jakob Bernoulli and, as we will see, Wolff, to name just some scholars mentioned in this essay). His logical and philosophical theses are also the result of 
those interactions, and probably some of them circulated even without the support of publication. Despite the great interest of Leibniz's logic from a contemporary point of view, Leibniz was a seventeenth century logician, not a twentieth century logician in disguise.

\section{Logic in Germany in the first half of the eighteenth century}

In the period we are considering, German logic deserves special attention. Since logic was a subject included in most academic curricula, it became a privileged field of study and a great number of logical texts were published (cf. Risse 1965). Many German logicians enter the debate on Cartesianism, are fully aware of Bacon's exhortation to work at a logic of empirical sciences, pay attention to the notion of probability, examine the relationship between logic and mathematics, and seem open to the suggestions of facultative logic. If one had to name a single author who takes a stand on all these questions, one should mention Leibniz. But, as already said, in this period Leibniz's logic enters marginally in the official picture of German logic, not only because his strictly logical production was unknown at that time, but also because he did not belong to the academic world. What was known of Leibniz's philosophy and logic influenced a number of German logicians of that time, but the logical scene of the first two generations of the German Enlightenment was dominated by Christian Thomasius and Christian Wolff.

Christian Thomasius (1655-1728) was the son of Jakob Thomasius, Leibniz's teacher. However, he does not share Leibniz's view of logic, in as much as he agrees with the humanists in criticizing schoolmen for having instructed generations of students in the making of useless subtleties. At the same time he advocates the study of logic. This is less paradoxical than it sounds. While the Port-Royal Logic recommended a logical instruction because common sense is not so common as people believe, Thomasius offers a moral and religious justification. He maintains that, because of the original sin, mankind has darkened its natural light (lumen naturale) and has to achieve a healthy reason through a process of purification, so as to avoid the errors it usually makes. This cathartic process is entrusted by Thomasius to logic because logic can teach how to counteract errors in judgment and their main source, i.e. prejudice (in particular, the prejudice of authority and the prejudice of self love). In this way Thomasius agrees with Tschirnhaus and the Port-Royal Logic that logic is a medicine and its primary aim is the correctness of judgments (Thomasius [1691b], Dedication). From the Port-Royal Logic - translated into Latin (Arnauld and Nicole 1704) by one of his followers Thomasius borrows arguments for rejecting Aristotelian categories (Thomasius 1702, VII $\S$ 25).

Such a concept of logic requires that technicalities should be abolished: only an 'easy' logic can dispel prejudices and teach how to profit from the few precepts needed for the rational conduct of common human beings - and not only learned scholars - in the search of truth and in the practical exercise of prudence. Thomasius' precepts consist of two basic rules of method: 1) to proceed from what is easy and known to what is more difficult and unknown, 2) to connect remote conclusions to principles only through near (propinquae) conclusions. In these two rules one can find an echo of Descartes. But Thomasius is not a Cartesian since he opposes the doctrine of innate ideas, convinced that in the intellect there is nothing that has not been in the senses (a thesis he argues for independently of Locke). He also rejects the tradition of the mos geometricus because he holds it responsible for the degenerate Spinozistic version of Cartesianism so that, from this point of view, he differs also from Tschirnhaus. Thomasius is rather an eclectic (Beck [1969], 247-56) who encourages the study of other philosophers' ideas, thus promoting studies in the history of philosophy and also in the history of logic: from 1697 to the first decades of the eighteenth century it is possible to register a number of essays on the latter subject (Risse 1964-70 II, 507). Thomasius' eclecticism can be easily appreciated if one considers that, on the one hand, he adds precepts derived from the 
tradition of humanistic dialectic to his apparently Cartesian rules of method and, on the other hand, he insists that logic should concentrate on the problem of certainty in empirical knowledge. Like many others in this period, Thomasius believes that, although in empirical matters complete certainty is not attainable, it is still possible to avoid skepticism by working on the notion of probability. However, Thomasius' interest for probability is not to be overestimated, since he inclines to a notion of probability still strongly connected with Aristotelian dialectic and with the doctrine of topical syllogism.

Thomasius' ideas were well received by the incipient age of Enlightenment that looked favourably to a logic meant for ordinary people (and this favoured the proliferation of textbooks) and, from a more theoretical point of view, approved of Thomasius' anti-skeptic battle regarding empirical knowledge. Nevertheless, Thomasius not only advocated a rigid separation between mathematics and philosophy, but also opposed any formalism in logic and deplored the enormous growth of syllogistic, convinced that the first figure is sufficient, though incapable of guaranteeing the truth of the conclusions (Thomasius 1702, IX, § 12; [1691a], XII, §§ 19-21). Many of his followers agreed on these matters, with a notable exception. In Halle, where a Thomasian circle was flourishing, Andreas Rüdiger tried to reconcile Thomasius' views on logic and philosophy with his own research on the nature and scope of logic.

Andreas Rüdiger (1673-1731) agrees with Thomasius that, due to the original sin, mankind no longer participates in God's archetypal logic and is prey of prejudices, thus making it necessary to conquer a recta ratio through the study of logic (Rüdiger 1722, I, i, 1). Rüdiger also agrees with Thomasius that logic should deal with probability as a response to skepticism, and to this effect produces an articulated doctrine of probability that obtained remarkable diffusion through the first edition of the Philosophishes Lexicon (Walch 1726) published by Johann Georg Walch (1693-1775). But what seems to interest Rüdiger most is that logic should be recognized as a legitimate means for finding truths and should be proved capable of attaining this purpose with a procedure as different as possible from the procedure of mathematics.

Rüdiger believes that Spinozism rests on two pillars: the doctrine of innate ideas and the illegitimate application of the mathematical method outside mathematics. Therefore, he rejects both. He is perfectly aware that mathematics is inventive, but he makes this depend on the fact that mathematical proofs can resort to sensibility. Rüdiger does not ascribe the sensibility of mathematical proofs to the use of 'visual' aids, such as geometric figures, but to the demonstrative procedures based on numeration. In his opinion: 1) mathematics is the science of quantity, 2) all quantities are measurable, 3) we can measure only in so far as we can numerate, 4) "all numeration is of individuals, in so much as their terms are perceived by the senses". His conclusion is: "Therefore all numeration is sensible: but the entire way of mathematical reasoning is numeration, then this entire way [of reasoning] is sensible Q.E.D." (Rüdiger 1722, II, iv, 1a). The possibility to avail themselves of this kind of sensible reasoning (ratiocinatio sensualis) enables mathematicians to refer to sensible data that would escape their attention if they could rely on intellect alone, whereas sensible data offer them the basis for the discovery of unknown (mathematical) truths (Rüdiger 1722, II, iv, 3c; cf. Cassirer 1922, 525-27).

The heuristic capacity of ratiocinatio sensualis rests on Rüdiger's theory of truth. According to Rüdiger, the truth of our judgements (which he calls logical truth) consists in the agreement of our knowledge with our sensation ("convenientia cognitionis nostrae cum sensione" (Rüdiger 1722, I, i, 12)). But we can trust the agreement of our knowledge with sensation only because there is a metaphysical truth that consists in the agreement of sensation with its objects ("convenientia ipsius sensionis cum illo accidente, quod sentitur"). This means that the metaphysical truth, which makes us trust our logical truth, presupposes that our senses are not fallible (Rüdiger 1722, I, i, 11). It is because our senses are not fallible 
(under God's guarantee) that the certainty and inventive power of mathematics can rest on sensible reasoning.

Outside mathematics, however, and in particular in the field of philosophy, we work only with ideas and cannot resort to the ratiocinatio sensualis. It is nevertheless possible to use a logical way of reasoning meant for ideas (ratiocinatio idealis) and as inventive as the ratiocinatio sensualis: the syllogism. By claiming that syllogism is inventive, Rüdiger openly challenges a long series of scholars, including Thomasius, who had criticized syllogism for being sterile. He argues that the inventive function of syllogism has not been appreciated because syllogism has been used for finding the premises of a given conclusion. This means that syllogism has been used analytically, whereas syllogism can be inventive if it is used synthetically, as a means for searching an unknown conclusion beginning from a given premise (Rüdiger 1722, II, vi, 1).

In order to show how a synthetic syllogistic is possible, Rüdiger assumes that every proposition (of the four kinds that can enter into syllogisms, A, E, I, O) expresses a precise relation between the subject and the predicate, a relation belonging to a set Rüdiger carefully classifies: subordination, opposition, partial diversity (he considers identical ideas as the same idea, cf. Rüdiger 1722, I, xii, 2, 3). On this assumption he maintains that we make a synthetic syllogism beginning with a premise whose two terms stand in one of the admissible idea-relations. We then obtain a conclusion by connecting one of the terms of the premise with any unknown idea that stands in a definite relation (included in the set of classified idea-relations) with the other term. For instance, given a universal affirmative proposition 'All A are B' (where A is subordinated to B) as premise, we can connect the predicate B with any idea $\mathrm{C}$ of which we only know the relation it entertains with the subject A. Let such a relation be that of subordination: we can validly conclude that the unknown idea $\mathrm{C}$, being subordinated to A is also subordinated to $\mathrm{B}$, so that, since the relation of subordination can be expressed by a universal affirmative proposition, we obtain the 'new' conclusion 'All $\mathrm{C}$ are B' (Rüdiger 1722, II, vi, 55 1-4). This single example makes it clear that Rüdiger's synthetic syllogistic is founded on the old technique of the pons asinorum (Thom 1981, 72-75), traditionally used for finding premises, a technique that Rüdiger could find in works of the Peripatetic tradition he knew well, pace Thomasius who had ridiculed it (Thomasius [1691a], XII, § 11). Rüdiger simply reverses the pons asinorum in the search for a conclusion, as it can be appreciated from the graphical representations he gives of his synthetic syllogisms (reunited in a single representation by Schepers $(1959,99)$ ).

Rüdiger expressed his views on ratiocinatio idealis in a logical environment in which they must have been unpopular. It is not surprising, therefore, that his direct followers, who approved of his separation of mathematics from logic, were no longer interested in his reason for separating them, i.e. his passionate defence of the inventive capacity of syllogism. Adolph Friedrich Hoffmann (1703-1741) and Christian August Crusius (1715-1775) choose to refer to Rüdiger as the philosopher who did not simply denounce, like Thomasius, the ill effects of the application of the mos geometricus to philosophy, but had argued that mathematics and philosophy should never be mixed because they have different objects and different methods of reasoning (Tonelli 1959). It may seem paradoxical, therefore, that Rüdiger's classification of idea-relations, supporting his doctrine of syllogism (as well as his doctrine of conversion and other non-syllogistic inferences) and connected to his thesis of the independence of logical from mathematical reasoning, was to stimulate later logicians to once again take up projects of an algebraic calculus of ideas. But such projects were not resumed until the Thomasian school, including its peculiar Rüdigerian variant, was no longer dominant, due to the emergence of Christian Wolff and his school.

Christian Wolff (1679-1754) has much in common with the first generation of the German Enlightenment. Like the Thomasians, he believes that philosophy should improve human life and give due importance to empirical knowledge. He also shares some of their 
religious motivations and their appreciation for Locke (see above sec. 6). What divides Wolff from Thomasius on logical matters is, first, a very different evaluation of mathematics and of the tradition of the mos geometricus: Wolff had received a mathematical education and was professor of mathematics in Halle. Secondly, Wolff acknowledges the intellectual influence exerted on him by Leibniz, with whom he exchanged a correspondence that ended only with Leibniz's death. In one of his letters Leibniz had recommended to Wolff to pay due attention to syllogism: "I absolutely never dared to say that the syllogism is not a means for finding truths" (Leibniz [1860], 18).

Consequently Wolff, far from contrasting syllogistic and the mathematical method, makes a double revolution with respect to the Thomasian school. He: a) assumes mathematical reasoning as an example to be followed in any research field, b) claims that the allegedly empty and useless syllogism is the inner fabric of any reasoning, including the exemplary mathematical one. In different places - but especially in his logical works, the socalled German Logic of 1713 and the so called Latin Logic first published in 1728 - Wolff considers geometrical demonstrations as chains of common syllogisms in the first figure (Wolff [1713], IV, §§ 20-25, Wolff [1740] § 551), and concludes that, where understanding and reason are concerned, there is a single rational procedure, a single method, a single logic valid for mathematics and philosophy alike: "both philosophy and mathematics derive their method from logic" (Wolff [1740], Preliminary Discourse $\S 139$ note).

The importance of syllogism is justified by Wolff by the argument that syllogism mirrors the natural way of reasoning. But he does not ground logic on empirical psychology alone (better: on the empirical psychology of a privileged set of men, the mathematicians, cf. Engfer 1982, 225). He declares that logic has a solid foundation also in ontology (Wolff [1740], Preliminary Discourse § 89).

Both pillars of this foundation of logic conspire in favouring syllogism: 1) ontology, as it was established in the Scholastic tradition, justifies the dictum de omni et nullo that presides over syllogism in the first figure (Wolff [1740], § 380), 2) empirical psychology ensures that the model of natural inference is the simplest syllogistic inference, i.e. syllogism in the first figure. Wolff's foundation of syllogism - and indeed of logic - on ontology and empirical psychology grants an absolute privilege to syllogisms of the first figure. To this effect, Wolff maintains that figures different from the first (he does not admit the fourth figure) are not simply reducible to it, but are already syllogisms in the first figure in disguise: they are cryptic first figure syllogisms (Wolff [1740], §§ 382-399; cf. Capozzi 1982, 109-21). He also maintains that non-categorical syllogisms, consequentiae immediatae and any other kind of inference are reducible to syllogisms in the first figure. In this way, Wolff contrasts anti-syllogistic conceptions, but makes no concessions to Rüdiger: the syllogisms he refers to are absolutely standard and in no way synthetic. In a letter to Leibniz, he scorns Rüdiger's synthetic syllogistic and refers to the idea of a mathematical ratiocinatio sensualis as to one of the "paradoxa" of Rüdigerian logic (Leibniz [1860], 117).

Despite his meagre syllogistic, Wolff offers a deeply 'logicist' philosophy of logic, for not only does he bring logic and mathematics together, but he also considers logic prior to mathematics. This makes one wonder why he did not try a mathematical calculus of ideas. This problem is clearly related to the possibility of a heuristic. Wolff knows that mathematicians use heuristic devices not reducible to syllogisms. In his German Logic he denies that "the whole algebraic calculus [..] takes place only according to syllogisms in form" (Wolff [1713], IV,$\S 24)$. A similar statement is to be found in his Latin Logic: "logic [i.e. logic centered on syllogism] has a notable and famous use in the art of discovery, but nevertheless it does not exhaust it" (Wolff [1740], § 563). Elsewhere he explains that, in order to discover hidden truths, it is sometimes necessary to resort to heuristic artifices such as, in the a priori invention, the artifices of the ars characteristica (cf. Arndt 1965). For, he says, this art helps separate geometric and arithmetic truths from images, so as to obtain truths from 
the data by means of a calculus. He grants that such an art is the most perfect science, but he believes that we only have a few examples of that art in algebra, yet none outside it (Wolff [1713] IV, § 22). The latter statement is revealing: to Wolff the establishment of a suitable alphabet of thoughts as a prerequisite of the ars characteristica combinatoria must have appeared too great an obstacle. We know that this was a problem for Leibniz and we know how he dealt with it. But apparently Wolff was convinced that a calculus in logicis is utopian and considered it a mere desideratum.

As to Leibniz's interest in a logic of probability to be used when deliberating about political, military, medical and juridical matters (Leibniz [1860] 1971, 110), Wolff seems to doubt that a mathematical ars conjectandi could be of practical use regarding such matters (Leibniz [1860] 1971, 109). Wolff's doubt was not so strong as to make him exclude that Leibniz's wish could ever come true, but was strong enough to make him exclude that it could come true in the foreseeable future. Nevertheless, Wolff includes probability in the practical part of his logic, paying attention to the features of probable propositions, in particular to the ratio of sufficient and insufficient reasons that make it possible to consider probability a measurable degree of certainty. In this way, he definitely abandons not only Thomasius' obsolete treatment of probability reminiscent of the old topic, but also Rüdiger's non-mathematical analysis of probable knowledge.

Wolff made a great impact on German philosophy and some of his doctrines were well received in Europe at large, as can be appreciated from the evident Wolffian imprint of some entries in the French Encyclopédie (Carboncini 1991, 188 ff.), where Locke and Port-Royal Logic had already found much space (Risse 1964-70, II 528). However, at first Wolff met with harsh criticism, albeit not for his logical but for his metaphysical views. In 1723, the Halle circle succeeded in convincing King Friedrich Wilhelm to banish Wolff from the city because of his alleged determinism, inherited from Leibniz, was a peril to religion (Wundt [1945], 234-44; Beck [1969], 258). Wolff went to Marburg, where he wrote a series of works in Latin, beginning with the Latin Logic. Wolff's Latin works increased the number of his followers, so much so that a second anti-Wolffian offensive, launched in 1734, ended in a defeat when, in 1740, Wolff was readmitted to Halle with great honors.

The Wolffian era, as concerns logic, was very positive. Despite literature that considers Wolff an exponent of the dark ages of logic, it is difficult not to give him credit for proposing a positive image of the discipline resting not only on its function as a guide in making judgments and in avoiding errors, but also on the power of its inferences. But, above all, it is impossible to ignore that his revaluation of syllogism differed from Rüdiger's because he used it to counteract the idea of a gap between logic and mathematics. This explains why Wolff's success promoted a revival of logic that did not simply contribute to the production of new logical textbooks - given the importance he accorded to logic in academic curricula - but spurred logical investigations. It must be stressed that those who were encouraged by Wolff's philosophy to engage in logical research did not usually follow the details of his logic. Independent authors, as well as a number of Wolffians, referred to old logical literature, including sixteenth and seventeenth century Aristotelian and Scholastic treatises, and even to the works of anti-Wolffians, especially those of Rüdiger, undoubtedly the most distinguished of them. In this sense one must agree with Risse that, if one excludes the very first generation of Wolff's followers, it is difficult to draw precise boundaries between the Wolffian School and its opponents (Risse 1964-70, II, 615).

An example of the new post-Wolffian logicians is Johann Peter Reusch (1691-1758). In his fortunate Systema logicum (Reusch [1734]), though in many respects faithful to Wolff, Reusch admits the influence of Aristotle, Jungius, the Port-Royal Logic, Johann Christian Lange (1669-1756) and Rüdiger (Reusch [1734], Preface). As to the question of syllogistic, Reusch informs his readers about traditional doctrines and about the combinatory of syllogistic moods with a reference to Leibniz's De arte combinatoria (Reusch [1734] § 530). 
Nevertheless, he also proposes a syllogistic that, he maintains, opens the gates of the syllogistic moods (modorum cancelli) (Reusch [1734] § 543), being founded upon a single rule to which all syllogisms of any figure must conform: "The entire business of reasoning is done by substitution of ideas in the place of the subject or of the predicate of the fundamental proposition, that some call equation of thoughts" (Reusch [1734] § 510). In other words, Reusch conceives of syllogisms as consisting of a single premise (propositio fundamentalis) and a conclusion obtained by assuming a new idea and substituting it for either the subject or the predicate of the propositio fundamentalis by a substitution rule. Such a substitution rule which he means as a version of the old dictum de omni et nullo - is governed by the principle of contradiction and presupposes a network of relations among ideas.

The description of the admissible idea-relations is so important for Reusch's syllogistic, and indeed for his whole logic, that two chapters of his Systema logicum - De convenientia et diversitate idearum and De subordinatione idearum - are devoted to it. This study is clearly influenced by Rüdiger (Capozzi 1990, lxvi), but Reusch did not refer to Rüdiger as the defender of a synthetic inventive syllogistic, but as the author of a syllogistic based on a definite set of idea-relations. That this was the outstanding feature of Rüdiger's logic was clear to the historian of logic von Eberstein who, though unfavourable to Rüdigerian philosophy, in 1794 stated that Rüdiger had been the first to determine "syllogistic figures according to the relations of concepts and not according to the position of the middle term" (von Eberstein [1794-99], I, 112-3). No wonder the independent Wolffian Reusch was attracted to this approach to syllogistic so as to prefer it to Wolff's idolatry for the first figure and to Leibniz's combinatory of moods in the De arte combinatoria.

In Reusch, however, there is no hint of a separation between the ratiocinatio sensualis of mathematics and the non-mathematical ratiocinatio idealis advocated by Rüdiger as an argument in favour of the inventive power of his synthetic syllogisms. This is true not only of Reusch. After Wolff, logic is acknowledged as the only argumentative structure used in every field of knowledge, from mathematics to philosophy. This is why a few logicians felt entitled to take a further step: if, according to Wolff, there is no longer a gap between logic and mathematics, nothing prevents from disregarding Wolff's restriction of logic as an outdated syllogistic. These logicians felt entitled to apply mathematical tools to ideas according to the study of idea-relations made by the adversaries of Wolffian logic or by independent Wolffians.

\section{Logical calculi in the eighteenth century}

In Jena, where Reusch was professor of logic and metaphysics since 1738, his attitude towards logic was not an exception, as can be seen in the logical work of Joachim Georg Darjes (1714-1791). But the outstanding work written in this logical context is an essay that Reusch recommended in the 1741 edition of his Systema logicum to his more specialized readers. This work is the Specimen Logicae universaliter demonstratae (Segner [1740] 1990) written by the mathematician and scientist Johann Andreas Segner (1704-1777) with the explicit aim of treating syllogistic by way of a calculus (per calculum) based on the example of algebra.

To this end, Segner builds an axiomatic system consisting of 16 definitions, 3 postulates and 2 axioms. The definitions introduce ideas, their relations, and their arrangement in a hierarchy of genera and species and the operations for forming ideas. Segner defines 'idea' as a mental representation of something. If the idea is simple, its contents are obscure ideas and the simple idea is confuse for us; if the idea is composite, its contents are clear ideas and the composite idea is distinct for us. Consequently, by definition, every idea contains some idea within itself. In this way, Segner can presuppose the relation of containment (viewed from an intensional perspective) as the basic relation between two ideas. 
But it must be clear that Segner does not identify the content of an idea with its comprehension in the sense of the Port-Royal Logic. He simply says that, given two ideas A and $\mathrm{B}, \mathrm{A}$ is contained (or involved) in B if, whenever B is posited, A is also posited.

The notion of containment is used to define all the relations between two ideas that are relevant for the construction of a calculus. Segner designates such relations by special algebraic symbols ' - ' , ' $=$ ', '>', ' $<$ ', ' $\times$ ', and defines them as follows:

I. $A$ is opposed to $B$, if $A$ contains $-B$ and $B$ contains $-A$

II. $A$ is identical to $B(A=B)$, if $A$ contains $B$ and $B$ contains $A$

III. $A$ is superior to $B(A>B)$, if $A$ does not contain $B$ and $B$ contains $A$

IV. $A$ is inferior to $B(A<B)$, if $A$ contains $B$ and $B$ does not contain $A$

$\mathrm{V}$. $\mathrm{A}$ is coordinated to $\mathrm{B}(\mathrm{A} \times \mathrm{B})$, if $\mathrm{A}$ does not contain $\mathrm{B}$ and $\mathrm{B}$ does not contain $\mathrm{A}$.

As can be seen from this list, Segner does not have a symbol for the relation of opposition, but expresses the opposition between $\mathrm{A}$ and $\mathrm{B}$ by saying that $\mathrm{A}$ contains $-\mathrm{B}$ and $\mathrm{B}$ contains $-\mathrm{A}$. By the expression $-\mathrm{A}$ Segner refers to the idea that is infinitely opposite to A, and defines $A$ as infinitely opposite to $-\mathrm{A}$ if $\mathrm{A}$ contains - $-\mathrm{A}$, and $--\mathrm{A}$ contains $\mathrm{A}$. It must be stressed that Segner does not intend an idea designated by $-\mathrm{A}$ as a 'negative' idea opposed to a 'positive' one: if by A we indicate 'non-triangle', by -A we indicate 'triangle'.

Ideas, that can be put in a hierarchy of subordination, can also be submitted to the operations of composition and abstraction, whose possibility Segner guarantees by two special postulates. A further postulate guarantees that if $\mathrm{A}$ is an idea, then $-\mathrm{A}$ is an idea. Segner finally states two axioms that express conditions satisfied by some of the operations:

Axiom I: if $A$ and $B$ are opposite ideas, then there is no idea $C$ such that $C=A B$

Axiom II: if A contains $\mathrm{B}$, then $\mathrm{AB}=\mathrm{A}$

In this simple system (somewhat simplified here) Segner derives a number of propositions (either problems or theorems) strictly connected to his calculus. Among the most important are the following:

1. Given an idea $A$, by abstracting some of its contents, find an idea $B$ such that $B>A$

2. If, given two ideas $A$ and $B$, there is an idea $A B$ different from either $A$ or $B$, then $A \times B$

3. Given a universal idea $A$ and its coordinate idea $B, A B<A$ and $A B<B$

4. No infinite idea can be inferior or identical to a finite idea

5. The defined relations among ideas are exhaustive and reciprocally exclusive: they are not reducible one to the other.

A number of theorems establish how the relation (and therefore the sign) between two ideas changes if one of them is replaced by its opposite:

6. If $A=B$, then $-A=-B$

7. $\mathrm{A}<\mathrm{B}$, then $-\mathrm{A}>-\mathrm{B}$

8. If $A>B$, then $A \times-B$

9. If $A \times B$, then $-A \times B$; if $-A \times B$, then either $-A \times B$ or $A>B$.

Further theorems give an exhaustive list of valid syllogisms:

10. $\mathrm{A}=\mathrm{B}$ and $\mathrm{C}=\mathrm{B}$, then $\mathrm{C}=\mathrm{A}$

11. $\mathrm{A}=\mathrm{B}$ and $\mathrm{C}>\mathrm{B}$, then $\mathrm{C}>\mathrm{A}$

12. $\mathrm{A}=\mathrm{B}$ and $\mathrm{C}<\mathrm{B}$, then $\mathrm{C}<\mathrm{A}$

13. $\mathrm{A}=\mathrm{B}$ and $\mathrm{C} \times \mathrm{B}$, then $\mathrm{C} \times \mathrm{A}$

14. $\mathrm{A}>\mathrm{B}$ and $\mathrm{C}<\mathrm{B}$, then $\mathrm{C}<\mathrm{A}$

15. $\mathrm{A}>\mathrm{B}$ and $\mathrm{C} \times \mathrm{B}$, then either $\mathrm{C}<\mathrm{A}$ or $\mathrm{C} \times \mathrm{A}$

16. $A>B$ and $C>B$, then $C$ is consentient with $A$ (i.e. is not opposite).

Segner also proves a theorem that singles out all invalid syllogisms. Then he pays attention to some non-syllogistic inferences and claims that "they shine of their own light", whether or not we can give them syllogistic form. In particular, he proves the following inferences by composition:

17. If $\mathrm{A}=\mathrm{B}$ and $\mathrm{C}=\mathrm{D}$, then $\mathrm{AC}=\mathrm{BD}$ 
18. If $\mathrm{A}=\mathrm{B}$ and $\mathrm{C}<\mathrm{D}$, then $\mathrm{AC}<\mathrm{BD}$

19. If $\mathrm{A}<\mathrm{B}$ and $\mathrm{C}<\mathrm{D}$, then $\mathrm{AC}<\mathrm{BD}$

Segner then proves the following theorem concerning inferences by abstraction:

20. If $\mathrm{A}$ is consentient with $\mathrm{B}$, if $\mathrm{C}$ has been abstracted from $\mathrm{A}$, and if $\mathrm{D}$ has been abstracted from $B$ (so that $C>A$ and $D>B$ ), then $C$ is consentient with $D$.

Thanks to a number of further definitions and three further propositions, Segner applies his system to the verbal expressions of common logic (he also pays attention to singular ideas and to strictly particular propositions whose subjects bear the prefix 'only'):

'All $\mathrm{A}$ are $\mathrm{B}$ ' means either $\mathrm{A}=\mathrm{B}$ or $\mathrm{A}<\mathrm{B}$

'No $A$ is $B$ ' means only $A<-B$

'Some $\mathrm{A}$ is $\mathrm{B}$ ' means either $\mathrm{A}=\mathrm{B}$, or $\mathrm{A}<\mathrm{B}$ or $\mathrm{A}>\mathrm{B}$ or $\mathrm{A} \times \mathrm{B}$

'Some $\mathrm{A}$ is not $\mathrm{B}$ ' means either $\mathrm{A}<-\mathrm{B}$ or $\mathrm{A} \times-\mathrm{B}$.

Segner's work proves that not all attempts to construct a logical calculus in an intensional perspective were destined to failure. Segner succeeds where Bernoulli failed (see above sec. 7) because he never assumes that every idea has a (Port-Royalist) comprehension made of necessary attributes that cannot be modified without destroying it. Therefore, given two ideas, he simply considers three possible cases: provided that $\mathrm{A}$ and $\mathrm{B}$ are not opposite, either $\mathrm{A}$ contains $\mathrm{B}$, and then $\mathrm{A}<\mathrm{B}$, or $\mathrm{A}$ is contained in $\mathrm{B}$, and then $\mathrm{A}>\mathrm{B}$, or neither idea contains the other, and then $\mathrm{A} \times \mathrm{B}$. Thus Segner, unlike Bernoulli (apparently unknown to him), is under no obligation to use nouns of ordinary language as signs of ideas so as to recall their unchangeable comprehension, but uses literal symbols. And, when he considers the expressions of idea-relations in verbal propositions, he is under no obligation to change his intensional perspective and to consider the extensions of ideas whenever a predicate is not contained in the comprehension of a subject. We can affirm a predicate B of a subject A even if they are coordinate ideas, i.e., ideas whose relation is, by definition, a relation at one time of consent and of non-containment.

Some interpreters have suggested that Segner is similar to Leibniz and even a "disciple of Leibniz" (Vailati 1899, 88). Actually, Segner and Leibniz differ at least inasmuch as Segner's relation of coordination - being a relation of non-containment - does not respond to the Leibnizian predicate-in-notion criterion. But there certainly are striking similarities. In the Specimen calculi universalis and in its Addenda, Leibniz uses an algebraic notation and an intensional perspective (see above sec. 8). Moreover, what for Leibniz is a per se true proposition of one of the forms ' $a b$ is $a$ ', ' $a b$ is $b$ ' or ' $a$ is $a$ ', has a detailed treatment in Segner. According to Segner, 'A is B' is an affirmation that can rest on one of the following relations between $\mathrm{A}$ and $\mathrm{B}$, all of which produce truths:

$\mathrm{AB}=\mathrm{A}$, if $\mathrm{A}<\mathrm{B}$ (according to Axiom I),

$A B<A$ or $A B<B$ if $A \times B$ (n. 3 in the list of Segner's propositions above).

Equally, in his list of valid syllogisms (10-16), Segner includes Leibniz's per se valid conclusion ('if $a$ is $b$ and $b$ is $c$, then $a$ is $c$ '). As to Leibniz's principle by which the repetition of a term is irrelevant, Segner also maintains that: "the idea of the subject composed with itself cannot produce a new idea" (Segner [1740], 149). Also Leibniz's praeclarum theorema, "if $\mathrm{A}$ is $\mathrm{B}$, and $\mathrm{D}$ is $\mathrm{C}$, then $\mathrm{AD}$ will be $\mathrm{BC}$ " (see above sec. 8) has an elaborate equivalent in Segner's inferences by composition. Other similarities can be found if one compares Segner's logic with the Generales Inquisitiones, notably with respect to the calculus with negative terms (on the problems posed by the use of negative or infinite predicates instead of negative propositions, and on Segner's skilful solution, cf. Capozzi 1990, clx-clxiv).

Segner did not know these Leibnizian doctrines, but the undeniable similarities we have stressed are not due to a miracle. They have an explanation in the fact that Segner, like Leibniz, was able to unify a variety of existing doctrines in a single system, depending on his practice of mathematics and using only an intensional approach. But that means that Segner's logical background, albeit unsupported by knowledge of Leibniz's relevant texts, was rich 
enough to offer him a firm ground on which to build his calculus. In this respect, the changes that took place in German logic in the first three decades of the eighteenth century show that Segner is representative of the logic of his time and not an inexplicable exception. But, as in the case of Leibniz, this does not detract from his merits: it only emphasizes them. For, let us consider one of the most interesting features of his system: the five idea-relations. Segner was not the first to consider such relations, but depended on Rüdiger and Reusch. He was well acquainted with Reusch's logic (the Specimen is dedicated to him) and he also knew Rüdiger's idea-relations. In an academic dissertation of 1734, discussed by one of his students under his guidance, he expressly quotes Rüdiger's logical work on such matters (Capozzi 1990, xcix). This does not make him less original, for it is due to him that such idea-relations are proved exhaustive and exclusive, and are used as part of an adequate calculus.

In this respect, Segner can be compared to the later mathematician Joseph Diez Gergonne (1771-1859). In his Essai de dialectique rationelle (Gergonne 1816-17) Gergonne considers five idea-relations using the notion of containment as basic but giving it an extensional interpretation: "the more general notions are said to contain the less general ones, which inversely are said to be contained in the former; from this the notion of relative extension of two ideas originates" (Gergonne 1816-17, 192). This extensional interpretation of the notion of containment is used by Gergonne $(1816-17,200)$ to classify the relations between two ideas on a par with the circles of Leonhard Euler (1707-1783) (see below in this section) and to designate each of them by a symbol. Two ideas A and B, where A is the less general idea and B is the more general one, can: 1) have nothing in common, so that they stand in the relation $\mathrm{H} ; 2$ ) intersect each other, so that they stand in the relation X; 3) coincide, so that they stand in the relation I; 4) be such that $\mathrm{A}$ is contained in $\mathrm{B}$, so that they stand in the relation $\mathrm{C} ; 5$ ) be such that that $\mathrm{B}$ is contained in A, so that they stand in the relation $\mathrm{J}$.

Like Segner, Gergonne also gives a correspondence list between the standard A, E, I, $\mathrm{O}$ propositions and the relations of ideas expressed by them:

\begin{tabular}{|c|c|c|}
\hline Gergonne & propositions & Segner \\
\hline I & All A are B & $\mathrm{A}=\mathrm{B}$ \\
C & & $\mathrm{A}<\mathrm{B}$ \\
\hline H & No A is B & $\mathrm{A}<-\mathrm{B}$ \\
\hline I & Some A is B & $\mathrm{A}=\mathrm{B}$ \\
C & & $\mathrm{A}<\mathrm{B}$ \\
J & & $\mathrm{A}>\mathrm{B}$ \\
$\mathrm{X}$ & & $\mathrm{A} \times \mathrm{B}$ \\
\hline $\mathrm{H}$ & Some A is not B & $\mathrm{A}<-\mathrm{B}$ \\
$\mathrm{X}$ & & $\mathrm{A} \times-\mathrm{B}$ \\
$\mathrm{J}$ & & \\
\hline
\end{tabular}

However, Gergonne and Segner differ in that, whereas Gergonne states that a proposition expresses the relation $\mathrm{C}$ because $\mathrm{A}$ is contained in $\mathrm{B}$, Segner would say that A contains B. Moreover, whereas Gergonne uses the symbol H for the opposition of ideas, Segner uses none, since he treats the relation of opposition as containment of the opposite idea. As a matter of fact he admits that "every affirmative proposition can be made negative without change of sense, and vice versa; to this end one has only to replace the attribute by a word which is its exact negation, as one sees from this example: 'Lagrange is dead, Lagrange is not alive" (Gergonne 1816-17, 197 fn.). However, he does not change negative propositions into affirmative ones by replacing the predicate by its opposite (this makes him forbid the conversion of particular negative propositions, while in Segner's logic they are convertible). Apart from such differences, the systems of Gergonne and Segner are perfectly comparable, which shows that, at least at this level, the perspectives of intension and extension can be translated into one another. If anything, Segner's calculus and symbolism 
would better suit Ernst Schröder (1841-1902) who acknowledged Gergonne as a forerunner of his own work (Schröder [1890-95] 1966, II, 106). For Segner treated negative concepts and used a symbolism more similar to Schröder's than to that of Gergonne's (cf. Capozzi 1990, clxx-clxxii).

Segner, who was much appreciated as a mathematician, scientist and physician, did not meet with the success he deserved for his logical work. His calculus and symbolism is mentioned in Hoffbauer ([1792] 1969) who does not follow him completely for he uses the symbol '\#' for opposition. More attention was paid by contemporaries to other interesting attempts to build calculi of ideas, notably the attempts made by Gottfried Ploucquet and Johann Heinrich Lambert.

Gottfried Ploucquet (1716-1790), professor of philosophy at the university of Tübingen, developed a logical calculus in stages, resorting to different symbolisms. In his Fundamenta (Ploucquet 1759), he gives a theory of judgment in which he not only considers the quantity of the subject but also the quantity of the predicate. Ploucquet feels justified in doing so by the traditional doctrine of conversion of propositions. For he believes that the conversio simplex of a universal negative proposition, e.g. the conversion of 'No man is stone' in 'No stone is man', depends on the tacit assumption that subject and predicate have the same universal quantity, whereas the conversio per accidens of a universal affirmative proposition, e.g. the conversion of 'All men are rational' in 'Some rational (being) is man', depends on the tacit assumption that the subject is quantified universally and the predicate particularly. In this work we also find two diagrams of universal syllogisms in the first figure, and a symbolism for the calculus that Ploucquet will modify in later essays.

In 1763, Ploucquet published two essays: a Methodus tam demonstrandi directe omnes syllogismorum species (1763a) and a Methodus calculandi in Logicis (1763b). Both contain his technical results, but it is in the second and longer of them that Ploucquet explains the meaning of his logical investigations. He begins by defining 'calculus': "In the most generally accepted sense calculus is the method to determine unknown things beginning from known things according to constant rules" (Ploucquet 1763b, 31). Then Ploucquet discusses the possibility of an ars calculatoria, capable of application not only to numbers but also to geometrical quantities, forces, and logical concepts. His conclusion is that there is no ars combinatoria, or calculus of forms, containing as its parts the calculus of quantities and the calculus of qualities. In his opinion, every calculus must be adjusted to some particular object of investigation since "by nature and according to logical order every calculus comes after the understanding of the matter to which the calculus is applied. Then, if a universal calculus were to be imagined, one would suppose (a kind of) knowledge of things that could not be supposed for any mortal being. He who invents does not begin from a calculus, but from the consideration of things" (Ploucquet 1763b, 36).

There is no doubt that Ploucquet wants to differentiate his position from that of Leibniz. According to Ploucquet, Leibniz simply proposes a new version of an ancient utopian and unattainable project, as his characteristica combinatoria does not differ from Lull's art. To support this judgment Ploucquet quotes the rather reductive appraisal of Leibniz's 1666 essay on the combinatoria given by Leibniz himself in the Acta Eruditorum of 1700 (Ploucquet 1763b, 39-40). And in 1714 in a letter to Remond, he also stresses that Leibniz spoke of a mere wish to find a general speciosa in which all the truths of reason would be reduced to a kind of calculus. Ploucquet reserves similar criticisms for the Inventum novum quadrati Logici Universalis of Johann Christian Lange (Lange 1714) (Ploucquet 1763b, 43).

In Ploucquet's view, tentative investigations about the possibility of a universal calculus are to be praised because without them we would be even more ignorant. Nevertheless, he considers dealing with a plurality of calculi for each area of knowledge more realistic. Therefore, his efforts are limited to the construction of a calculus capable of making 
syllogistic inference intuitive and immediately clear, so as to avoid errors (Ploucquet 1763b, 46-7). In his opinion, since a logical calculus pays attention only to the formal structure of thought, it makes it easier to learn and use logic, so that "even uncultivated people and those who do not clearly perceive the strength of the calculus or of the ratiocination, can be educated, given the premises, to find, without fear of error, those conclusions to which they would not come by themselves" (Ploucquet 1763b, 74). Thus, bringing a recurrent motive in the logic of the first German Enlightenment to unexpected consequences, Ploucquet extends to uncultivated people Leibniz's invitation to calculate as a means to put an end to the disputes of scholars.

As to Ploucquet's actual logical construction, he assumes that when we judge, i.e., when we compare a subject and a predicate, we understand [intelligere] either their identity or their diversity (Ploucquet 1763b, 48). In the first case we have an affirmative judgement and in the second case a negative judgement. Now, an affirmative judgement as conceived by our mind is not an understanding of two things but of one thing only: "When I intuit a round stone and pronounce these words: this stone is round, what I actually think by this proposition is nothing but one notion, i.e. the notion of round stone [...]" (Ploucquet 1763b, 52). This conception holds also for syllogism: "all affirmative syllogisms reduce to a single notion", and "all negative syllogisms reduce to two notions, one of which is diverse from the other" (Ploucquet 1763b, 73-74). As Ploucquet explains in a polemical essay of 1766 against Lambert, this means that when we think of the shining sun there is no distinction between subject and predicate, but, when we want to communicate our thought to others, our language requires more signs, and we say 'the sun is shining' [Bök [1766], 245). The same applies to syllogism. It is because of the constitution of our language that we need a rigorous logical calculus adequate to our spoken propositions and syllogisms.

In the first of the two essays of 1763, Ploucquet $(1763 \mathrm{a}, 18)$ declares that all his previous work devoted to the question of finding the correct conclusion from given premises can be replaced by a single praeceptum: the two terms of the conclusion must maintain the same extension they have in the premises. This praeceptum, once complemented with the traditional rules that veto four terms and two negative premises in a syllogism, eliminates the traditional classification of syllogisms according to figures and moods, as well as the need to reduce all syllogisms to the first figure. By referring to the extension of both subject and predicate in the conclusion, Ploucquet makes his formerly implicit choice of quantifying the predicate explicit, a choice highly praised in the following century by Hamilton (1860-9, II, 322; Aner 1909, 22 ff.).

The symbolism used by Ploucquet in 1763 is a variant of that used in 1759 (there are small differences also between the two 1763 essays). His definitive choice is the following. Upper case letters stand for universal terms; lower case letters stand for particular terms; juxtaposition of terms, such as $\mathrm{AB}$ or $\mathrm{Ab}$, means affirmation; the sign ' $>$ ' between two letters means negation (cf. Venn, [1894], 499). Ploucquet, who takes an extensional point of view, maintains that in an affirmative proposition the predicate is taken particularly. He says that this kind of particularity holds "in a comprehensive sense [sensu comprehensivo]" (Ploucquet 1763b, 52). Thus 'All men are rational' means 'All men are some rational beings', a proposition that in his symbolism can be written as ' $\mathrm{Mr}$ ', where the letters signify the initials of the subject and the predicate. The particularity 'in a comprehensive sense' of the predicate does not exclude that there could be other individuals apart from those under consideration. As for negative propositions, they are usually meant as having a universal predicate, but here too, though this may seem absurd in common language, they can have a particular predicate, as is the case with 'All men are not some animals', meaning, for instance, that they are not irrational animals. In this logical framework, Ploucquet develops a doctrine of subalternation and conversion that, contrary to accepted rules, allows the conversion of particular negative propositions, for 'Some A is not B' correctly converts into 'No B is some A'. As to the 
syllogistic calculus, all one has to do is to represent the premises by Ploucquet's symbolism and check that the premises are not both negative and that they do not contain four terms. Under these conditions, one can draw the conclusion by deleting the middle term and relating the two remaining terms, taking care that they preserve the same quantity they had in the premises. In this calculus also a syllogism in the first figure of the form 'All $\mathrm{M}$ are $\mathrm{P}, \mathrm{No} \mathrm{S}$ are $\mathrm{M}$, then No $\mathrm{S}$ are $\mathrm{P}$ ', which is invalid according to traditional doctrines, becomes acceptable, for it can be symbolized as follows: Mp, $\mathrm{S}>\mathrm{M}$, then $\mathrm{S}>\mathrm{p}$ (cf. Menne 1968).

Another author of logical calculi is Johann Heinrich Lambert (1728-1777). This famous and eclectic scientist contributed to the study of language, metaphysics and logic, in addition to important research in the fields of optics, geometry (conic sections, perspective, theory of parallel lines, writing on the latter subject one of the basic texts in the history of non-Euclidean geometries), astronomy (comets), physics, technical applications of his theoretical works, and cosmology.

Lambert's interest in logic dates back to the Fifties when he wrote the so-called Six essays of an art of the signs in logic [Sechs Versuche einer Zeichenkunst in der Vernunftlehre], published only after his death (Lambert [1782-87, I]). It is rather difficult to explain why Lambert decided not to publish these essays at the time that he wrote them, especially as they contain the general outline of his calculus, as well as comments on the nature of definition and on the representation of relations (cf. Dürr 1945). According to some interpreters (Barone 1964, 88), this decision depended on the fact that, as Lambert confessed, in these writings he was attracted to the idea of discovering what "was concealed in the Leibnizian characteristic and in the ars combinatoria". For, while Segner did not enter into these matters and Ploucquet refused the very idea of a universal calculus, Lambert adopted Leibniz's ideal and, given his ignorance of the latter's relevant texts, wanted to pursue Leibniz's end by his own means. Now, a calculus aiming at being both formal and real presupposes an alphabet of simple elements. Therefore, Lambert had to postpone the publication of his early technical results till his philosophical investigation could establish such an alphabet of simple and first concepts which, not containing composition in themselves, could not contain contradictions.

Meanwhile, Lambert wrote the Neues Organon (Lambert [1764]), an important and famous book in which, according to the idea of mathesis universalis, he devoted himself to searching for the basic concepts that could help to insert already acquired knowledge into a rational system and to promote new discoveries. The Neues Organon consists of four parts: Dianoiology, Alethiology, Semeiotics and Phenomenology, to which we will refer beginning with Alethiology and ending with Dianoiology.

Alethiology, the doctrine of truth and error, deals with elementary concepts. Lambert gives a list of the latter including conscience, existence, unity, duration, succession, will, solidity, extension, movement and force. In Lambert's view, connecting simple concepts produces truths that are not subject to time and space, and therefore can be considered as 'eternal truths'. Eternal truths permit the provision of a foundation for all a priori sciences, in particular arithmetic, geometry and chronometry.

Semeiotics studies the relation between sign and meaning, and therefore introduces both a theory of language and the project of a characteristic.

Phenomenology is the doctrine of appearance. Here Lambert, in discussing certainty and its relations to truth and error, also considers the degrees of possible certainty, and the probability of cognitions of which we have no absolute certainty.

Dianoiology investigates the laws of the understanding. This part of the Neues Organon contains diagrams representing concept relations in propositions and syllogisms. Lambert represents a concept - considered in extension, i.e., with respect "to all the individuals in which it appears" (Lambert 1764, Dian. § 174) - as a line that can either be 
finished or open. He then represents the relations that two concepts entertain in the four basic propositions of categorical syllogisms:

\begin{tabular}{|c|c|c|c|}
\hline All $A$ are $B$ & No $A$ is $B$ & Some A is B & Some $\mathrm{A}$ is not $\mathrm{B}$ \\
\hline$\ldots . \mathrm{B} \_\mathrm{b} \ldots .$. & $\mathrm{A} \_$_ ${ }^{\mathrm{a}} \quad \mathrm{B} \_$_ & $\mathrm{B}_{\ldots \ldots \mathrm{A}} \mathrm{b}$ & $\mathrm{B}_{\ldots}{ }_{\ldots}^{\mathrm{b}} \mathrm{A} \ldots \ldots$. \\
\hline
\end{tabular}

In the diagram representing universal affirmative propositions, what counts, in addition to the length of the lines, is that $\mathrm{A}$ is drawn under $\mathrm{B}$. The diagram representing universal negative propositions is clear. As for particular affirmative propositions, the diagram shows that we only know some individuals $\mathrm{A}$ that are $\mathrm{B}$, or at least one individual $\mathrm{A}$ that is B. Therefore, it remains indeterminate if also all A are B, or even all B are A. In the case of particular negative propositions the diagram shows not only that $\mathrm{A}$ is indeterminate, but also that $\mathrm{A}$ is neither under $\mathrm{B}$ nor completely beside it, as in the case of universal negative propositions. On this basis one cannot only immediately make all valid conversions, but also represent all syllogisms, with the advantage of dispensing with the reduction to the first figure (cf. Wolters 1980, 129-66).

When the Neues Organon was published diagrams were no novelty, though Lambert introduced his diagrams before the already mentioned circular diagrams by Leonhard Euler (Euler 1768-72):

\begin{tabular}{|l|l|l|l|}
\hline All A are B & No A is B & Some A is B & Some A is not B \\
\hline & & & \\
& & & \\
\hline
\end{tabular}

In fact, representations of concepts, propositions and syllogisms by means of circles, lines and other figures had already been devised by Johann Christoph Sturm (1661), who also introduced circular diagrams representing new syllogisms having negative terms; by Johann Christian Lange (1712,1714); by Ploucquet (1759), and by Leibniz himself (on the history of diagrams in logic cf. Gardner 1983; Bernhard 2001).

From what we have seen of Lambert's and Ploucquet's logical work we can understand why their contemporaries were intrigued by their different approaches to the problem of a logical calculus and wanted to assess their comparative merits. In a public debate in which Lambert and Ploucquet took part directly - reported in Bök [1766] Ploucquet's Methodus calculandi was compared with Segner's logical work, while Lambert's diagrams in the Neues Organon underwent severe criticism. On the occasion of this debate Lambert began a correspondence with Georg Jonathan Holland (1742-1784), a pupil of Ploucquet. In a letter to Holland Lambert criticized Ploucquet's use of the traditional rule that nothing follows from two negative premises in order to exclude non conclusive syllogism. $\mathrm{He}$ also criticized Ploucquet for using letters standing for the initials of substantives in syllogisms, thus showing his lack of a true symbolism (Lambert [1782] 1968, 95-96). But, in an article of 1765, Lambert, though claiming that his diagrams in the Neues Organon were an example of a characteristic, acknowledged that they were only a little thing with respect to his project of a general logical calculus (Bök [1766], 153).

At last, Lambert's logical calculus was published in his Disquisitio (Lambert [1765], dated 1765 but actually printed in 1767). Here he states the aim of his calculus and lists the requisites any calculus must satisfy. As to his aim, Lambert says that he wants to find a 
method for treating qualities similar to the method used in algebra for treating quantities. Just as in algebra we employ the ideas of relation, equality, proportion, etc., so in the logical calculus we have to employ the ideas of identity, identification and analogy. As to the requisites a calculus must satisfy, they are the following. 1) For every operation we introduce, there must be the inverse operation, in full analogy with algebra where, when two quantities are added, it is always possible to obtain either by subtracting it from the total. 2) Given the object, the relations and the operations of the logical calculus, an adequate symbolism must be found. The symbols must be a perfect replacement for the things they symbolize in order to be safely used in their place. This means that we need a characteristic that mirrors things, a real characteristic, in which simple signs stand for simple things and are capable, once composed, to stand for composed things, so that it is also possible to proceed inversely from a composite to its simple elements. 3) Lambert also requires that we have a clear knowledge of the simple elements and the basic relations of the calculus; we must therefore know the combinatorial part of the ars characteristica combinatoria. In his opinion, the simple elements are qualities, i.e. the special affections of things we can consider as their attributes. Qualities are simple elements because, according to established ontological doctrines, they can be considered as 'absolute' attributes, whereas other attributes, notably quantity, must be thought only 'relatively' (a similar conception occurs in Leibniz's De arte combinatoria).

Lambert's calculus in the Disquisitio, as it was the case with his unpublished essays of the Fifties, is intensional, i.e. "does not concern individuals but properties" (Letter to Holland 21.4.1765, Lambert [1782] 1968, 37). After trying the extensional perspective in the Neues Organon, his return to his early preference for the intension of concepts is undoubtedly due to a conscious choice. For Lambert wants to find what is 'simplest' and 'first' in concepts, but to obtain what is simpler it is necessary to consider what is more complex and, in the case of concepts, the more complex concepts are those containing the simpler ones. Therefore, it is necessary to consider concepts as properties, as concepts containing other concepts, thus disregarding the class of individuals to which they extend.

When dealing with judgments and syllogisms, Lambert's first aim is to establish the identity of the subject and predicate of judgments. Therefore, given the judgement 'All A are B', where A and B are not already obviously identical, Lambert establishes their identity by considering the subject as containing the predicate plus other properties. Hence the following symbolism (Lambert [1765], 461-462):

\begin{tabular}{|c|c|c|c|}
\hline All A are B & No A is B & Some A is B & Some A is not B \\
\hline $\mathrm{A}=\mathrm{nB}$ & A:p=B:q & $\mathrm{mA}=\mathrm{nB}$ & $\mathrm{mA}: \mathrm{p}=\mathrm{B}: \mathrm{q}$ \\
\hline
\end{tabular}

In the universal affirmative, $A=n B, n$ stands for the qualities which can be found in the subject $A$ but not in the predicate $B$. In the universal negative, $A: p=B: q$, the sign ':' stands for a logical division and expresses which qualities, $\mathrm{p}$ and $\mathrm{q}$, must be subtracted from the subject and the predicate, because neither belongs both to the subject and the predicate, so as to obtain $A=B$. Similarly, in the particular affirmative, $m A=n B$, and in the particular negative, $\mathrm{mA}: \mathrm{p}=\mathrm{B}: \mathrm{q}$. On this basis, Lambert obtains a general formula expressing any kind of judgement: $A / p=n B / q$ (here Lambert substitutes the sign of fraction for the sign ' $:$ '). From this formula one can easily derive a formula expressing any kind of syllogism:

$$
\begin{aligned}
& \mathrm{mA} / \mathrm{p}=\mathrm{nB} / \mathrm{q} \\
& \mu \mathrm{A} / \pi=\nu \mathrm{C} / \rho \\
& \mathrm{m} v \mathrm{C} / \mathrm{p} \rho=\mu \mathrm{nB} / \pi \mathrm{q}
\end{aligned}
$$


To give an example of how this general formula applies to particular syllogisms, a syllogism Barbara, whose premises are $\mathrm{B}=\mathrm{mA}$ and $\mathrm{C}=\mathrm{B}$, has the conclusion $\mathrm{C}=\mathrm{mA}$, whereas a syllogism Celarent, whose premises are $\mathrm{B} / \mathrm{q}=\mathrm{A} / \mathrm{p}$ and $\mathrm{C}=\mathrm{vB}$, has the conclusion $\mathrm{C} / \mathrm{q}=\mathrm{vA} / \mathrm{p}$ (Lambert [1782-87], I, 102-3, 107).

Despite the fact that the Disquisitio's treatment of syllogism is very different from that of the Neues Organon, it was disappointing for Lambert's most competent readers. Holland sent Lambert a letter in which (beside mentioning his own tentative calculus) observed that, however good Lambert's calculus was, it did not achieve Lambert's declared aim to find symbols mirroring reality. What are A, B, m, n, etc. symbols of? And, above all, which are the primitives that they are supposed to be symbols of? A definite answer, Holland concluded, could perhaps be expected from a new work Lambert had announced (Lambert [1782] 1968, 259-266). The work Holland referred to, titled Architectonic (Lambert [1771]), was published a few years later. In this treatise, which promised to give a theory of what is simple and first in philosophical and mathematical knowledge, the author collects the results of his philosophical research going back to the mid Forties. But, for all its importance as the summa of Lambert's thought, the Architectonic provides no formal treatment, nor gives a new and complete list of simple elements that could be used as basic elements of a real characteristic, since it contains the same elements already listed in the Neues Organon.

The conclusion to be drawn is that Lambert's project shared Leibniz's ambitions and in this respect went far beyond Segner's and Ploucquet's calculi, but perhaps was too ambitious and, though providing interesting details in the application of algebra to logic, can be said to be unachieved. In a sense, Lambert admitted as much in a letter (14.3.1771) to Johann Heinrich Tönnies: "should the universal characteristic belong to the same class as the philosopher's stone or the squaring of the circle, it can at least, just as these, induce other discoveries" (Lambert [1782] 1968, 411).

Ploucquet's refusal of Leibniz's project and Lambert's sombre admission to Tönnies may sound too pessimistic if one considers how much they and other eighteenth century logicians - not to mention Leibniz - had progressed since Bernoulli's failed parallelism. But especially Lambert's assessment of universal characteristic as something similar to the squaring of the circle makes it apparent that these authors believed that the construction of a satisfactory logical calculus was hindered by a possibly insurmountable obstacle: the overpowering amount of philosophical analysis to be done in the fields of metaphysics, semiotics and natural language in order to reach a suitable alphabet of thoughts. As a matter of fact, unknown to these eighteenth century logicians, there was an obstacle, not only on the side of philosophical analysis, but also on the side of mathematics. Nineteenth century logicians will find out that one had to reflect also on the nature of mathematics and algebra, especially on their apparently exclusive link with quantity, before an algebra of logic could come to life.

\section{Kant}

Interest for logical calculi seems to vanish at the end of the eighteenth century. We have mentioned some of the reasons behind this phenomenon, but according to a still widely received opinion this was due to the influence exerted on logic by Immanuel Kant (1724-1804). This opinion is usually justified by saying that Kant introduced confusion in logic through his notion of transcendental logic. As a matter of fact, Kant had a definite concept of general logic, which he tried to free from his own transcendental philosophy and which is interesting from the viewpoint of the history of logic.

In order to evaluate Kant's concept of logic, one must take into account his forty years long activity as a logic teacher, using as a textbook Georg Friedrich Meier's Auszug aus der Vernunftlehre (Meier 1752), a short version of the latter's Vernunftlehre (Meier 1752a) (on 
Meier's logic cf. Pozzo 2000). We have several texts related to this teaching activity, which constitute the so-called Kantian logic-corpus. Apart from the programs of the courses, such texts are: 1) Kant's handwritten annotations on Meier's Auszug (the so-called logical Reflexionen, in Kant 1900, XVI), 2) lecture-notes taken by students (Kant 1900-, XXIV; Kant 1998a; Kant 1998b), and 3) I. Kant's Logik, a book published in 1800 by Gottlob Benjamin Jäsche by collecting a selection of Kant's annotations on Meier's Auszug with Kant's consent (Kant 1900-, IX, 1-150). These texts must be used with care and must always be compared with Kant's published production. Nonetheless, they are essential to assess his views on logic, allowing a deeper insight into the importance of logic for Kant's philosophy, and testifying to his knowledge of the discipline he was due to teach. As it is impossible to give details here of Kant's treatment of logical doctrines, we will only discuss his general concept of logic 2 .

A comparative study of the Kantian logic-corpus shows that Kant's concept of logic is the result of a sustained effort of reflection lasting several years. For he began more or less as an orthodox Wolffian, founding logic on empirical psychology and ontology (Logik Blomberg, Kant 1900-, XXIV, 28). In his mature conception, however, he took the opposite view and denied that logic could be founded on either empirical psychology or ontology.

To this effect Kant argues that a logic founded on empirical psychology could describe human logical behaviour but not prescribe laws to it. In his opinion, logical rules do not mirror what we actually do when we think, but are the standard to which our thoughts must conform if they are to have a logical form: logic considers "not how we do think, but how we ought to think" (I. Kant's Logik, Kant 1900-, IX, 14). As to the formerly accepted foundation of logic on ontology, Kant simply suppresses it, to the dismay of many of his contemporaries and later idealist philosophers. In particular, opposing Kant, Hegel proposed a new logic identical to metaphysics which, like old metaphysics, would admit that "thought (with its immanent determinations) and the true nature of things are one and the same content" (Barone 1964, 202). Thus it is rather surprising that William and Martha Kneale claim that it was Kant "with his transcendentalism who began the production of the curious mixture of metaphysics and epistemology which was presented as logic by Hegel and other Idealists of the nineteenth century" (Kneale and Kneale 1962, 355).

The independence of logic from ontology and empirical psychology raises the problem of the origin of logic. Kant gives an indirect answer to this problem by way of a comparison of logic with grammar. Logic and grammar - he maintains - are similar in as much as we learn to think and to speak without previous knowledge of grammatical and logical rules, and only at a later stage we become conscious of having implicitly used them. Nonetheless logic and grammar differ because, as soon as we become aware of grammatical rules, we easily see that they are empirical, contingent and subject to variations. On the contrary, once we become conscious of the logical structure of our thought, we cannot fail to appreciate that without that structure we could not have been thinking at all. Therefore logic precedes and regulates any rational thinking and is necessary in the sense that we cannot consider it contingent and variable. Kant concludes that logic "is abstracted [abstrahirt] from empirical use, but is not derived [derivirt]" from it (Reflexion 1612, Kant 1900-, XVI, 36) so that it can be considered a "scientia scientifica", whereas grammar is only a "scientia empirica" (Logik Busolt, Kant 1900-, XXIV, 609). Moreover, logical principles such as that of contradiction are accepted without proof: "All rules that are logically provable in general are in need of a ground

\footnotetext{
2 The amount of literature on Kant is enormous, and also literature on Kantian logic is very extensive, ranging from the relation between general and transcendental logic, to the doctrines of concepts, judgments, and inferences, not to mention topics such as the relations between logic and language and mathematics. We will mention only Shamoon 1981, Capozzi 1987, Pozzo 1989, Brandt 1991, Reich 1992, Wolff 1995, Capozzi 2002, Capozzi forth. (the latter containing an extensive bibliography). A precious research tool is provided by an impressive Kantian lexicon, still in progress, many of whose volumes are devoted to Kant's logic-corpus (Hinske 1986-).
} 
[Grund] from which they are derived. Many propositions (e.g. that of contradiction) cannot be proved at all, neither a priori nor empirically" (Logik Dohna-Wundlacken, Kant 1900-, XXIV, 694). In other words, logical rules, "once known, are clear by themselves" (Reflexion 1602, Kant 1910-, XVI, 32).

All this means that logic not only is necessary, scientific and a priori, but also is capable of justifying itself. These features make logic one of the means Kant uses in carrying through his philosophical project of explaining the possibility of experience according to his Copernican revolution. For an important part of this project consists in showing that it is possible to find all the general forms of thought - categories - without having to fall back on metaphysics or experience. Now logic (rather, one of its most important parts, i.e. the functions of judgment), which Kant has made no longer dependent on empirical psychology and ontology, qualifies as the perfect clue to the categories. But, since categories have to be completely enumerated in order to be employed in a complete list of principles of the understanding, which define the field of possible experience, logic has to satisfy a further requisite: it has to be complete. Hence Kant's well-known statement that logic "seems to all appearance to be finished and complete" (Kant 1997, B viii). Kant has been criticized for this statement and also in our opinion he lacks conclusive arguments to support it. But one must consider that a proof of the completeness of logic would have been easy if Kant had preserved the foundation of logic on empirical psychology and ontology, both ultimately guaranteed by God. It is also fair to point out that Kant envisages the possibility, for a closed system, of growing 'from within', on a par with living organisms that grow with no addition of new parts (Kant 1997, A 832/B 860). If this applies to logic one could say that some growth in logic is possible, although within the boundaries of a systematic structure.

The scientific, necessary and self-justifying nature of logic guarantees that it has great autonomy and the maximum spectrum of application. Such prerogatives are counterbalanced by precise limitations: "Nobody can dare to judge of objects and to assert anything about them merely with logic without having drawn on antecedently well-founded information about them from outside logic" (Kant 1997, A 60/B 85). Consequently, logic is the supreme canon of truth with respect to the form of thought, but must be indifferent to its contents.

The first consequence of this conception is that logic has to be analytic, although not in the sense that it deals with analytic judgements only. For logic does not even consider the analytic/synthetic distinction which is left to transcendental logic: "The explanation of the possibility of synthetic judgments is a problem with which general logic has nothing to do, indeed whose name it need not even know" (Kant 1997, A 154/B 193). Logic is analytic in two senses. 1) "General logic analyzes the entire formal business of the understanding and reason into its elements, and presents these as principles of all logical assessment of our cognition" (Kant 1997, A 60/B 84). 2) Logic has nothing to do with dialectic, both intended as the rhetorical art of disputation and as the part of logic dealing with probability.

The most evident and better known reason for Kant's separation of logic from dialectic is the connection between dialectic and rhetoric. A rhetorical dialectic is an art for deceiving adversaries in a dispute and for gaining consent not only disregarding truth, but also purporting to produce the semblance [Schein] or illusion of truth. Kant condemns this kind of 'logic' as unworthy of a philosopher (cf. Kant's Logik, Kant 1900-, IX, 17). As to the association of dialectic with probability, it goes back to the distinction of Aristotelian logical treatises between analytic, i.e. the part of logic dealing with truth and certainty, and dialectic, i.e. the part of logic dealing with what is probable, according to Boethius' translation of the Greek éndoxos with the Latin probabile. This distinction was adopted by many eighteenth century logicians, notably by Meier who divides logic into analytica or "logic of completely certain erudite cognition", and dialectica or logica probabilium, defined as "logic of probable erudite cognition" (Meier 1752b, § 6, in Kant 1900-, XVI, 72). Like many philosophers (including Leibniz), till the early Seventies Kant hoped that a logic of the uncertain could be 
found. Such a logic was intended to be different from the Aristotelian and humanist doctrines of probability, but attentive to the late seventeenth century results in the field of probability calculus and capable of dealing with qualitative matters concerning justice, politics etc. Later on, Kant completely changed his view. He considered probability as a measurable degree of certainty (in this Kant agreed with Wolff), which "can be expressed like a fraction, where the denominator is the number of all possible cases, the numerator is the number of actual cases" (Logik Pölitz, Kant 1900-, XXIV, 507). This view restricts probability to matters that can be subjected to a numerical calculus (games of chance and statistically based events such as mortality indexes), and excludes not only for the time being, but in general, that there could ever be an instrumental art for weighing, rather than numbering, heterogeneous reasons pro and contra a given qualitative question, so as to choose the more 'probable' one. An instrumental art of this kind, if it were possible, would be used especially when empirical data are defective and/or experience itself is impossible. Against this alleged art Kant objects that it is based on a misuse of the term 'probability' [Wahrscheinlichkeit, probabilitas], for it really concerns the notion of 'verisimilitude' [Scheinbarkeit, verisimilitudo], a notion not related to a calculus of reasons but to a subjective evaluation of the weight of reasons. Hence his claim that probability proper, being contiguous to truth, belongs to the analytic part of logic and need not be dealt with in a special part of logic called dialectic, because dialectic is not "a doctrine of probability" (Kant 1900-, A 293/B 349). Kant's solution is drastic: logic and dialectic must part and go separate ways. This solution is a milestone in the history of logic. After Kant, dialectic began a new philosophical career, but disappeared from the further development of logic

The second consequence of Kant's view that logic is a mere formal canon of truth is that the content of logic must be limited to the doctrine of elements - concepts, judgements and inferences - plus the doctrine of method. Therefore, logic must not trespass into the domains of anthropology and psychology, nor give advice for the use of logic in the fields of the natural sciences or of practical life. Indeed, Kant separates logic from epistemology. This does not mean that the texts of the Kantian logic-corpus do not contain epistemological parts. On the contrary, these texts make very interesting reading on matters such as opinion, belief, knowledge, hypotheses, probability, etc. But these matters are no longer intended as belonging to pure logic because, in order to deal with them, one must take into account the content of knowledge and human cognitive constitution, including sensibility, or at least the form of sensibility. This means that Kant breaks away from the major trend of European logic, which had tried to give new life to the discipline by stressing its usefulness either as a guide for judging, or as a kind of methodology for empirical research, or as a medicine against errors. In particular, Kant breaks away from Locke's view of logic, despite the fact that he had formerly praised it, for he maintains that the study of the origin of concepts "does not belong to logic, but rather to metaphysics" (Logik Dohna-Wundlacken, Kant 1900-, XXIV, 701).

The third consequence of the formality of logic is that it is incapable of invention. Kant's sharp distinction between logic and mathematics contributes to this view. Kant agrees with Wolff that there is a single logic to be respected by mathematicians and non-mathematicians alike, but logic is insufficient to explain why mathematics is ampliative. According to Kant, mathematics is the science that constructs a priori its concepts, i.e. exhibits a priori the intuitions corresponding to them. Thus, mathematics relies also on the form of sensible intuition, so that it has content and can be inventive with respect to it. This applies not only to arithmetic and geometry, but also to algebra, which is inventive because it refers (albeit mediately) to a priori intuitions. Therefore, Kant rejects the view of those who "believe that logic is a heuristic (art of discovery) that is an organ of new knowledge, with which one makes new discoveries, thus e.g. algebra is heuristic; but logic cannot be a heuristic, since it abstracts from any content of knowledge" (Logik Hechsel, Kant 1998, $279=$ 
ms. 9). These statements are not borne out of ignorance. Kant knew the outlines of Leibniz's ars characteristica combinatoria, on whose utopian nature he commented in an essay of 1755 (Nova dilucidatio, Kant, 1900-, I, 390) in terms that seem to anticipate analogous statements by Ploucquet and Lambert. Moreover, his logic-corpus, as well as his works and correspondence, provide evidence that: 1) he was well acquainted with the combinatorial calculus of syllogistic moods, 2) he used Euler's (whom he quotes) circular diagrams to designate concepts, judgments and syllogisms, 3) he knew the linear diagrams of Lambert, with whom he corresponded, 4) he probably had some knowledge of Segner's and Ploucquet's works, and 5) he actively promoted the diffusion of Lambert's posthumous works containing the latter's algebraic calculus. But all this did not shake his conviction that an algebraic symbolism of idea-relations and the use of letters instead of words are not by themselves a means to invention. Therefore, although he objected to Wolff's reduction of all inferences to syllogisms, he supported Wolff's contention that categorical syllogisms are not only reducible to the first figure, but are first figure syllogisms in disguise.

If we consider the development of logic from Humanism onwards, we see that one of the basic motivations of logical research in the whole period was the demand to make logic inventive. The humanist theories of inventio, Bacon's studies on induction, Descartes' theory of problem solving, the ars inveniendi and a large part of Leibniz's ars characteristica combinatoria, etc., can be viewed in this perspective. Kant objected that this kind of research, while claiming to be purely formal, was meant to deal with the content of knowledge. The condition (and cost) of his objection to an inventive logic was the separation of logic from mathematics, but in this way he achieved his aim of separating logic from metaphysics and psychology, as well as from any transcendent foundation. Therefore, Venn's claim that Kant had "a disastrous effect on logical method" (Venn [1894], xxxv) contrasts with what Venn says at the beginning of his own system of logic: "Psychological questions need not concern us here; and still less those which are Metaphysical" (Venn [1894], xxxix). Perhaps it would have been more difficult for him to make such a statement if Kant had not already made that very same statement. 


\section{REFERENCES}

Agricola, Rodolphus. [1479] 1967. De inventione dialectica, reprint of the ed. Köln 1539, with Alardus' Commentary, Frankfurt: Minerva.

Agricola, Rodolphus. [1479] 1992. De inventione libri tres. Drei Bücher über die Inventio dialectica, ed. L. Mundt, Tübingen: Niemeyer.

Aldrich, Henry. 1691. Artis Logicae Compendium, Oxford.

Aquinas, Thomas. 1888-1889. Opera omnia iussu impensaque Leonis XIII P. M. edita, t. 4-5: Pars prima Summae theologiae, Roma: Typographia Polyglotta S. C. de Propaganda Fide.

Argens, Jean Baptiste d'. 1737. La philosophie du bon sens, ou réflexions philosophiques sur l'incertitude des connoissances humaines, à l'usage des cavaliers et du beau-sexe, London.

Arnauld, Antoine, and Claude Lancelot. [1676] 1966 Grammaire générale et raisonnée critical ed. of the 1676 edition by Herbert E. Brekle (1st ed. 1660), Stuttgart-Bad Cannstatt: Frommann-Holzboog; English trans. Arnauld and Nicole 1975.

Arnauld, Antoine, and Claude Lancelot 1975. General and Rational Grammar: The Port Royal Grammar, ed. and trans. Jacques Rieux and Bernard E. Rollin, The Hahue: Mouton.

Arnauld, Antoine, and Pierre Nicole. [1683] 1981. La Logique ou l'art de penser, critical ed. of the 5th ed., Paris 1683, eds. P. Clair and F. Girbal, (1st ed. 1662) Paris: Vrin; English trans. in Arnauld and Nicole 1996.

Arnauld, Antoine, and Pierre Nicole. 1996. Logic or the Art of Thinking. Trans.and ed. J. Vance Buroker, Cambridge: Cambridge University Press.

Arnauld, Antoine, and Pierre Nicole. 1704. Logica sive Ars cogitandi, trans. J. Fr. Budde.

Bacon, Francis. [1620] 2000, The New Organon, trans. L. Jardine and M. Silverthorne, Cambridge: Cambridge University Press.

Becher, Johann Joachim. 1661. Character pro notitia linguarum universali, Frankfurt: Ammon and Serlin.

Beck, Cave. 1657. The Universal Character, by which all the Nations in the World may Understand One Another's Conceptions (...), London: Maxey and Weekley.

Bernoulli, Jakob. [1685] 1969. Parallelismus ratiocinii logici et algebraici, in Die Werke von Jakob Bernoulli, vol. I, ed. Naturforschende Gesellschaft in Basel, Basel: Birkhäuser; English trans. in Boswell 1990, 211-24.

Bernoulli, Jakob [1713] 1975. Ars conjectandi in Die Werke von Jakob Bernoulli, vol. III, ed. Naturforschende Gesellschaft in Basel, Basel: Birkhäuser.

Bök, August Friedrich (ed.). [1766] 1970. Sammlung der Schriften, welche den logischen Calcul Herrn Prof. Ploucquets betreffen, mit neuen Zusätzen, reprint (ed. A. Menne), Stuttgart-Bad Cannstatt: Frommann- Holzboog.

Budde, Johann Franz. 1731. Compendium historiae philosophiae observationibus illustratum, ed. Johann Georg Walch, Halle.

Burgersdijk, Franco. [1626] 1645. Institutionum logicarum libri duo, Leiden: Officina Commelini.

Caesarius, Johannes. [1520] 1545. Dialectica, Mainz: Schoeffer.

Clauberg, Johann. [1654] 1658. Logica vetus et nova. Amsterdam: Officina Elzeviriana.

Condillac, Étienne Bonnot de. [1780] 1948. La Logique ou les premiers développements de l'art de penser, in Oeuvres philosophiques de Condillac, ed. G. Le Roy, vol. II, 368416, Paris: Presses Universitaires de France.

Condillac, Étienne Bonnot de. [1798] 1948. La langue des calculs, in Oeuvres philosophiques de Condillac, ed. G. Le Roy, vol. II, 418-529, Paris: Presses Universitaires de France.

Crousaz, Jean Pierre de. 1724. Logicae systema, Genève. 
Dalgarno, George. [1661] 1961. Ars Signorum, London: Hayes, reprint Menston: Scholar Press.

Descartes, René. 1964-76. Ouvres de Descartes, ed. C. Adam and P. Tannery, Paris: Vrin.

Descartes, René. [1637] 1994. Discours de la méthode. A bilingual edition and an interpretation of René Descartes' philosophy of method. Ed. and trans. G. Heffernan, Notre Dame: Notre Dame University Press.

Duncan, William. [1748] 1968. Elements of Logick, London, reprint Hildesheim: Olms.

Eberstein, Wilhelm Ludwig Gottlob von. [1794-99] 1970. Versuch einer Geschichte der Logik und Metaphysik bey den Deutschen von Leibniz bis auf den gegenwärtige Zeit, 2 vols., Halle, reprint Bruxelles: Culture et Civilisation.

Euler, Leonhard [1768-72] 1911. Lettres à une Princesse d'Allemagne sur divers sujets de physique et de philosophie, St. Petersbourg, in Leonhardi Euleri Opera omnia, ed. Soc. scient. Nat. Helv., Leipzig: Teubner.

Fabri, Honoré. 1646. Philosophiae tomus primus, Lyon: Champion.

Gergonne, Joseph Diez. 1816-1817. Essai de dialectique rationelle, Annales des Mathématiques pures et appliquées, VII, 189-228.

Geulincx, Arnold. 1891-3. Opera Philosophica, ed. J.P.N. Land, The Hague: Nijhoff.

Hobbes, Thomas. [1839] 1961. Elementorum philosophiae sectio prima. De corpore. Pars prima, Computatio sive logica, London, 1st ed. 1655, in Thomae Hobbes Malmesburiensis Opera Philosophica quae latine scripsit omnia, ed. G. Molesworth, vol. I, reprint Aalen: Scientia Verlag.

Hoffbauer, Johann Christoph. [1792] 1969. Analytik der Urtheile und Schlüsse. Mit Anmerkungen meistens erläuternden Inhalt, Halle, reprint Bruxelles: Culture et Civilisation.

Hutcheson, Francis. 1759. Logicae compendium, Glasgow.

Izquierdo, Sebastian. 1659. Pharus Scientiarum, Leiden: Bourgeat and Liétard.

Jungius, Joachim. [1638] 1957. Logica Hamburgensis, ed. R.W. Meyer, Hamburg: Augustin.

Jungius, Joachim. 1977. Logica Hamburgensis Additamenta, ed. W. Risse, Göttingen: Vandenhoeck \& Ruprecht.

Kant, Immanuel. 1900- I. Kant's gesammelte Schriften, ed. Königlich Preußische Akademie der Wissenschaften (and successors), Georg Reimer: Berlin, later publisher Walter de Gruyter: Berlin-Leipzig.

Kant, Immanuel. 1992. Lectures on Logic. Trans. M. Young, Cambridge: Cambridge University Press (Logik Blomberg, Wiener Logik, Logik Dohna-Wundlacken, Logik. Ein Handbuch zu Vorlesungen, bearing on the margin the number of the pages of Kant 1900- ; also contains a partial trans of Kant 1998b).

Kant, Immanuel. 1997. Critique of pure reason. Trans. P. Guyer and W. Wood, Cambridge: Cambridge University Press (references are to the pages of the 1781 (A) and 1787 (B) edition).

Kant Immanuel. 1998a. Logik-Vorlesung: unveröffentlichte Nachschriften I, Logik Bauch, ed. T. Pinder, Hamburg: Meiner.

Kant Immanuel. 1998b. Logik-Vorlesung: unveröffentlichte Nachschriften II, Logik Hechsel; Warschauer Logik, ed. T. Pinder, Hamburg: Meiner.

Keckermann, Bartholomaeus. 1614. Opera omnia quae extant. Köln: Aubertus.

Kircher, Athanasius. 1663 Polygraphia nova et universalis ex combinatoria arte detecta, Roma: Varesius.

Lambert, Johann Heinrich. [1764] 1965. Neues Organon 2 vols, Leipzig, reprint in J. H. Lambert, Philosophische Schriften, vols. I-II, ed. H. W. Arndt, Hildesheim: Olms.

Lambert, Johann Heinrich. [1765] 1981. De universaliori calculi idea Disquisitio, una cum adnexo specimine, Nova Acta Eruditorum, 441-473, reprint in microform, Hildesheim-New York: Olms. 
Lambert, Johann Heinrich. [1771] 1965. Anlage zur Architechtonic oder Theorie des Einfachen und Ersten in der philosophischen und mathematischen Erkenntnis, 2 vols., Riga, reprint in J. H. Lambert, Philosophische Schriften, vols. III-IV, ed. H. W. Arndt, Hildesheim: Olms.

Lambert, Johann Heinrich. [1782-7] 1967-9. Logische und philosophische Abhandlungen, 2 vols., Berlin, reprint in J. H. Lambert, Philosophische Schriften, vols. VI-VII, Hildesheim: Olms.

Lambert, Johann Heinrich.[1782] 1968. Deutscher gelehrter Briefwechsel, Berlin, reprint in J. H. Lambert, Philosophische Schriften, vol. 9.1, Hildesheim: Olms.

Lange, Johann Christian. 1712. Nucleus logicae Weisianae...variis addimentis novis...auctus et illustratus, Giessen.

Lange, Johann Christian. 1714. Inventum novum quadrati logici universalis, in trianguli quoque formarum commode redacti, Giessen.

Leibniz, Gottfried Wilhelm. [1686] 1982. Generales Inquisitiones de Analysi Notionum et Veritatum, ed. and German trans. F. Schupp, Hamburg: Meiner.

Leibniz, Gottfried Wilhelm. [1860] 1971. Briefwechsel zwischen Leibniz und Christian Wolff, ed. C. I. Gerhardt, Halle: [s.n.], reprint Hildesheim-New York: Olms.

Leibniz, Gottfried Wilhelm. [1875-1890] 1978. Die philosophischen Schriften, 7 vols., ed. C.I. Gerhardt, Berlin: Weidmannsche Buchhandlung, reprint Hildesheim-New York: Olms.

Leibniz, Gottfried Wilhelm. [1903] 1966. Opuscules et fragments inédits de Leibniz, ed. L. Couturat, Alcan: Paris, reprint Hildesheim-New York: Olms.

Leibniz, Gottfried Wilhelm. 1923- Sämtliche Schriften und Briefen. Herausgegeben von der Preussischen (Deutschen) Akademie der Wissenschaften zu Berlin, Darmstadt-LeipzigBerlin: Akademie.

Leibniz, Gottfried Wilhelm. 1973. Philosophical Writings, ed. G.H.R. Parkinson, trans. M. Morris and G.H.R. Parkinson, London: J.M. Dent and Sons Ltd.

Locke, John. [1690] 1975. An Essay concerning Human Understanding, ed. P. H. Nidditch, Oxford: Clarendon Press.

Locke, John. [1706] 1993. Of the Conduct of the Understanding, in Posthumous Works, London, reprint Bristol: Thoemmes Press.

Locke, John. [1755] 1996. Johann Lockens Anleitung zur Erkäntniß der Wahrheit nebst derselben Abhandlung von der Wunderwerken, Königsberg: Hartnung, reprint (eds. T. Boswell, R. Pozzo and C. Schweiger), Stuttgart-Bad Cannstatt : Fromman- Holzboog.

Malebranche, Nicolas. [1674] 1962. De la recherche de la verité, in Oeuvres complètes, t. IIII, ed. G. Rodis-Lewis, Paris: Vrin.

Meier, Georg Friedrich. 1752a. Vernunftlehre, Halle.

Meier, Georg Friedrich. [1752b] 1914. Auszug aus der Vernunftlehre, Halle, reprint in Kant 1900 -, vol. XVI.

Melanchthon, Philipp. 1520. Compendiaria dialectices Ratio. Wittebergae: Melchior Lotter.

Melanchthon, Philipp. 1528. De Dialectica libri IV. Haganoe: Secerius.

Melanchthon, Philipp. [1547] 1846. Erotemata dialectices, in: C.G. Bretschneider (ed.), Corpus Reformatorum, vol. XIII. Halis Saxonum: Schwetschke.

Pascal, Blaise. [1658 or 1659] 1914. De l'ésprit géométrique, in Oeuvres de Blaise Pascal, vol. IX, 229-294, eds. L. Brunschvicg, P. Boutroux and F. Gazier, Paris: Hachette.

Petrarca, Francesco. 1933-42. Epistolae familiares, ed. V. Rossi and U. Bosco, Firenze: Sansoni.

Ploucquet, Gottfried. 1759. Fundamenta philosophiae speculativae, Tübingen.

Ploucquet, Gottfried. 1763a. Methodus tam demonstrandi directe omnes syllogismorum species, quam vitia formae detegendi, ope unius regulae, Tübingen, in Bök [1766] 1970, 17-28. 
Ploucquet, Gottfried. 1763b. Methodus calculandi in Logicis inventa a G. P. Praemittitur commentatio de arte characteristica, Frankfurt-Leipzig, in Bök [1766] 1970, 31-80.

Ramus, Petrus. [1543] 1964. Dialecticae Institutiones - Aristotelicae Animadversiones, repr. with Introduction by W. Risse, Stuttgart: Fromann.

Ramus, Petrus. [1555] 1964(2). Institutions Dialectiques, ed. M. Dassonville, Genève: Droz..

Ramus, Petrus. [1555] 1996. Dialectique, ed. N. Bruyère, Paris: Vrin.

Reusch, Johann Peter. [1734] 1990. Systema logicum antiquiorum atque recentiorum item propria praecepta exhibens, Jena, in C. Wolff, Gesammelte Werke, Sect. III, vol. 26, Hildesheim: Olms.

Rüdiger, Andreas. 1722. De sensu veri et falsi libri IV, Halle (2nd ed.; 1st ed. 1709).

Saccheri, Gerolamo. [1697] 1986. Logica demonstrativa, reprint of the ed. Torino 1697 (ed. W. Risse) Hildesheim: Olms.

Saccheri, Gerolamo. [1733] 1986. Euclides ab Omni Naevo Vindicatus, ed. and trans. G.B. Halsted, New York: Chelsea.

Sanderson, Robert. [1615] 1985. Logicae artis compendium, reprint of the ed. Oxford 1618 (ed. J. Ashworth), Bologna: CLUEB.

Segner, Johann Andreas. [1740] 1990. Specimen logicae universaliter demonstratae. Appendices: Two dissertations De syllogismo, reprint (ed. and with an Introduction by M. Capozzi), Bologna: CLUEB.

Schröder, Ernst [1890-95] 1966. Vorlesungen über die Algebra der Logik, 3 vols, Leipzig, reprint New York: Chelsea Publishing Company.

Schott, Kaspar. 1664. Technica Curiosa VII - Mirabilia graphica, sive nova aut rariora scribendi artificia, Nürnberg: Endter.

Seton, John. 1545. Dialectica, London.

Simon of Faversham, Commentary on Peter of Spain's 'Tractatus', ed. by L.M. De Rijk in On the genuine text of Peter of Spain's 'Summule Logicales'. Part II. Simon Faversham (d. 1306) as a commentator of the Tract I-V of the Summule, Vivarium VI, 2, 69-101, partial trans. J. Longeway, < http://uwp.edu/ longeway/peterspa.htm>.

Soto, Domingo de. 1543. In Dialecticam Aristotelis Commentarii. Salamanca: J. de Junta.

Soto, Domingo de. [1554] 1980. Summulae (1st ed. 1529). Salamanca, reprint (ed. W. Risse) Hildesheim: Olms.

Sturm, Johann Cristoph. 1661. Universalia Euclidea, The Hague.

Suárez, Francisco. [1597] 1965. Disputationes Metaphysicae, reprint of vv. XXV-XXVI of Opera Omnia (ed. C. Berton, Paris, Vivès 1861), Hildesheim: Olms.

Suárez, Francisco. [1597] 1996. On Being of Reason, Metaphysical Disputation LIV, ed. and trans. J.P. Doyle, Milwaukee: Marquette University Press.

Thomasius, Christian. [1691a] 1968, Einleitung zu der Vernunftlehre, Halle, reprint (ed. W. Schneiders), Hildesheim: Olms.

Thomasius, Christian. [1691b] 1968. Ausübung der Vernunftlehre, Halle, reprint (ed. W. Schneiders), Hildesheim: Olms.

Thomasius, Christian. 1702. Introductio ad philosophiam aulicam, seu lineae primae libri de prudentia cogitandi et ratiocinandi, ubi ostenditur media inter praejudicia Cartesianorum et ineptias Peripateticorum, veritatem inveniendi via (1st ed 1688), Halle.

Toletus, Franciscus. 1985. Introductio in universam Aristotelis Logicam (1st ed. 1560) and Commentaria in universam Aristotelis Logicam (1st ed. 1572), in Opera Omnia Philosophica, reprint of the ed. Köln 1615-16 (ed. W. Risse), Hildesheim: Olms.

Tschirnhaus, Ehrenfried Walter von. [1695] 1964. Medicina mentis, sive artis inveniendi praecepta generalia (1st ed. 1687), reprint of the 2nd. ed., Leipzig (with an Introduction by W. Risse), Hildesheim: Olms. 
Valla, Laurentius, 1982, Repastinatio Dialecticae et Philosophiae, ed. G. Zippel, Padova: Antenore.

Walch, Johann Georg. 1726. Philosophisches Lexicon, Leipzig.

Wallis, John. 1687. Institutio logicae, Oxford.

Watts, Isaac. 1725. Logick, or the right use of reason in the enquiry after truth, London.

Watts, Isaac. 1741. The improvement of the mind, or a supplement to the Art of Logick, London.

Wolff, Christian. [1713] 1978. Vernünfftige Gedanken von den Kräfften des menschlichen Verstandes, Halle, in C. Wolff, Gesammelte Werke, Sect. I, vol. I, ed. H. W. Arndt, Hildesheim: Olms.

Wolff, Christian. [1740] 1983. Philosophia rationalis sive Logica, reprint of the 2 nd ed. Frankfurt-Leipzig (1st. ed. 1728), in C. Wolff, Gesammelte Werke, Sect. II, vols. I/2-3. ed. J. École, Hildesheim: Olms.

Zabarella, Jacopo. [1578] 1966. Opera Logica, reprint of the ed. Köln 1597 (with an introduction by W. Risse), Hildesheim: Olms.

Zabarella, Jacopo. [1572] 1985. De methodis libri quatuor. Liber de regressu. reprint of the ed. Venice 1578 (Introduction by C. Vasoli), Bologna: CLUEB.

\section{SECONDARY LITERATURE}

Aner, Karl. 1909. Gottfried Ploucquets Leben und Lehren, Halle: Niemeyer.

Angelelli, Ignacio. 1990. On Johannes Raue's Logic, in I. Marchlewitz and A. Heinekamp (eds.), Leibniz' Auseinandersetzung mit Vorgängern und Zeitgenossen, Studia Leibnitiana Supplementa XXVII, Stuttgart: Steiner, 184-190.

Arndt, Hans Werner. 1965. Christian Wolffs Stellung zu 'ars characteristica combinatoria', Studi e ricerche di storia della filosofia, LXXI, 3-12.

Arndt, Hans Werner. 1971. Methodo scientifica pertractatum. Mos geometricus und Kalkülbegriff in der philosophischen Theorienbildung des 17. und 18. Jahrhunderts, Berlin-New York: de Gruyter.

Ashworth, Earline Jennifer. 1974. Language and Logic in the Post-Medieval Period, Dordrecht-Boston: Reidel.

Ashworth, Earline Jennifer. 1978. Theories of the Proposition: Some Early Sixteenth Century Discussions, in Franciscan Studies 38, XVI, 81-121 (reprinted with the same pagination in Ashworth 1985).

Ashworth, Earline Jennifer. 1980. The Scholastic Background to Locke's Theory of Language, in Progress in Linguistic Historiography, ed. Konrad E. F. Koerner, 59-68. Amsterdam: Benjamins.

Ashworth, Earline Jennifer. 1982. The structure of mental language: Some Problems Discussed by Early Sixteenth Century Logicians, Vivarium XX, 1, 59-83 (reprinted with the same pagination in Ashworth 1985).

Ashworth, Earline Jennifer. 1984. Locke on Language, Canadian Journal of Philosophy, XIVI/1, 45-73 (reprinted with the same pagination in Ashworth 1985).

Ashworth, Earline Jennifer. 1985. Studies in Post-Medieval Semantics, London: Variorum Reprints.

Ashworth, Earline Jennifer. 1985b. Introduction to Sanderson (1985), ix-lv.

Ashworth, Earline Jennifer. 1990. Domingo de Soto (1494-1560) and the Doctrine of Signs, in De Ortu Grammaticae. Studies in Medieval Grammar and Linguistic Theory in Memory of Jan Pinborg (eds. G.L. Bursill-Hall, S. Ebbesen, K. Koerner), Amsterdam: Benjamins, 35-48.

Ashworth, Earline Jennifer. 1995. Suárez on the Analogy of Being: Some Historical Background, Vivarium XXXIII, 50-75. 
Auroux, Sylvain. 1993. La logique des idées, Montréal-Paris: Bellarmin-Vrin.

Barone, Francesco. 1964. Logica formale e logica trascendentale, vol. I: Da Leibniz a Kant, Torino: Edizioni di "Filosofia" (2nd ed., 1st. ed. 1957).

Beck, Lewis White. [1969] 1996. Early German Philosophy. Kant and His Predecessors, Cambridge Mass: The Belknap Press at Harvard U. P., reprint. Bristol: Thoemmes.

Bernhard, Peter. 2001. Euler-Diagramme. Zur Morphologie einer Repräsentationsform in der Logik, Paderborn: Mentis.

Blanché, Robert. [1970] 1996. La logique et son histoire, chapter XII Jacques Dubucs, Paris: Colin/Masson.

Bos, Egbert P. and Krop, Henri A. (eds.). 1993. Franco Burgersdijk (1590-1635), Amsterdam: Rodopi.

Boswell, Terry. 1990. The Brothers James and John Bernoulli on the Parallelism between Logic and Algebra, History and Philosophy of Logic, 11, 173-184.

Brandt, Reinhard. 1991. Die Urteilstafel. Kritik der reinen Vernunft A 67-76/B 92-101, Hamburg: Meiner.

Braakhuis, Henk A. 1988. Agricola's View on Universals, in Rodolphus Agricola Phrisius (1444-1485): Proceedings of the International Conference at the University of Groningen, ed. F. Akkerman and A.J. Vanderjagt, Leiden: Brill.

Bruyère, Nelly. 1984. Méthode et dialectique dans l'oeuvre de Pierre de La Ramée, Paris : Vrin.

Buickerood, James G. 1985. The Natural History of the Understanding: Locke and the Rise of Facultative Logic in the Eighteenth Century, History and Philosophy of Logic, 6: 15790.

Camporeale, Salvatore. 1986. Lorenzo Valla, 'Repastinatio liber primus': retorica e linguaggio, in Lorenzo Valla e l'umanesimo italiano, ed. O. Besomi and M. Regoliosi, Padova: Antenore, 217-39.

Capozzi, Mirella. 1982. Sillogismi e proposizioni singolari: due aspetti della critica di Wolff a Leibniz, in La grammatica del pensiero: Logica, linguaggio e conoscenza nell'età dell'Illuminismo, eds. D. Buzzetti and M. Ferriani, 103-150. Bologna: Il Mulino.

Capozzi, Mirella. 1987. Kant on Logic, Language and Thought, in Speculative Grammar, Universal Grammar and Philosophical Analysis of Language, eds. D. Buzzetti and M. Ferriani, 97-147, Amsterdam-Philadelphia: Benjamins.

Capozzi, Mirella. 1990. Editor's Introduction to Segner [1740], xi-clxxii, Bologna: CLUEB.

Capozzi, Mirella. 1994. Algebra e logica in Jakob Bernoulli, Atti del Congresso Logica e filosofia della scienza: problemi e prospettive (Lucca 7-10 gennaio 1993), 55-74, Pisa: ETS.

Capozzi, Mirella. 2002. Kant e la logica, vol. I, Napoli: Bibliopolis.

Capozzi, Mirella. forth. Kant e la logica, vol. II, Napoli: Bibliopolis.

Carboncini, Sonia. 1991. Transzendentale Wahrheit und Traum. Christian Wolffs Antwort auf die Herausforderung durch den Cartesianischen Zweifel, Stuttgart-Bad Cannstatt: Frommann-Holzboog.

Cassirer, Ernst. 1922. Das Erkenntnisproblem in der Philosophie und Wissenschaft der neuern Zeit, 3rd ed., vol. II, Berlin: B. Cassirer.

Chomsky, Noam. 1966. Cartesian Linguistics. A Chapter in the History of Rationalist Thought, New York-London: Harper and Row.

Coombs, Jeffrey. 1990. The Truth and Falsity of Modal Propositions in Renaissance Nominalism, PhD Diss., Austin: The University of Texas at Austin.

Couturat, Louis. 1901. La Logique de Leibnitz d'après des documents inédits, Paris: Alcan.

Daston, Lorraine. 1988. Classical Probability in the Enlightenment, Princeton: Princeton University Press. 
De Angelis, Enrico. 1964. Il metodo geometrico nella filosofia del Seicento, Pisa: Istituto di Filosofia.

Di Liso, Saverio. 2000. Domingo de Soto. Dalla logica alla scienza. Bari: Levante.

Dominicy, Marc. 1984. La naissance de la grammaire moderne. Language, logique et philosophie à Port-Royal, Liège: Mardaga.

D’Ors, Angel. 1981. Las 'Summulae' de Domingo de Soto. Pamplona: Universidad de Navarra (tesi doctoral).

Doyle, John P. 1969. Suarez on the Analogy of Being, The Modern Schoolman, XLVI, 21949 and $232-41$.

Doyle, John P. 1987-1988. Suarez on Beings of Reason and Truth, Vivarium XXV, 47-75 and XXVI, 51-72.

Doyle, John P. 1995. Another God, Chimerae, Goat-Staggs, and Man-Lions: a seventeenthcentury debate about impossible objects, Review of Metaphysics XLVIII, 771-808.

Doyle, John P. 2001. The Conimbricenses: Some Questions on Signs. Milwaukee: Marquette University Press.

Dürr, Karl. 1945. Die Logistik Johann Heinrich Lamberts, in Festschrift zum 60. Geburtstag von Prof. Dr. Andreas Speiser, 47-65, Zürich.

Engfer, Hans-Jürgen. 1982. Philosophie als Analysis. Studien zur Entwicklung philosophischer Analysiskonzeptionen unter dem Einfluss mathematischer Methodenmodelle im 17. und fruhen 18. Jahrhunderts, Stuttgart-Bad Cannstatt: Fromman-Holzboog.

Feingold, Mordechai; Freedman, Joseph S.; Rother, Wolfgang (eds.). 2001. The Influence of Petrus Ramus, Basel: Schwabe.

Fitch, Gregory. 1979. Analyticity and Necessity in Leibniz, Journal of the History of Philosophy, XVII/1, 29-42 (reprint in Woolhouse 1993).

Friedman, Russell L. and Nielsen, Lauge O. 2003. The Medieval Heritage in Early Modern Metaphysics and Modal Theory, 1400-1700, Dordrecht: Kluwer.

Gardner, Martin. 1983. Logic Machines and Diagrams, 2nd ed., Brighton: The Harvester Press.

Garin, Eugenio, 1960. La cultura fiorentina nella seconda metà del '300 e i 'barbari britanni', in Rassegna della letteratura italiana, s. VII, 64, 181-195.

Giard, Luce. 1985. La production logique de l'Angleterre au XVIe siècle, in Les Ètudes Philosophiques 3, 303-324.

Gilbert, Neal W. 1960. Renaissance Concepts of Method. New York: Columbia University Press.

Gilson, Étienne. 1913. Index scolastico-cartésien. Paris: Felix Alcan.

Gilson, Étienne. 1958. Notes sur une frontière contestée, in Archives d'Histoire Doctrinale et Littéraire du Moyen Age 25, 59-88.

Gaukroger, Stephen. 1989. Cartesian Logic. An Essay on Descartes's Conception of Inference. Oxford : Clarendon Press

Green-Pedersen, Niels Jorgen. 1984. The Tradition of The Topics in the Middle Ages: The Commentaries on Aristotle's and Boethius' Topics, München-Wien: Philosophia Verlag.

Hacking, Ian. 1975a. Why does Language matter to Philosophy?, Cambridge: Cambridge University Press.

Hacking, Ian. 1975b. The Emergence of Probability, Cambridge: Cambridge University Press.

Hamilton, William. 1860-9. Lectures on Metaphysics and Logic, 2nd ed., vol. II, Appendix, eds. H. L. Mansel and J. Veitch, Edinburgh-London: Blackwood.

Harnack, Adolf. von. [1900] 1970. Geschichte der Königliche Preussischen Akademie der Wissenschaften zu Berlin, 3 vols., Berlin, reprint Hildesheim: Olms. 
Hatfield, Gary. 1997. The Workings of the Intellect: Mind and Psychology, in Logic and the Workings of the Mind: The Logic of Ideas and Faculty Psychology in Early Modern Philosophy, ed. Patricia A. Easton, 21-45, Atascadero, Calif.: Ridgeview.

Hickman, Larry. 1980. Modern Theories of Higher Level Predicates. Second Intentions in the Neuzeit. Munchen: Philosophia.

Hinske, Norbert. 1986-. Kant-Index, Stuttgart-Bad Cannstatt: Frommann-Holzboog .

Howell, Wilbur Samuel. 1971. Eighteenth Century British Logic and Rhetoric, Princeton N. J.: Princeton University Press.

Ishiguro, Hidé. 1991. Leibniz's Philosophy of Logic and Language, Cambridge: Cambridge University Press (2nd. ed., 1st. ed. 1972).

Jardine, Lisa. 1982. Humanism and the Teaching of Logic, in Kretzmann, N., Kenny, A., Pinborg, J. (1982), pp. 797-807.

Jardine, Lisa. 1988. Humanistic Logic, in Schmitt, Charles B.; Skinner, Quentin; Kessler, Eckhard (eds.) (1988) pp. 173-198.

Kitcher, Patricia. 1991. Kant's Transcendental Psychology, New York-Oxford: Oxford University Press.

Kneale, William, and Kneale, Martha. [1962] 1975. The Development of Logic, Oxford: Clarendon Press.

Kretzmann, Norman; Kenny, Anthony; Pinborg, Jan (eds.). 1982. The Cambridge History of Later Medieval Philosophy, Cambridge: Cambridge University Press.

Lenzen, Wolfgang. 1986. 'Non est' non est 'est non' - Zu Leibnizens Theorie der Negation, Studia Leibnitiana 18, 1-37.

Lenzen, Wolfgang. 1990. Das System der Leibnizschen Logik, Berlin: de Gruyter

Lenzen, Wolfgang. 2000. Guilielmi Pacidii Non plus ultra - oder: Eine Rekonstruktion des Leibnizschen Plus-Minus-Kalküls, Philosophiegeschichte und logische Analyse 3, 71118.

Lenzen, Wolfgang. 2003. Grundfragen des logischen Kalküls - Eine Art Rezension von F. Schupp (Hrg.), G. W. Leibniz, Die Grundlagen des logischen Kalküls, History and Philosophy of Logic 24, 141-162.

Lenzen, Wolfgang. 2004. Calculus Universalis. Studien zur Logik von G. W. Leibniz, Paderborn: Mentis.

Mack, Peter. 1993. Renaissance Argument. Valla and Agricola in the Traditions of Rhetoric and Dialectic, Leiden-New York-Köln: Brill.

Mahoney, Michael S. 1980. The Beginnings of Algebraic Thought in the Seventeenth Century, in Descartes. Philosophy, Mathematics and Physics, ed. Stephen Gaukroger, 141-155. Brighton: The Harvester Press.

Maierù, Alfonso. 1993. La dialettica. in G. Cavallo, C. Leonardi, E. Menestò (eds.), Lo spazio letterario del medioevo latino. 1 - La produzione del testo, II, 273-294, Roma: Salerno.

Mates, Benson. 1986. The Philosophy of Leibniz: Metaphysics and Language, Oxford: Oxford University Press.

Menne, Albert. 1968. Zur Logik von Gottfried Ploucquet, Akten des XIV Internationalen Kongresses für Philosophie, 45-49, Wien: Herder.

Mondadori, Fabrizio. 1973. Reference, essentialism, and modality in Leibniz's metaphysics, Studia Leibnitiana V, 74-101 (reprint in Woolhouse 1993).

Mugnai, Massimo. 1992. Leibniz' Theory of Relations, Studia Leibnitiana Supplementa XXVIII, Stuttgart: Steiner.

Muller, François. 1993. Das Weiterleben der mittelalterlichen Logik bei Melanchthon und Jungius, in W. Harms e J.M. Valentin (eds.), Mittelalterliche Denk- und Schreibmodelle in der deutschen Literatur der frühen Neuzeit, Amsterdam-Atlanta: Rodopi, 95-110.

Muñoz Delgado, Vicente. 1970. La obra lógica de los españoles en París (1500-1525), in Estudios 26, 209-280. 
Murdoch, John. 1974. Philosophy and the Enterprise of Science in the Later Middle Ages, in Y. Elkana (ed.), The Interaction between Science and Philosophy, Atlantic Highlands (N.J.): Humanities Press, pp. 51-74.

Nuchelmans, Gabriel. 1980. Late-Scholastic and Humanist Theories of the Proposition, Amsterdam-Oxford-New York: North-Holland Publishing Company.

Nuchelmans, Gabriel. 1983. Judgment and Proposition. From Descartes to Kant, Amsterdam-Oxford-New York: North-Holland Publishing Company.

Nuchelmans, Gabriel. 1991. Dilemmatic Arguments: Towards a History of Their Logic and Rhetoric, Amsterdam: North Holland Publishing Company.

Ong, Walter J. 1958. Ramus, Method and the Decay of Dialogue: From the Art of Discourse to the Art of Reason, Cambridge: Harvard University Press.

Pariente, Jean-Claude. 1985. L'analyse du langage à Port-Royal. Six études logicogrammaticales, Paris: Minuit.

Pérez-Ilzarbe, Paloma. 1999. El significado de las proposiciones. Jerónimo Pardo y las teorías medievales de la proposición, Pamplona: Eunsa.

Perreiah, Alan R. 1982. Humanist critiques of scholastic dialectic, in Sixteenth Century Journal 13. pp. 3-22.

Pozzo, Riccardo. 1989. Kant und das Problem einer Einleitung in die Logik. Ein Beitrag zur Rekonstruktion der historischen Hintergründe von Kants Logik-Kolleg, Frankfurt am Main-Bern-New York-Paris: Peter Lang.

Pozzo, Riccardo. 2000. Georg Friedrich Meiers "Vernunftlehre". Eine historischsystematische Untersuchung, Stuttgart-Bad Cannstatt: Fromman-Holzboog.

Reich, Klaus. 1992. The Completeness of Kant's Table of Judgments, trans. J. Kneller and M. Losonsky of Die Vollständigkeit der kantischen Urteilstafel, Berlin (2nd ed) 1948 Hamburg 1986 (3rd ed), Stanford: Stanford University Press.

Risse, Wilhelm. 1964-70. Die Logik der Neuzeit, 2 vols., Stuttgart-Bad Cannstatt: FrommannHolzboog.

Risse, Wilhelm. 1965. Bibliographia Logica: Verzeichnis der Druckschriften zur Logik mit Angabe ihrer Fundorte, vol. I: 1472-1800, Hildesheim: Olms.

Roncaglia, Gino. 1988. Modality in Leibniz' Essays on Logical Calculus of April 1679, Studia Leibnitiana XX/1, 43-62.

Roncaglia, Gino. 1996. Palaestra rationis. Discussioni su natura della copula e modalità nella filosofia 'scolastica' tedesca del XVII secolo, Firenze: Olschki.

Roncaglia, Gino. 1998. Sull'evoluzione della logica di Melantone, Medioevo XXIV, 235-265.

Russell, Bertrand. 1900. A Critical Exposition of the Philosophy of Leibniz. Cambridge: Cambridge University Press.

Schepers, Heinrich. 1959. Andreas Rüdigers Methodologie und ihre Voraussetzungen, (KantStudien, Ergänzungsheft 78), Köln: Kölner Universitäts-Verlag.

Schmitt, Charles B.; Skinner, Quentin; Kessler, Eckhard (eds.). 1988. The Cambridge History of Renaissance Philosophy, Cambridge: Cambridge University Press.

Schupp, Franz. 2000. Introduction, trans. and commentary to G. W. Leibniz, Die Grundlagen des logischen Kalküls, Hamburg: Meiner.

Shamoon, Alan. 1981. Kant's Logic, Columbia University Ph. D. Dissertation (1979), Ann Arbor: University Microfilms International.

Swoyer, Chris. 1995. Leibniz on Intension and Extension, Nous, 29/1, 96-114.

Thom, Paul. 1981. The Syllogism, München: Philosophia Verlag.

Tonelli, Giorgio. 1959. Der Streit über die mathematische Methode in der Philosophie in der ersten Hälfte des 18. Jahrhunderts und die Entstehung von Kants Schrift über die 'Deutlichkeit', Archiv für Begriffsgeschichte, IX, 37-66.

Vailati, Giovanni. 1899. La logique mathématique et sa nouvelle phase de développement dans les écrits de M. J. Peano, Revue de Métaphysique et de Morale, 7, 86-102. 
Vasoli, Cesare. 1968. La dialettica e la retorica dell'umanesimo, Milano: Feltrinelli.

Vasoli, Cesare, 1974, Intorno al Petrarca e ai logici 'moderni', Miscellanea Medievalia IX, Antiqui und Moderni, Berlin: De Gruyter, 142-54.

Venn, John. [1894] 1971. Symbolic Logic, reprint of the 2nd ed., New York: Chelsea Publ. Co.

Waswo, Richard. 1999. Theories of Language, in The Cambridge History of Literary Criticism III - The Renaissance, ed. G.P. Norton, Cambridge: Cambridge University Press, 25-35.

Wolff, Michael. 1995. Die Vollständigkeit der kantischen Urteilstafel. Mit einem Essay über Freges Begriffsschrift, Frankfurt am Main: Klostermann.

Wollgast, Siegfried. 1988. Ehrenfried Walther von Tschirnhaus und die deutsche Frühaufklärung, Berlin: Akademie-Verlag.

Wollgast, Siegfried. 1988 (2nd ed.). Philosophie in Deutschland zwischen Reformation und Aufklärung 1550-1650, Berlin: Akademie-Verlag.

Wolters, Gereon. 1980. Basis und Deduktion. Studien zur Entstehung und Bedeutung der Theorie der axiomatischen Methode bei J. H. Lambert (1728-177), Berlin-NewYork: Walter de Gruyter.

Woolhouse, Roger S. (ed.). 1993. Gottfried Wilhelm Leibniz: Critical Assessments, Vols I IV, London-New York: Routledge

Wundt, Max. [1945] 1964. Die deutsche Schulphilosophie im Zeitalter der Aufklärung, Tübingen, reprint Hildesheim: Olms.

Yolton, John. 1986. Schoolmen, Logic and Philosophy, in The History of the University of Oxford, vol. V: The Eighteenth Century, eds. L. S. Sutherland and L. G. Mitchell, 565591, Oxford: Clarendon Press.

Zalta, Edward. 2000. A (Leibnizian) Theory of Concepts, Philosophiegeschichte und logische Analyse / Logical Analysis and History of Philosophy, III, 137-183. 